\title{
THE DEVELOPMENT OF THE FIRST GENERATION OF EXO- AFFINITY LABELING AGENTS, INACTIVATORS OF PROTEIN TYROSINE PHOSPHATASE 1B
}

\author{
A Thesis
}

Presented to

The Faculty of the Graduate School

At the University of Missouri-Columbia

In Partial Fulfillment

of the Requirements for the Degree

Master of Science

by

Puminan Punthasee

Dr. Kent Gates, Thesis Supervisor

July 2014 
The undersigned, appointed by the dean of the Graduate School, have examined the thesis entitled

\section{THE DEVELOPMENT OF THE FIRST GENERATION OF EXO-AFFINITY LABELING AGENTS, INACTIVATORS OF PROTEIN TYROSINE PHOSPHATASE 1B}

presented by Puminan Punthasee, a candidate for the degree of Master of Science and hereby certify that, in their opinion, it is worthy of acceptance.

Professor Kent S. Gates

Professor Michael Harmata

Professor Paul R. Sharp

Associate Professor Xiaoqin Zou 
Dedicated to the living love of my Mom \& Dad

Mrs. Pornsiri and Mr. Theera Punthasee

For giving me strength and perseverance to pursue Ph.D. 


\section{ACKNOWLEDGEMENTS}

I would like to express my sincere gratitude to my advisor Prof.Kent S. Gates for his excellent mentorship. He has been of great advisor, teacher, mentor, and co-worker. I deeply appreciate all his knowledge, scientific attitude as well as opportunity to improve myself in order to become an excellent scientist. I always admire his love and passion of science that will always be an example of scientist in the next generation.

I also would like to thank my committee members Dr. Michael Harmata, Dr.Paul Sharp, and Dr.Xiaoqin Zou for their valuable time and support.

I would like to thank all my co-workers for their time as friends, colleagues, and trainers. Especially, Nicholas Santo and Kasi Viswanatha Raju Ruddraraju who always motivate me to move forward even during the time of difficulty.

Another important group of people who play an important role in my life here are $\mathrm{CCH}$ and $\mathrm{CRU}$ people. They have always been such a great help not only my career but also my life in the US. To my best friends, Andrew White, Marc Ehlers, Ryan Buttrey, and Rebecca Beckham who always understand and give me heartfelt help and support. Thanks for always be there when I need someone. I also would like to thank David Sower as a teacher, a mentor, and a friend who has been praying and offering deeply sincere motivation. (Happy for Ryan and Rebecca, they are getting married!)

Lastly, mom and dad have been of great moral support to me all through-out my life miles away from home. For three years, they have provided strength and perseverance to pursue Ph.D. Without them, this work would have not been successful. I will always love you two. 


\section{TABLES OF CONTENTS}

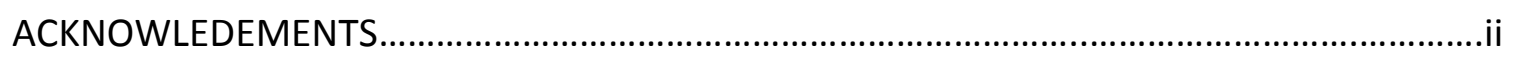

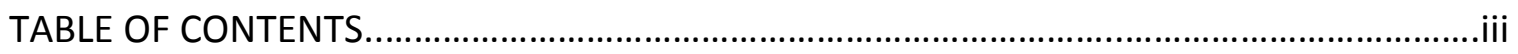

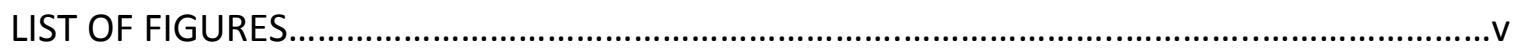

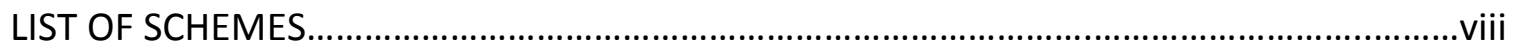

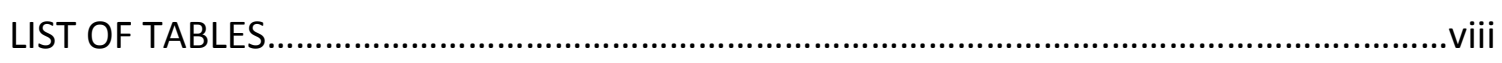

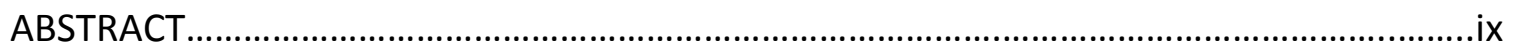

\section{Chapter 1 Type II Diabetes, PTP1B, \& Current Inhibitors of PTP1B.}

1.1) Introduction: Type II Diabetes, a nationwide problem ........................................1

1.2) Insulin signaling transduction and Protein Tyrosine Phosphatases (PTPs)............2

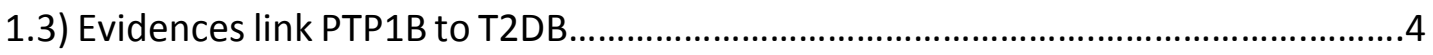

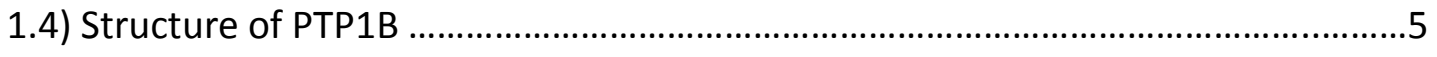

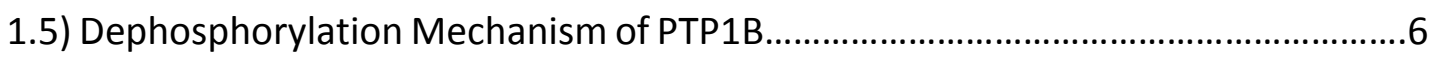

1.6) Current PTP1B inhibitors and their inadequate inhibitory activity.......................

1.7) Growing Interest of Covalent Drugs................................................................... 11

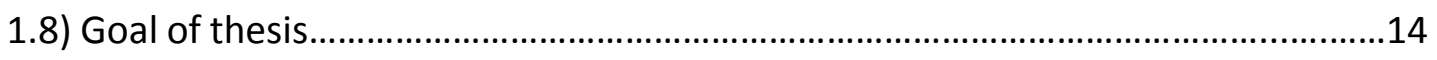

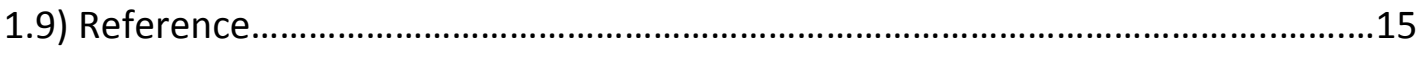

Chapter 2 First Generation of Exo-affinity Labeling Agents and Inactivation of PTP1B

2.1) Exo-affinity Labeling Agent, a novel covalent inhibitor of PTP1B........................19

2.2) Advantages of affinity labeling agent over reversible inhibitors........................20

2.3) Design of Exo-Affinity Labeling Agents of PTP1B................................................26 
2.4) Synthetic Route to first generation of E-L-pYi

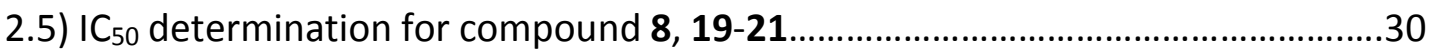

2.6) Kinetics of the inactivation of PTP1B by Me Thioester TDZ ....................................36

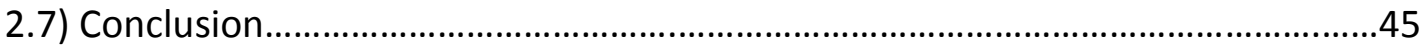

2.8) Materials and Methods...................................................................................46

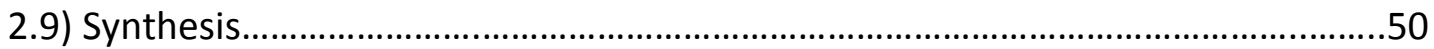

2.10) Reference 


\section{LIST OF FIGURES}

\section{Chapter 1}

Figure 1.1 Insulin Signaling Transduction scheme. The signaling pathway is negatively

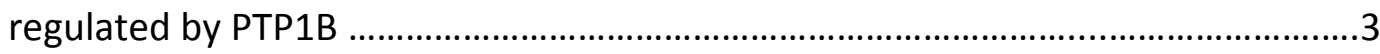

Figure 1.2 Binding mode of typical dual binding inhibitor......................................... 8

Figure 1.3 Difluoromethyl Phosphate 1 developed by Zhang et. al. and Benzotriazo DFMP 2 developed by Merck Frosst.....................................................................

Figure 1.4 Carboxylic acid-containing PTP1B inhibitors 3-5 developed by

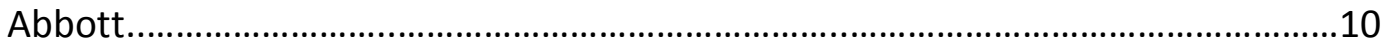

Figure 1.5 Tyrosine Acid 6 and Thiophene diacid 7 developed by The Institutes for Pharmaceutical Discovery and Wyeth respectively...................................................10

Figure 1.6 PTP1B inhibitors containing TDZ or IZD 8-11 ...........................................11

\section{Chapter 2}

Figure 2.1 Irreversible inhibition versus transient inhibition

Figure 2.2 Inactivation by the exo-affinity labeling agent (top) and inhibition by a dual binding inhibitor (bottom). The exo-affinity labeling agent bound to PTP1B with a covalent bond. This irreversible interaction was not affected by the competition with the substrate (top). Dual binding inhibitors bound to PTP1B with noncovalent interactions. This reversible interaction was affected by competition with the substrate (bottom). .23

Figure 2.3 Proximity-accelerated reaction of $E-L-p Y_{i}$ .24

Figure 2.4 Binding mode of an exo-affinity labeling agent to a) the target enzyme, b) other enzymes whose active sites are not complementary to the structure of the affinity labeling agent, c) common nucleophiles in physiological media and d) homologous enzyme without the reactive group or with the reactive group not located in the proper distance. .25

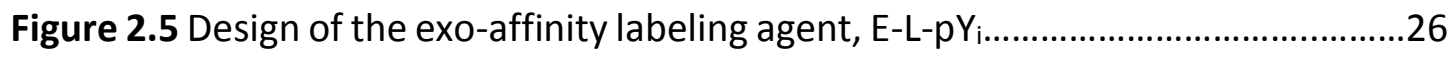


Figure 2.6 Pymol co-structure of $\mathbf{8}$ and PTP1B. The distances from $p$-carbon at the end of 8 to Asp48 and Cys32 are $5.2 \dot{A}$ and $14.2 \dot{A}$, respectively

Figure 2.7 Positions of nucleophilic residues in PTP1B proximal to the active site. 28

Figure 2.8 Plots of \% PTP1B Activity versus concentration of a) Me/Ph Thioester TDZ 19a and b) Me/Bn Thioester TDZ 20 and c) Me/Ph Amide TDZ 21. IC 50 with error bars (from $\geq 5$ experiment) of the compounds were $124 \pm 12 \mu \mathrm{M}, 270 \pm 36 \mu \mathrm{M}$, and $244 \pm 43 \mu \mathrm{M}$, respectively.

Figure 2.9 a) A semi-logarithmic of \%enzyme activity against time plot for each concentration of an exo-affinity labeling agent $\left(E-L-p Y_{i}\right)$. b) Re-plot $k_{\text {obs }}$ (slope from a)) vs concentration of the exo-affinity labeling agent and fit the data to the hyperbolic equation (Scheme 2.6). K/ was obtained as the concentration that gives half $k_{\text {obs }}$ and $k_{\text {inact }}$ was obtained as the maximum $k_{\text {obs, }}$ respectively... .37

Figure 2.10 Plot $k_{\text {obs }}$ vs concentration of 19a, 20, and 21 in 5\%DMSO and 20\%DMSO

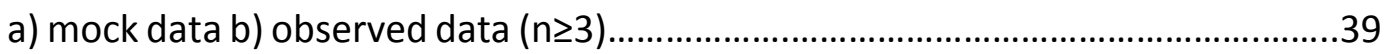

Figure 2.11 Plot In (\%Activity) vs time of a) 19a (5\%DMSO), b) 19a (20\%DMSO), c) 20

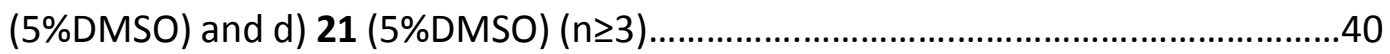

Figure 2.12 Plot $k_{\text {obs }}$ vs concentration of 19a, 20, and 21. a) 19a (5\%DMSO), b) 19a (20\%DMSO), c) 20 (5\%DMSO) and d) 21 (5\%DMSO) ( $n \geq 3)$

Figure 2.13 a) Plot $k_{\text {obs }}$ vs concentration of 19a in 5\% DMSO ( $\left.n=1\right)$; Fitting $k_{\text {obs }}$ values of $10,50,75$, and $100 \mu \mathrm{M}$ to the hyperbolic equation gave $\mathrm{R}^{2}$ of 0.986845194 . However, fitting all $k_{\text {obs }}$ values to the equation gave $\mathrm{R}^{2}$ of 0.611790504 . b) Plot $k_{\text {obs }}$ vs concentration of $\mathbf{2 1}$ in $5 \%$ DMSO $(n=3)$ showed that $k_{\text {obs }}$ values of the concentrations above $500 \mu \mathrm{M}>0 \mathrm{~s}^{-1}$................ .44

Figure $2.14 \mathrm{IC}_{50}$ of $\mathbf{8}$ in a) 20\%DMSO-high salt, b) 20\%DMSO-low salt, and c) 4\%DMSOlow salt...

Figure $2.15 \mathrm{IC}_{50}$ of $19 \mathrm{~b}$ in a) $20 \% \mathrm{DMSO}$-high salt, b) $20 \% \mathrm{DMSO}-$ low salt, and c) 4\%DMSO-low salt.

Figure $2.16 \mathrm{IC}_{50}$ of 17 in a) 20\%DMSO-high salt, b) 20\%DMSO-low salt, and c) $4 \% \mathrm{DMSO}-$ low salt.

Figure $2.17 \mathrm{IC}_{50}$ of $19 \mathrm{a}$ in a) $20 \% \mathrm{DMSO}$-high salt, b) $20 \% \mathrm{DMSO}-\mathrm{low}$ salt, and c) 4\%DMSO-low salt. .62 
Figure $2.18 \mathrm{IC}_{50}$ of $\mathbf{2 0}$ in a) 20\%DMSO-high salt, b) 20\%DMSO-low salt, and c)

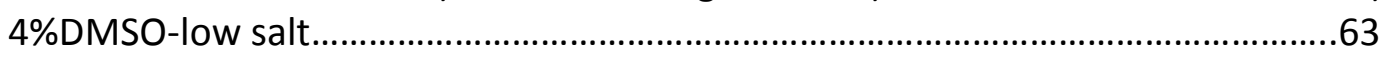

Figure $2.19 \mathrm{IC}_{50}$ of $\mathbf{2 1}$ in a) $20 \% \mathrm{DMSO}$-high salt, b) $20 \% \mathrm{DMSO}-\mathrm{low}$ salt, and c)

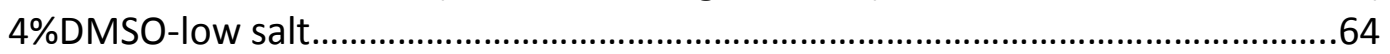




\section{LIST OF SCHEMES}

\section{Chapter 1}

Scheme 1.1 Dephosphorylation Mechanism of PTP1B

\section{Chapter 2}

Scheme 2.1 Inactivation of an enzyme by an affinity labeling agent

Scheme 2.2 Synthesis of bi-aryl TDZ by Black's method. (17a and all OMe analogs were synthesized by my colleague Ruddraraju, K. V. R.)

Scheme 2.3 Synthesis of E-L-pY. Variety of functional groups and linker lengths offer an opportunity for the exo-affinity labeling agent to form covalent bond with active group on the enzyme surface. (OMe family was synthesized by my colleague Ruddraraju, K. V. R.). 30

Scheme 2.4 Reaction of $p$ NPP and PTP1B yielding $p$-nitrophenoxide $\left(\lambda_{\max }=410\right.$ $\mathrm{nm})$....... 31

Scheme 2.5 a) Dose-Response Equation, where $\min$ is minimum enzyme activity, max is maximum enzyme activity, $I C_{50}$ is concentration of an inhibitor where $50 \%$ of its target activity is inhibited, $[x]$ is the inhibitor concentration, and $\mathrm{n}_{H}$ is Hill's coefficient. b) Cheng-Prusoff equation, where $K_{/}$is the binding affinity of the inhibitor, $[S]$ is fixed substrate concentration and $K_{m}$ is the concentration of substrate at which enzyme activity is at half maximal $\left(K_{m}=0.4 \mathrm{mM} p N P P\right)$.

Scheme 2.6 A hyperbolic equation to obtain values of $\mathrm{K}_{/}$and $k_{\text {inact. }}$ where $k_{\mathrm{obs}}=$ observed $1^{\text {st }}$-order rate of inactivation, $k_{\text {inact }}=1^{\text {st }}$-order rate of inactivation, $\mathrm{K}_{\mathrm{I}}=$ dissociation constant, $[\mathrm{I}]=$ concentration of an inactivator 38

\section{LIST OF TABLES}

\section{Chapter 1}

Table $2.1 \mathrm{IC}_{50}$ values in $4 \%$ and $20 \%$ DMSO, and low and high salt condition. 


\begin{abstract}
Type II Diabetes (T2DB) is one of the worldwide problems characterized by ineffective insulin signal transduction as a result of insulin resistance and impaired glucose homeostasis. Protein Tyrosine Phosphatase 1B (PTP1B), an enzyme in phosphatase family that share a conserved structure in their catalytic domain, is a major regulator of the signal transduction. The enzyme functions by dephosphorylation of insulin receptor and insulin receptor substrate. Genetic and experimental evidences suggested that the enzyme is an attractive drug target for Type II Diabetes. Many research groups have attempted to develop inhibitors of PTP1B. However, none of them has made it to the drug market due to inefficiency to function. Development of PTP1B inhibitor has proven rather difficult owing to three main challenges, i.e. potency, selectivity, and cell permeability. Here, we report a novel strategy that possibly overcomes those main challenges. I describe the development of potential exo-affinity labeling agents targeting PTP1B function, investigation of potency of the agents which were are reported as $I_{50}$ values, as well as kinetics study of those compounds against the enzyme.
\end{abstract}




\section{Chapter 1 \\ Type II Diabetes, PTP1B, \& Current Inhibitors of \\ PTP1B}

\section{1) Introduction: Type II Diabetes, a nationwide problem.}

Diabetes is a metabolic disease resulting from either failure of insulin production by $\beta$-cells in the pancreas or impaired insulin sensitivity. ${ }^{1}$ Diabetes is a national health problem with data from the 2011 National Diabetes Fact Sheet showing that 25.8 million children and adults in the United States $-8.3 \%$ of the population-have the disease. ${ }^{2}$ Moreover, diabetes is linked to many other health issues. In 2004, for example, $68 \%$ and $16 \%$ of people in the age of 65 or older died from diabetes-related heart disease and diabetes-related stroke, respectively. Furthermore, diabetes also leads to high blood pressure, blindness, kidney disease, nervous system disease, and amputation. In 2007, diabetes was the seventh leading cause of death, accounting for 231,404 deaths. Additionally, cost of diagnosed diabetes in the US was \$245 billions in 2012 . These show that diabetes is a serious nation's health problem and new medical treatments are needed.

Diabetes is divided into two major types. Type 1 diabetes (T1DB), so-called insulindependent, is commonly found in children and young adults and is characterized by failure to produce insulin due to the body's immune destruction of pancreatic $\beta$-cells. ${ }^{3}$ People with T1DB need insulin from external sources such as insulin injection or pump. The other type of diabetes is type 2 diabetes (T2DB) which is called non-insulindependent diabetes. T2DB is the most common and accounts for about $90 \%$ to $95 \%$ of all 
diagnosed cases of diabetes. ${ }^{4}$ Unlike T1DB, this type of diabetes is characterized by insulin resistance and impaired glucose tolerance (IGT). ${ }^{4,5}$ In other words, cells of people with T2DB do not response properly to insulin, a peptide hormone that normally signals glucose uptake. Consequently, the glucose in blood stream is accumulated, leading to high blood glucose (hyperglycemia) and at this point glucose becomes toxic (glucotoxicity). Meanwhile, pancreatic $\beta$-cells is in stress due to producing more insulin to compensate for insulin resistant. Increasing this stress overtime, IGT evolves to T2DB. 6,7 T2DB was previously observed primarily in adult populations, associated with a sedentary lifestyle, but has now also become a medical problem in children. ${ }^{8,9}$ Increase in these driving factors of T2DB as well as inadequate and ineffective current therapeutic methods have caused the disease to become an epidemic. ${ }^{9}$ Therefore, a new approach to the cure and understanding the mechanism associated with the disease are needed.

\section{2) Insulin signaling transduction and Protein Tyrosine Phosphatases}

\section{(PTPs)}

Insulin is a peptide hormone produced by $\beta$-cells of pancreas. The hormone functions by controlling carbohydrate and fat metabolism in peripheral (liver, muscle, fat) and central (hypothalamus) tissues ${ }^{7}$ through the mechanism called insulin signaling transduction.

Insulin signaling transduction begins with insulin-induced autophosphorylation at tyrosine residues of the Insulin Receptor (IR) (figure 1.1)..$^{10}$ This activation results in recruitment and chain phosphorylation of Insulin Receptor Substrates (IRS) and 
downstream substrates such as phosphatidylinositol 3-kinase (PI3K), protein kinase B and (PKB; also known as AKT). The activation of IR also leads to relocation of glucose transporter 4 (GLUT4) which transports glucose into the cell and subsequently decreases concentration of blood glucose. ${ }^{11,12}$ This process is negatively controlled by protein tyrosine phosphatases (PTPs). ${ }^{13}$ Studies have shown that several PTPs, i.e. receptor protein tyrosine phosphatase- $\alpha$ (rPTP- $\alpha)$, leukocyte antigen-related tyrosinephosphatase (LAR), SH2-domain-containing phosphotyrosine phosphatase (SHP2), and protein tyrosine phosphatase 1B (PTP1B) modulate the insulin signal transduction. ${ }^{13-15}$ PTP1B is the major contributor in modulating insulin signal transduction. ${ }^{15}$ Therefore, inhibition of PTP1B may offer a new therapeutic method of T2DB.

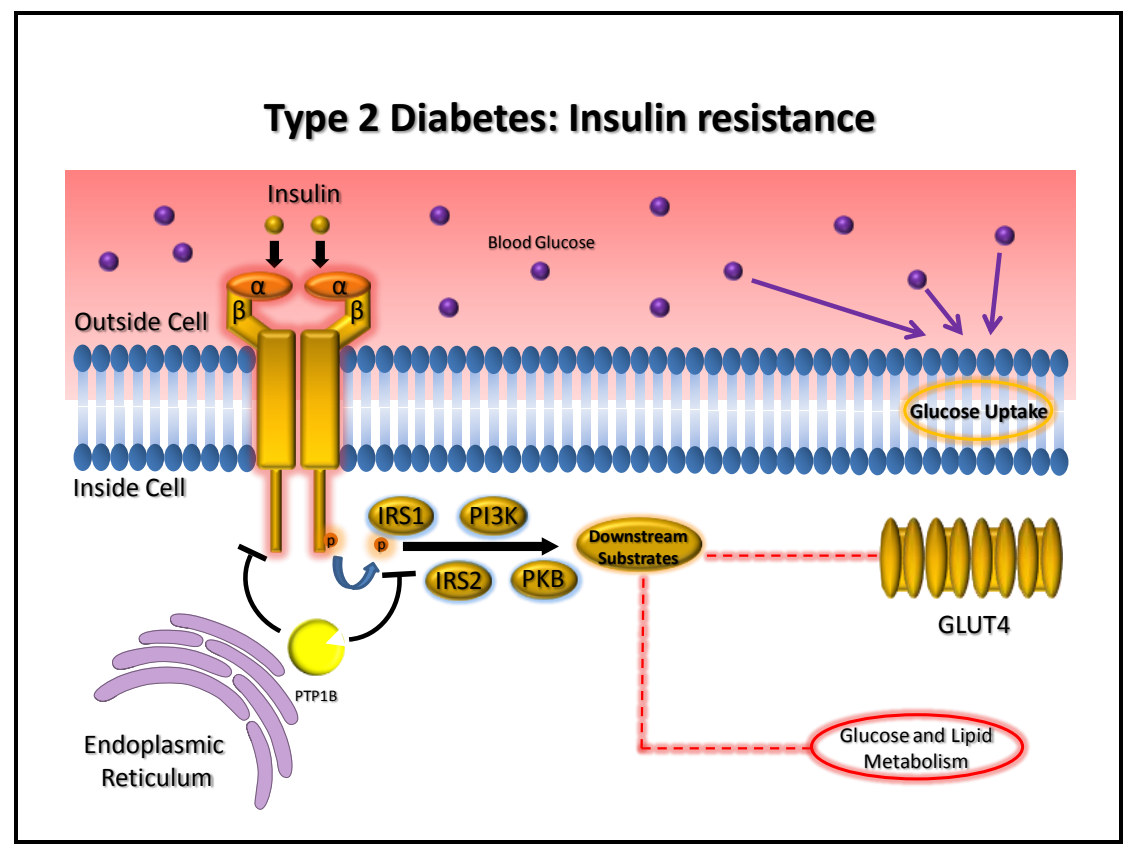

Figure 1.1 Insulin Signaling Transduction scheme. The signaling pathway is negatively regulated by PTP1B. 


\section{3) Evidences link PTP1B to T2DB}

There is evidence showing that PTP1B negatively regulates the insulin signaling pathway both in vitro and in vivo. For instance, two studies conducted by Chen et al. and Venable et al. showed that when PTP1B in rat primary adipose tissue was over expressed, insulin-sensitivity of GLUT4 translocation was decrease. ${ }^{16,17}$ Similarly, the effect of insulin on PTP1B activity is also studied by two independent groups. Mahadev et. al. discovered that insulin diminished PTP1B activity in vitro by promoting the production of hydrogen peroxide $\left(\mathrm{H}_{2} \mathrm{O}_{2}\right),{ }^{18}$ an active-site directed inactivator of PTP1B. Tao et. al. revealed that PTP1B activity was reversibly regulated by insulin through tyrosine phosphorylation in vivo. ${ }^{19}$ There are not only studies that associate PTP1B activity with insulin sensitivity, but also there are studies showing that PTP1B could be a potential drug target of T2DB. Firstly, studied in 1999 and 2000, PTP1B-deficient mice showed increased insulin sensitivity and resistance to weight gain on a high-fat diet. ${ }^{19,20}$ Secondly, an evidence from crossing the PTP1B-deficient mouse onto an ob/ob (genetically severe obesity with hyperphagia and diabetes) background revealed that resting metabolic rate was enhanced as well as adipose (fat) tissue was lowered resulting in reduced weight gain. ${ }^{21}$ Lastly, in 2002, when ob/ob mice was treated with PTP1B antisense oligonucleotide, reduced blood glucose levels and increased insulin sensitivity in fat and lever cell were observed. ${ }^{22}$ These evidences show that PTP1B inhibition could serve as a promising drug target for treatment of T2DB. 


\section{4) Structure of PTP1B}

Because PTP1B has been validated as a drug target of T2DB, structural and functional insight of PTP1B might be used to develop a new therapeutic approach. Following to the data connecting PTP1B and T2DB mentioned above, there have been many studies related to PTPs. 107 enzymes in PTP super family were identified as a result of completion of the human genome sequences in $2001 .{ }^{23}$ PTPs were divided into four subfamily, i.e. class I, class II, class III, and class IV. ${ }^{24}$ Class I is the largest and consists of 99 members which are compose of 61 dual-specific phosphatases and 38 classical PTPs. The latter PTPs comprised of 21 receptor PTPs and 17 non-receptor PTPs. PTP1B is a cysteine-based non-receptor PTP in this class.

PTP1B is composed of 435 amino acid residues, of which the residue 30-278 are the catalytic domain, 35 carboxy-terminal residues are proline rich which facilitate the interaction of the enzyme to the endoplasmic reticulum. Catalytic loop of the enzyme contains an active site, the WPD (Trp179, Pro180, and Asp181) loop and the secondary aryl-phosphate binding site which is catalytically inactive, and provides weaker binding interactions compared with the primary site. ${ }^{25}$ Additionally, YRD (Tyr46, Arg47, and Asp48) motif and the gateway residue Gly259 are located in the catalytic domain, controlling phosphatase substrate selectivity. The active site consists of residue 214221(His, Cys, Ser, Ala, Gly, Ile, Gly, and Arg) with Cys215 as a catalytic residue, as well as the residues residing on the catalytic cleft, Asp181, Phe182, Tyr46, Val49, Lys120 and Gln262 which contribute to catalysis and substrate recognition. The depth of the catalytic site is 8-9 A. This depth defies the substrate selectivity as serine and threonine substrate 
are not long enough to allow nucleophilic attack by Cys215. The WPD loop (Trp179, Phe180, Asp181) is also account for enzymatic catalysis by undergoing conformational change - open and closed conformations - upon substrate binding. ${ }^{26}$ When binding to a phosphotyrosine substrate (pY), WPD loop moves up to $12 \AA$ forming hydrophobic interactions with the phenyl ring of $\mathrm{pY}$ as well as Asp181 and Arg221 simultaneously relocate to provide general acid catalysis and optimized salt bridge interaction with the phosphate group of the substrate, respectively. The conformational change allows Cys215 to position for nucleophilic attack on the substrate phosphorous atom promoting dephosphorylation catalysis.

\section{5) Dephosphorylation Mechanism of PTP1B}

The general mechanism of PTP1B in dephosphorylation its phosphotyrosine substrate $(p Y)$ is described below (Scheme 1.1). The dianionic $p Y$ is recognized and bind to the positively charged active site of PTP1B that composes of eight amino acids residues His214-Arg221. The active site containing a nucleophilic Cys215 residue is unexposed to solvent. Stabilization within the active site causes Cys215 to possess an unusual decreased $\mathrm{pK}_{\mathrm{a}}$ value of 4.5-6 approximately compared to normal protein cysteines that have $\mathrm{pK}_{\mathrm{a}}$ value of about $8 .{ }^{27}$ When binding to $\mathrm{pY}$, Asp181 acting as a general acid moves closer onto the active site and facilitates nucleophilic attack by Cys215 at the phosphorous center of pY. The dephosphorylated substrate then diffuses off the active site and a water molecule subsequently undergoes nucleophilic attack of phospho-cysteine intermediate to 
regenerate the Cys215 in the active site. This process is catalyzed by Asp181 as a general base catalyst.
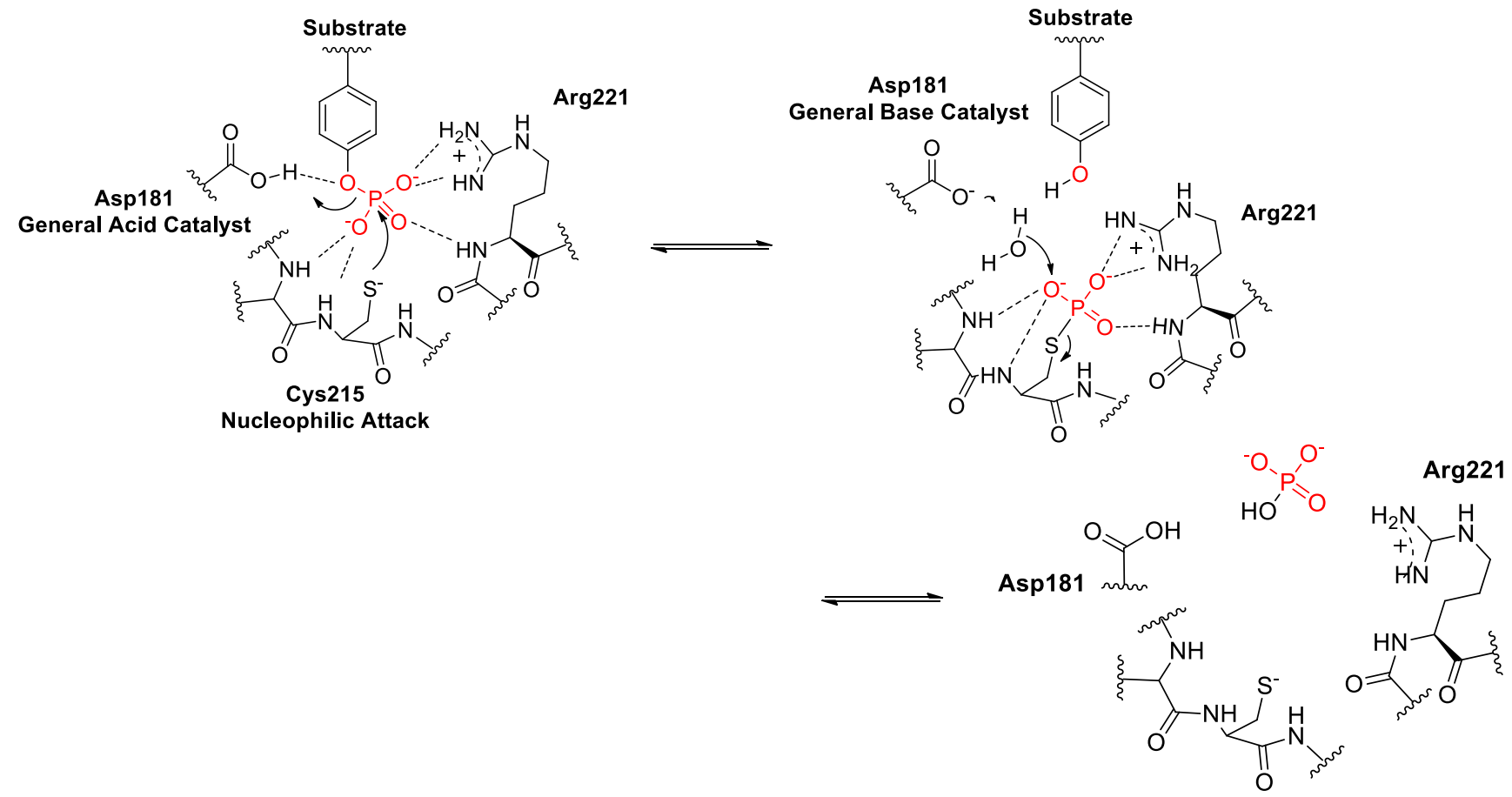

Scheme 1.1 Dephosphorylation Mechanism of PTP1B. ${ }^{28}$

\section{6) Current PTP1B inhibitors and their inadequate inhibitory activity}

There had been efforts to develop competitive inhibitors of PTP1B. However, the development was found to be rather difficult and three main challenges were addressed, i.e. potency/affinity, selectivity, and cell permeability.

Typical PTP1B inhibitors gained potency/affinity by binding two sites, i.e. the active site pocket and a site proximal to the active site, on the enzyme target (figure 1.2). The inhibitors bound to the active site by mimicking the binding manner of $\mathrm{pY}$ and simultaneously interacted with the proximal site to the active site. This binding mode, 
called "Dual Binding," allowed the inhibitors to bind to PTP1B more tightly than pY and gained higher affinity which led to greater potency.

Selectivity to PTP1B over PTPs still remained challenging. Although some of these inhibitors exhibited high affinity to the enzyme active site, they could not differentiate between the active site of PTP1B and the active sites of PTPs, resulting in promiscuous inhibition, especially the inhibition of T-Cell PTP (TC-PTP), the highly homologous (identical active site, WPD loop, YRD loop, and 74\% sequence identity in the catalytic domain) to PTP1B. The consequence of inhibiting TC-PTP was unclear but there was a study showing that TC-PTP-deficient mice died within 3-5 weeks. ${ }^{25}$ Therefore, good selectivity to PTP1B was one of the desired property of PTP1B inhibitor.

Unfortunately, few inhibitors that possessed high potency and good selectivity prevented them from penetrating cell membranes. Examples of current PTP1B inhibitors are provided below.
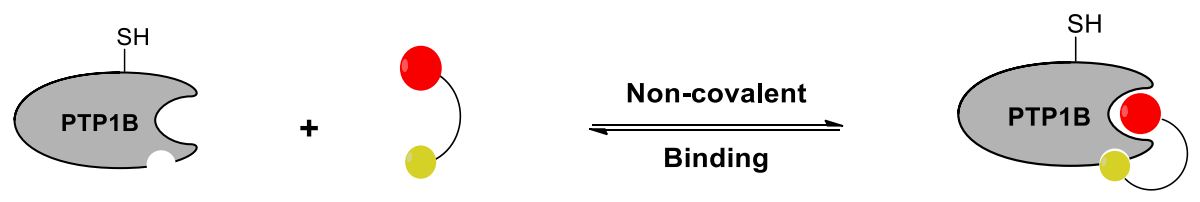

Dual Binding

Inhibitors

Figure 1.2 Binding mode of typical dual binding inhibitor.

Difluoromethyl Phosphonate (DFMP) Phosphotyrosine Isosteres which are the first major pY mimetic discovered by Burke et. al. in 1994 have been developed for decades. ${ }^{29}$ One of the most potent PTP1B inhibitor 1 to date was reported by Zhang et. al. (figure 1.3). Utilizing dual binding strategy with the active site and a secondary arylphosphate binding site as well as charge-charge interactions and interactions of difluorine 
atoms to several enzyme residues contributed to high potency with $\mathrm{K}_{\mathrm{i}}$ (dissociation constant) of $2.4 \mathrm{nM}^{30}$ Regardless of the high potency, the inhibitor was only 10 -fold selective to PTP1B over closely homologous TC-PTP. Furthermore, because of the bisanionic property, the inhibitor exhibited poor cell permeability and low oral bioavailability. ${ }^{31}$

Similarly, Merck Frosst developed a dual-binding benzotriazo DFMP 2 that possessed great potency with $\mathrm{IC}_{50}$ value of $5 \mathrm{nM}^{32}\left(\mathrm{IC}_{50}\right.$ is the inhibitor concentration where the enzyme activity is decreased by 50\%, figure 1.3). Co-crystal structure of $\mathbf{2}$ and PTP1B showed that the inhibitor bound to the active site and another secondary phosphotyrosine binding site. ${ }^{22,33}$ However, the compound achieved only 7-fold selectivity over TC-PTP and exhibited undesirable pharmacokinetics due to bis-anionic nature.
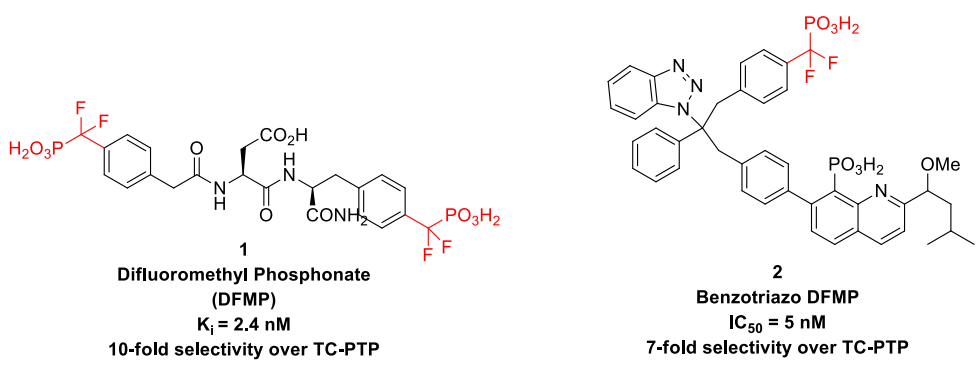

Figure 1.3 Difluoromethyl Phosphate $\mathbf{1}$ developed by Zhang et. al. and Benzotriazo DFMP $\mathbf{2}$ developed by Merck Frosst.

Mono and Dicarboxylic Acid Phosphotyrosine Isosteres The efforts to improve cell permeability, by reducing the negative charges, resulted in replacing DFMP scaffold with one or more carboxylic acid groups. Several novel carboxylic acid-containing inhibitors 3$5^{33-35}$ achieved good to excellent inhibitory potency $(5-1000 \mathrm{nM})$ with moderate selectivity 
over TCPTP (<20-fold) (figure 1.4). These compounds, however, still suffered from poor cell membrane penetration. ${ }^{33-35}$
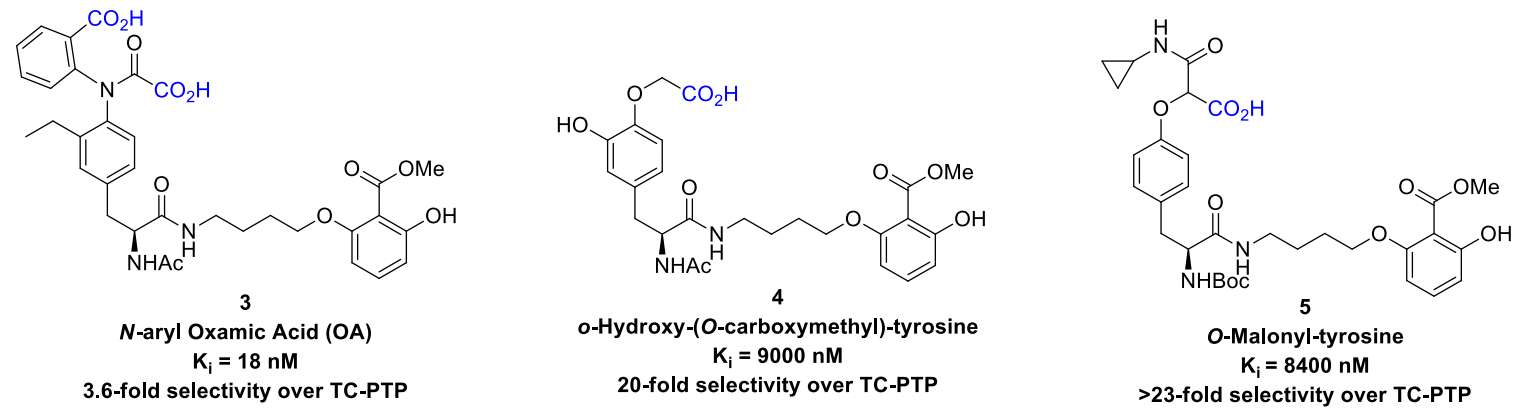

Figure 1.4 Carboxylic acid-containing PTP1B inhibitors 3-5 developed by Abbott.
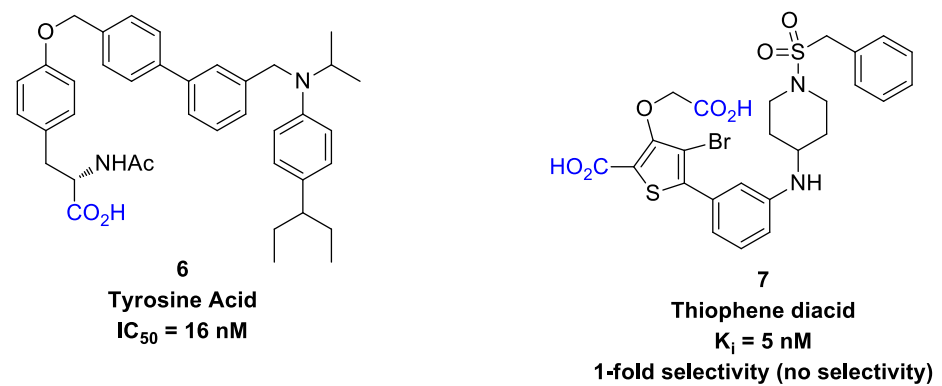

Figure 1.5 Tyrosine Acid $\mathbf{6}$ and Thiophene diacid $\mathbf{7}$ developed by The Institutes for Pharmaceutical Discovery and Wyeth respectively.

The Institutes for Pharmaceutical Discovery and Wyeth also published highly potent inhibitors of PTP1B $6\left(\mathrm{IC}_{50}=16 \mathrm{nM}\right)^{36}$ and $7\left(\mathrm{~K}_{\mathrm{i}}=5 \mathrm{nM}\right)^{37}$, respectively (figure 1.5). Nonetheless, due to extremely hydrophobic and high molecular weight (MW), 6 fell off the range of drug-like properties according to Lipinski's rule of $5 .^{38}$ Likewise, although 7 demonstrated excellent potency, it lacked of selectivity and cellular activity. 

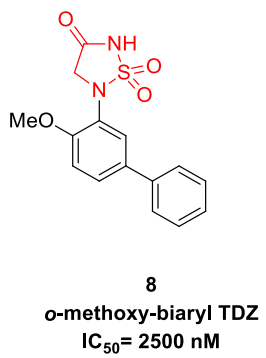
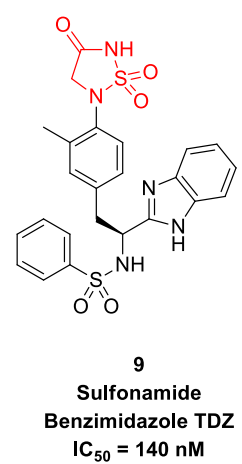
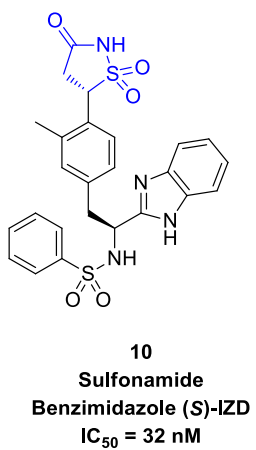
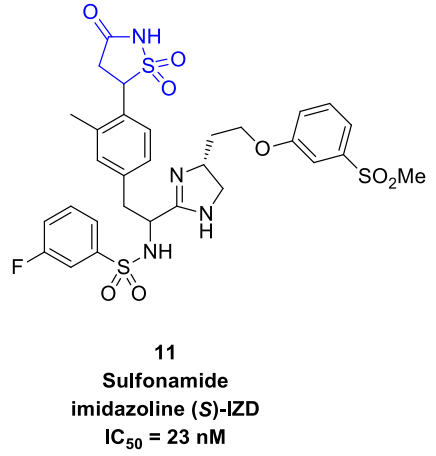

Figure 1.6 PTP1B inhibitors containing TDZ or IZD 8-11.

Heterocyclic Phosphotyrosine Isosteres Another class of PTP1B inhibitors contained a diffusely anionic heterocycles, 1,2,5-thiadiazolidin-3-one-1,1-dioxides (TDZs) $^{39,40,41,42-44}$ or (S)-isothiazolidinones ((S)-IZD) 8-11 (figure 1.6). ${ }^{45,46,47,48}$ This class was an attempt to reduce di-anionic charge found in DFMP and carboxylic acid-containing inhibitors, in order to improve cell membrane penetration. Based on parallel artificial membrane permeability assay (PAMPA) data, the cell permeability trend was TDZs (0.19$3.54 \mathrm{~nm} / \mathrm{s})>$ monoacid $(0.22 \mathrm{~nm} / \mathrm{s})>$ diacid $(0.00 \mathrm{~nm} / \mathrm{s}) \cdot{ }^{46}$ Furthermore, regarding low molecular mass, these inhibitors were also in the range of drug-like properties. ${ }^{46}$

Owing to the advantage of these heterocyclic compounds concerning cell permeability, TDZ is the $\mathrm{pY}$ isostere $\left(\mathrm{pY} \mathrm{Y}_{\mathrm{i}}\right)$ of choice that we employ in our work.

\section{7) Growing Interest of Covalent Drugs}

Regarding inadequate efficiency of the current PTP1B inhibitors, a new class of the inhibitor which possesses the desired potency, selectivity, and cell permeability as well as drug-like properties was needed. Intriguingly, there was growing interest in another type of inhibitor, called covalent inhibitors. ${ }^{49}$ This type of inhibitor, or so-called inactivator or irreversible inhibitor, bound to their targets similar to that of reversible inhibitor, but they 
were capable of forming a covalent bond to the targets, resulting in irreversible inhibition or inactivation of the target activity. For example, In 1998, Fry et al. reported an irreversible inactivator of epidermal growth factor receptor (EGFR). ${ }^{50}$ Due to covalently modification, the potency of the inactivator increased by 5 -fold in vivo. In 2005, Taunton and team reported fluoromethylketone-pa (fmk-pa) that specifically formed covalent bond with p90 ribosomal protein S6 kinase 1 (RSK1) and p90 ribosomal protein S6 kinase (RSK2) in mammalian cells. ${ }^{51}$ The cellular potency was also increased by 5-fold compared to that of reversible inhibitor fmk. In 2007, Cravatt's group ${ }^{52}$ designed covalent inhibitors which were highly selective to fatty acid amide hydrolase (FAAH), while non-covalent inhibitors modified multiple serine hydrolases. These studies proved that covalent inhibitor achieved high potency and selectivity as the main challenges in development of PTP1B inhibitor.

Furthermore, there were evidences showing that covalent modification could improve not only potency and selectivity of this type of inhibitor, but also rate of reaction via proximal acceleration. Proximal acceleration occurred when two reactive groups were held closely to each other and in the right conformation. The proximity and the complementary angle facilitated bond formation and thus enhanced the rate of reaction. ${ }^{53}$ For instance, Belshaw ${ }^{54}$ et. al. compared efficiency in inhibition of an engineered receptor-ligand with and without complementary reactive groups to a reactive cysteine residue of a receptor. Within $16 \mathrm{~h}$, the former reduced the activity of the receptor to $0 \%$, while the activity inhibited by the latter remained at $76 \%$. Meares and co-worker developed ligands containing electrophilic groups for mutant antibody (S95C 
and N96C) fab fragment. ${ }^{55}$ With covalent modification, $50 \%$ of the mutant fab containing a complementary group to that of the ligands was bound in $10 \mathrm{~min}$, whereas the same amount of mutant fab without the complementary group took 50-100 min at the same condition. Wells and team reported a proximity-accelerated reaction, called "Tethering Strategy" where a nucleophilic cysteine residue and an electrophilc disulfide were introduced into thymidylate synthase and a ligand (called tethering ligand), respectively. ${ }^{56}$ Due to the complementary groups, $\mathrm{K}_{\mathrm{i}}$ (dissociation constant) of the tethering ligand was found to be improved by 3000 -fold, comparing to a ligand without disulfide (called untethering ligand). Additionally, Gartner and Liu reported the enhanced rate of DNAdouble stranded synthesis through proximity acceleration when a DNA template was modified with an electrophilic group that non-complementary and complementary to a nucleophilic thiol group on DNA oligonucleotide. ${ }^{57}$ However, no reaction occured when the electrophilic group was non-complementary to the thiol group. Mentioned earlier, an irreversible and selective inhibitor of EGFR was made by Fry and team. ${ }^{50}$ With the proximity-acceleration reaction, the irreversible inhibitor containing an electrophilic acrylamide took 1 min to reach 100\% inhibition by labeling Cys773 of EGFR, whereas the reversible inhibitor did not showed inhibition even extending time to $8 \mathrm{~h}$. As far as the evidences above were concerned, the covalent modification was proved to be a promising key to achieve potency and selectivity of a novel class of PTP1B inhibitor. 


\section{8) Goal of Thesis}

T2DB has become a serious national problem in the past decades and the current treatments of T2DB are ineffective. PTP1B was proved to be a potential drug target to treat this disease, but the development of new PTP1B inhibitors with the desired inhibitory properties (potency/affinity, selectivity, and cell permeability) was rather difficult and remained challenging. This leads to the need in a novel strategy to combat T2DB.

Concomitantly, there was growing attention in development of covalent drug industry due to promising properties of the drugs that could provide greater inhibitory efficiency over non-covalent drug, i.e. improved potency, higher selectivity, and accelerated rate of inhibitory reaction. Therefore, utilizing covalent binding strategy became attractive to include in our strategy aiming PTP1B inhibition.

The goal of this thesis is to develop a new class of PTP1B inhibitors that provide the desired inhibitory efficiency and could serve as a new covalent drug of T2DB as well as to study inhibitory kinetics of the inhibitors for future optimization. 


\section{9) Reference}

(1) Gardner, D. G.; Shoback, D. M. G., F.S. Greenspan's Basic \& Clinical Endocrinology; McGraw-Hill Medical: New York, 2011.

(2) Prevention, C. f. D. C. a.; Department of Health and Human Services, Centers for Disease Control and Prevention: Atlanta, GA, 2011.

(3) Cihakova, D.; John Hopkins Medical Institutions: 2013; Vol. 2013.

(4) Kumar, V.; Fausto, N.; Abbas, A. Robbins and Cotran Pathologic Basis of Disease; 7 ed.; Saunders: Philadelphia, 2005.

(5) Groop, L.; Orho-Melander, M. J Intern Med 2001, 250, 105.

(6) Poitout, V.; Robertson, R. P. Endocrinology 2002, 143, 339.

(7) Tiganis, T. FEBS J. 2013, 280, 445.

(8) Sinha, R.; Fisch, G.; Teague, B.; Tamborlane, W. V.; Banyas, B.; Allen, K.; Savoye, M.; Reiger, V.; Taksali, S.; Barbetta, G.; Sherwin, R. S.; Caprio, S. N. Engl. J. Med. 2002, 346, 802.

(9) Rocchini, A. P. N Engl J Med 2002, 346, 854.

(10) Saltiel, A. R.; Pessin, J. E. Trends Cell Biol. 2002, 12, 65.

(11) Bryant, N. J.; Govers, R.; James, D. E. Nat. Rev. Mol. Cell Biol. 2002, 3, 267.

(12) Smith, U. Int J Obes Relat Metab Disord 2002, 26, 897.

(13) Cheng, A.; Dube, N.; Gu, F.; Tremblay, M. L. Eur. J. Biochem. 2002, 269, 1050.

(14) Ostman, A.; Bohmer, F. D. Trends Cell Biol. 2001, 11, 258.

(15) Goldstein, B. J.; Bittner-Kowalczyk, A.; White, M. F.; Harbeck, M. J. Biol. Chem. 2000, 275, 4283.

(16) Chen, H.; Wertheimer, S. J.; Lin, C. H.; Katz, S. L.; Amrein, K. E.; Burn, P.; Quon, M. J. J. Biol. Chem. 1997, 272, 8026.

(17) Venable, C. L.; Frevert, E. U.; Kim, Y.-B.; Fischer, B. M.; Kamatkar, S.; Neel, B. G.; Kahn, B. B. J. Biol. Chem. 2000, 275, 18318.

(18) Mahadev, K.; Wu, X.; Zilbering, A.; Zhu, L.; Lawrence, J. T. R.; Goldstein, B. J. J. Biol. Chem. 2001, 276, 48662. 
(19) Elchebly, M.; Payette, P.; Michaliszyn, E.; Cromlish, W.; Collins, S.; Loy, A. L.; Normandin, D.; Cheng, A.; Himms-Hagen, J.; Chan, C.-C.; Ramachandran, C.; Gresser, M. J.; Tremblay, M. L.; Kennedy, B. P. Science (Washington, D. C.) 1999, 283, 1544.

(20) Klaman, L. D.; Boss, O.; Peroni, O. D.; Kim, J. K.; Martino, J. L.; Zabolotny, J. M.; Moghal, N.; Lubkin, M.; Kim, Y.-B.; Sharpe, A. H.; Stricker-Krongrad, A.; Shulman, G. I.; Neel, B. G.; Kahn, B. B. Mol. Cell. Biol. 2000, 20, 5479.

(21) Cheng, A.; Uetani, N.; Simoncic, P. D.; Chaubey, V. P.; Lee-Loy, A.; McGlade, C. J.; Kennedy, B. P.; Tremblay, M. L. Dev. Cell 2002, 2, 497.

(22) Zinker, B. A.; Rondinone, C. M.; Trevillyan, J. M.; Gum, R. J.; Clampit, J. E.; Waring, J. F.; Xie, N.; Wilcox, D.; Jacobson, P.; Frost, L.; Kroeger, P. E.; Reilly, R. M.; Koterski, S.; Opgenorth, T. J.; Ulrich, R. G.; Crosby, S.; Butler, M.; Murray, S. F.; McKay, R. A.; Bhanot, S.; Monia, B. P.; Jirousek, M. R. Proc. Natl. Acad. Sci. U. S. A. 2002, 99, 11357.

(23) Combs, A. P. J. Med. Chem. 2010, 53, 2333.

(24) Wang, W.-Q.; Sun, J.-P.; Zhang, Z.-Y. Curr. Top. Med. Chem. (Sharjah, United Arab Emirates) 2003, 3, 739.

(25) Johnson, T. O.; Ermolieff, J.; Jirousek, M. R. Nat. Rev. Drug Discovery 2002, 1, 696.

(26) Jia, Z.; Barford, D.; Flint, A. J.; Tonks, N. K. Science (Washington, D. C.) 1995, 268, 1754.

(27) Denu, J. M.; Tanner, K. G. Methods Enzymol. 2002, 348, 297.

(28) Seiner, D. R.; LaButti, J. N.; Gates, K. S. Chem. Res. Toxicol. 2007, 20, 1315.

(29) Burke, T. R., Jr.; Kole, H. K.; Roller, P. P. Biochem. Biophys. Res. Commun. 1994, 204, 129.

(30) Puius, Y. A.; Zhao, Y.; Sullivan, M.; Lawrence, D. S.; Almo, S. C.; Zhang, Z.-Y. Proc. Natl. Acad. Sci. U. S. A. 1997, 94, 13420.

(31) Chen, L.; Wu, L.; Otaka, A.; Smyth, M. S.; Roller, P. P.; Burke, T. R., Jr.; den Hertog, J.; Zhang, Z.-Y. Biochem. Biophys. Res. Commun. 1995, 216, 976.

(32) Lau, C. K.; Bayly, C. I.; Gauthier, J. Y.; Li, C. S.; Therien, M.; Asante-Appiah, E.; Cromlish, W.; Boie, Y.; Forghani, F.; Desmarais, S.; Wang, Q.; Skorey, K.; Waddleton, D.; Payette, P.; Ramachandran, C.; Kennedy, B. P.; Scapin, G. Bioorg. Med. Chem. Lett. 2004, 14, 1043.

(33) Scapin, G.; Patel, S. B.; Becker, J. W.; Wang, Q.; Desponts, C.; Waddleton, D.; Skorey, K.; Cromlish, W.; Bayly, C.; Therien, M.; Gauthier, J. Y.; Li, C. S.; Lau, C. K.; Ramachandran, C.; Kennedy, B. P.; Asante-Appiah, E. Biochemistry 2003, 42, 11451.

(34) Liu, G.; Xin, Z.; Pei, Z.; Hajduk, P. J.; Abad-Zapatero, C.; Hutchins, C. W.; Zhao, H.; Lubben, T. H.; Ballaron, S. J.; Haasch, D. L.; Kaszubska, W.; Rondinone, C. M.; Trevillyan, J. M.; Jirousek, M. R. J. Med. Chem. 2003, 46, 4232. 
(35) Xin, Z.; Liu, G.; Abad-Zapatero, C.; Pei, Z.; Szczepankiewicz, B. G.; Li, X.; Zhang, T.; Hutchins, C. W.; Hajduk, P. J.; Ballaron, S. J.; Stashko, M. A.; Lubben, T. H.; Trevillyan, J. M.; Jirousek, M. R. Bioorg. Med. Chem. Lett. 2003, 13, 3947.

(36) Van Zandt, M. C.; The Institutes for Pharmaceutical Discovery, LLC, USA . 2008, p 221pp.

(37) Wilson, D. P.; Wan, Z.-K.; Xu, W.-X.; Kirincich, S. J.; Follows, B. C.; Joseph-McCarthy, D.; Foreman, K.; Moretto, A.; Wu, J.; Zhu, M.; Binnun, E.; Zhang, Y.-L.; Tam, M.; Erbe, D. V.; Tobin, J.; Xu, X.; Leung, L.; Shilling, A.; Tam, S. Y.; Mansour, T. S.; Lee, J. J. Med. Chem. 2007, 50, 4681.

(38) Lipinski, C. A.; Lombardo, F.; Dominy, B. W.; Feeney, P. J. Adv. Drug Delivery Rev. 2001, $46,3$.

(39) Black, E.; Breed, J.; Breeze, A. L.; Embrey, K.; Garcia, R.; Gero, T. W.; Godfrey, L.; Kenny, P. W.; Morley, A. D.; Minshull, C. A.; Pannifer, A. D.; Read, J.; Rees, A.; Russell, D. J.; Toader, D.; Tucker, J. Bioorg. Med. Chem. Lett. 2005, 15, 2503.

(40) Combs, A. P.; Zhu, W.; Crawley, M. L.; Glass, B.; Polam, P.; Sparks, R. B.; Modi, D.; Takvorian, A.; McLaughlin, E.; Yue, E. W.; Wasserman, Z.; Bower, M.; Wei, M.; Rupar, M.; Ala, P. J.; Reid, B. M.; Ellis, D.; Gonneville, L.; Emm, T.; Taylor, N.; Yeleswaram, S.; Li, Y.; Wynn, R.; Burn, T. C.; Hollis, G.; Liu, P. C. C.; Metcalf, B. J. Med. Chem. 2006, 49, 3774.

(41) Sparks, R. B.; Polam, P.; Zhu, W.; Crawley, M. L.; Takvorian, A.; McLaughlin, E.; Wei, M.; Ala, P. J.; Gonneville, L.; Taylor, N.; Li, Y.; Wynn, R.; Burn, T. C.; Liu, P. C. C.; Combs, A. P. Bioorg. Med. Chem. Lett. 2007, 17, 736.

(42) Barnes, D.; Bebernitz, G. R.; Coppola, G. M.; Nakajima, K.; Stams, T.; Topiol, S. W.; Vedananda, T. R.; Wareing, J. R.; Novartis A.-G., Switz.; Novartis Pharma G.m.b.H. . 2007, p 136pp.

(43) Barnes, D.; Bebernitz, G. R.; Coppola, G. M.; Stams, T.; Topiol, S. W.; Vedananda, T. R.; Wareing, J. R.; Novartis A.-G., Switz.; Novartis Pharma G.m.b.H. . 2007, p 108pp.

(44) Barnes, D.; Coppola, G. M.; Damon, R. E.; Nakajima, K.; Raudenbush, B. C.; Stams, T.; Topiol, S. W.; Vedananda, T. R.; Novartis A.-G., Switz.; Novartis Pharma G.m.b.H. . 2007, p 94pp.

(45) Douty, B.; Wayland, B.; Ala, P. J.; Bower, M. J.; Pruitt, J.; Bostrom, L.; Wei, M.; Klabe, R.; Gonneville, L.; Wynn, R.; Burn, T. C.; Liu, P. C. C.; Combs, A. P.; Yue, E. W. Bioorg. Med. Chem. Lett. 2008, 18, 66 .

(46) Wan, Z.-K.; Follows, B.; Kirincich, S.; Wilson, D.; Binnun, E.; Xu, W.; Joseph-McCarthy, D.; Wu, J.; Smith, M.; Zhang, Y.-L.; Tam, M.; Erbe, D.; Tam, S.; Saiah, E.; Lee, J. Bioorg. Med. Chem. Lett. 2007, 17, 2913.

(47) Ala, P. J.; Gonneville, L.; Hillman, M.; Becker-Pasha, M.; Yue, E. W.; Douty, B.; Wayland, B.; Polam, P.; Crawley, M. L.; McLaughlin, E.; Sparks, R. B.; Glass, B.; Takvorian, A.; Combs, A. P.; Burn, T. C.; Hollis, G. F.; Wynn, R. J. Biol. Chem. 2006, 281, 38013. 
(48) Ala, P. J.; Gonneville, L.; Hillman, M. C.; Becker-Pasha, M.; Wei, M.; Reid, B. G.; Klabe, R.; Yue, E. W.; Wayland, B.; Douty, B.; Polam, P.; Wasserman, Z.; Bower, M.; Combs, A. P.; Burn, T. C.; Hollis, G. F.; Wynn, R. J. Biol. Chem. 2006, 281, 32784.

(49) Guterman, L. Chemical \& Engineering News 2011, 89, 8.

(50) Fry, D. W.; Bridges, A. J.; Denny, W. A.; Doherty, A.; Greis, K. D.; Hicks, J. L.; Hook, K. E.; Keller, P. R.; Leopold, W. R.; Loo, J. A.; McNamara, D. J.; Nelson, J. M.; Sherwood, V.; Smaill, J. B.; Trumpp-Kallmeyer, S.; Dobrusin, E. M. Proc. Natl. Acad. Sci. U. S. A. 1998, 95, 12022.

(51) Cohen, M. S.; Zhang, C.; Shokat, K. M.; Taunton, J. Science (Washington, DC, U. S.) 2005, $308,1318$.

(52) Ahn, K.; Johnson, D. S.; Fitzgerald, L. R.; Liimatta, M.; Arendse, A.; Stevenson, T.; Lund, E. T.; Nugent, R. A.; Nomanbhoy, T. K.; Alexander, J. P.; Cravatt, B. F. Biochemistry 2007, 46, 13019.

(53) Silverman, R. B. The Organic Chemistry of Enzyme-catalyzed Reactions; illustrated, revised ed.; Academic Press, 2002.

(54) Levitsky, K.; Ciolli, C. J.; Belshaw, P. J. Org. Lett. 2003, 5, 693.

(55) Chmura, A. J.; Orton, M. S.; Meares, C. F. Proc. Natl. Acad. Sci. U. S. A. 2001, 98, 8480.

(56) Erlanson, D. A.; Braisted, A. C.; Raphael, D. R.; Randal, M.; Stroud, R. M.; Gordon, E. M.; Wells, J. A. Proc. Natl. Acad. Sci. U. S. A. 2000, 97, 9367.

(57) Gartner, Z. J.; Liu, D. R. J. Am. Chem. Soc. 2001, 123, 6961. 


\section{Chapter 2 \\ Exo-affinity Labeling Agents \& PTP1B Inactivation}

In recent decades, pharmaceutical companies and industries have developed small molecules to regulate PTP1B activity, aiming to treat T2DB. None of them, however, have made it to the clinic. ${ }^{1}$ Balancing potency, selectivity, and cell permeability are the main reasons why discovery of PTP1B inhibitor still remain challenging. The active site of PTP1B is highly cationic and favor binding to complementary multiple negatively charged molecules. ${ }^{2-3}$ Hence, Multiple negatively charged PTP1B inhibitor, for example DFMP 1 and 2 (chapter 1, page 8) exhibited high affinity binding to the active site pocket. Unfortunately, the charges prevented the molecules to enter the cell, thus disqualified the molecules as drug candidates. Lastly, the active site structure of PTPs to where most of PTP1B inhibitors bound was very well conserved. This presages the difficulty to design a small molecule that selectively inhibit PTP1B over other PTPs, especially TCPTP, the highest identical to PTP1B in catalytic domain. In this chapter, we introduced a radically different strategy to regulate PTP1 activity and promisingly provide the desired properties.

\section{1) Exo-affinity Labeling Agent, a novel covalent inhibitor of PTP1B}

An affinity labeling agent is an irreversible inhibitor, ${ }^{4}$ or an inactivator, that covalent modifies a residue located inside (endo-affinity labeling) or outside (exo-affinity labeling) the catalytic site of the enzyme. There are two steps involved in the inactivation 
(Scheme 2.1). The first step is a fast (usually occurs within micro- or millisecond), reversible formation of an enzyme-agent complex $E \cdot I$. During this step, several amino acid residues on the enzyme active site form non-covalent interactions to the affinity labeling agent with the rate $k_{1}$. Simultaneously, the complex can fall back to a free enzyme molecule and a free affinity labeling agent molecule with the rate $k_{-1}$. These two processes result in equilibrium with a dissociation constant $\left(K_{I}\right)$ which is defined by $k_{-1} / k_{1}$. The noncovalent binding step is followed by covalent modification where two reactive and complementary groups on the enzyme and the agent, typically a nucleophile on the enzyme and an electrophile on the affinity labeling agent, form a covalent bond to give an enzyme-inactivator adduct $E-I$. This process proceeds with the pseudo-first-order rate constant $\left(k_{\text {inact }}\right)$. Since the covalent bond is formed, the affinity labeling agent remains at the active site irreversibly and prevented enzyme's activity by blocking the interaction with its substrate. In this thesis, we developed a family of exo-affinity labeling agent of PTP1B. The detail will be discussed below.

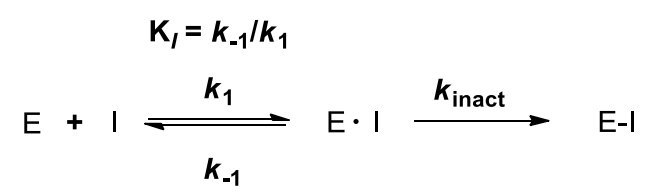

Scheme 2.1 Inactivation of an enzyme by an affinity labeling agent.

\section{2) Advantages of exo-affinity labeling agents over reversible inhibitors.}

We chose to explore exo-affinity labeling agents because of several advantages over the current PTP1B inhibitors, i.e. irreversible inhibition, higher inhibitory efficiency, and potentially greater specificity. 
Firstly, the enzyme inhibition by the exo-affinity labeling agents is irreversible but the inhibition by the current inhibitors is reversible. According to scheme 2.1 , the exoaffinity labeling agent binds to the target enzyme in two steps, non-covalent interactions

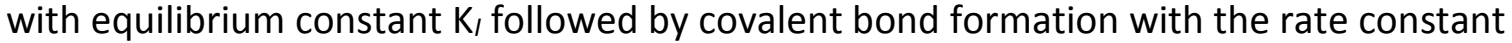
$k_{\text {inact. }}$ Upon the second step, the agents permanently bind to the target (infinite affinity), blocking the enzyme activity. Unlike permanent inhibition, the inhibition by current inhibitors is transient because they form only reversible interactions to the target enzyme. Therefore, as far as the covalent bond is concerned, the exo-affinity labeling agents provide irreversible inhibition or infinite affinity which will results in higher potency comparing to the current inhibitors.

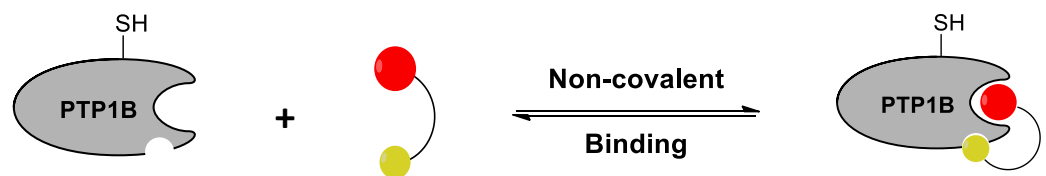

Dual Binding Inhibitors

Inhibited PTP1B

(Reversible Inhibition)

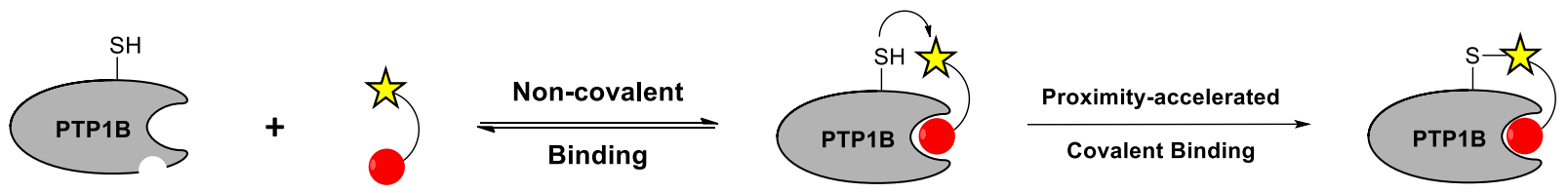

Exo-affinity Labeling Agent

Inactivated PTP1B (Irreversible Inhibition)

Figure 2.1 Irreversible inhibition versus transient inhibition.

Secondly, the affinity labeling agents have the potential for higher inhibitory efficiency, i.e. effective inhibition at high concentration of substrate, longer duration of inhibition, and lower required effective dose. First, at high concentration of an enzyme substrate, a competition for the enzyme active site between a reversible inhibitor and the 
substrate occurs, interrupting the equilibrium of the enzyme and the inhibitor. This interruption facilitates the rate of $E \cdot I$ complex breaking down $\left(k_{-1}\right)$ and causes the inhibition to be deficient. On the contrary, the exo-affinity labeling agents can bind to the target enzyme with the covalent bond. Once the permanent bond takes place, the exoaffinity labeling agents and the enzyme cannot fall back to their free forms. Thus, the competition might have no or little effect on the irreversible inhibition (Figure 2.2). Second, similar to the advantage of covalent drugs over non-covalent drugs, the exoaffinity labeling agents can also provide longer duration of inactivation. Once the covalent bond is formed, the activity of the enzyme will not be recovered until a new enzyme molecule is synthesized, resulting in longer inhibitory effect. Third, as long as the synthesis of the new enzyme was not too fast, another portion of the inactivator (or new dose of the drug) is not necessary and less dose is required to achieve a certain inhibitory effect, comparing to reversible inhibitors. Moreover, since less dose is needed, the possibility of possible adverse reactions which are highly concerned by many drug companies are also reduced. ${ }^{5}$ Taking these advantages to account, the affinity labeling agent could provide higher inhibitory efficiency than the current inhibitors. 


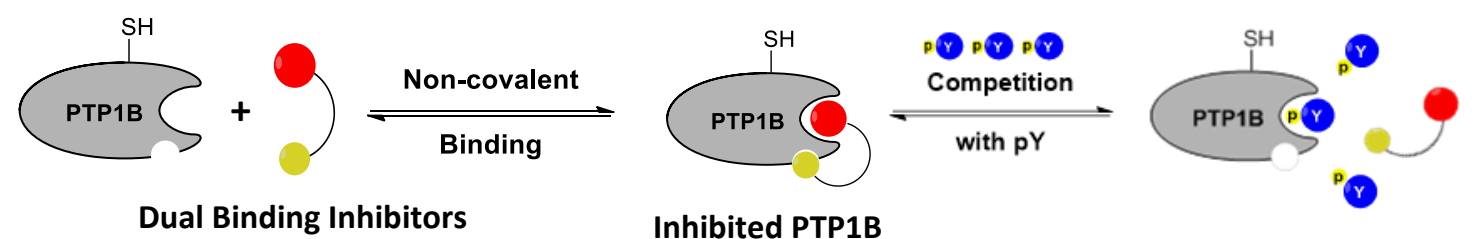

(The extent of Inhibition affected

by amount of $\mathrm{pY}$ )

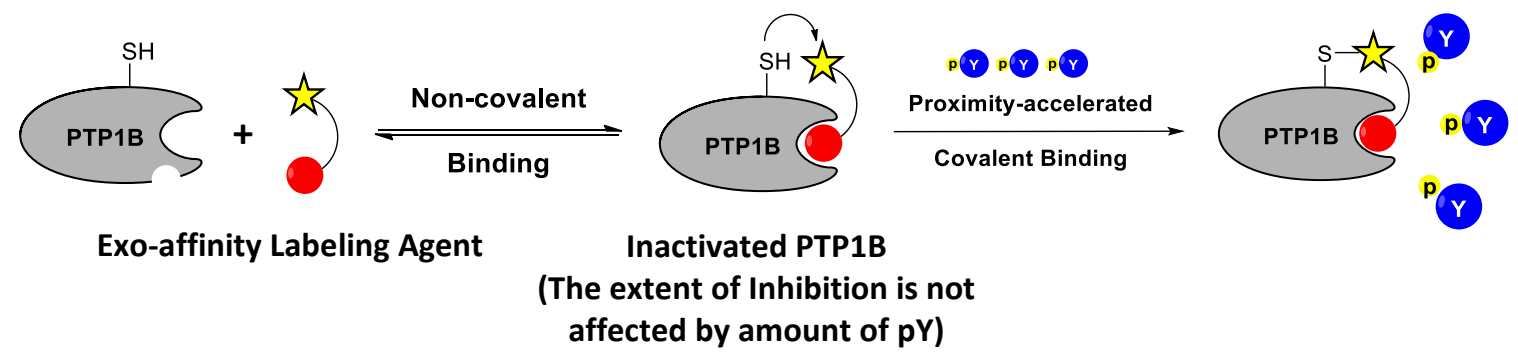

Figure 2.2 Inactivation by the exo-affinity labeling agent (top) and inhibition by a dual binding inhibitor (bottom). The exo-affinity labeling agent bound to PTP1B with a covalent bond. This irreversible interaction was not affected by the competition with the substrate (top). Dual binding inhibitors bound to PTP1B with non-covalent interactions. This reversible interaction was affected by competition with the substrate (bottom).

Lastly, greater selectivity over PTPs and common nucleophiles in physiological media can be achieved by the affinity labeling agents. There are two factors that contribute to the selectivity of the inactivators, i.e. proximity-accelerated reaction and targeting a distinct reactive residue. As mentioned earlier, the affinity labeling agents bind to the enzyme active site with fast and reversible non-covalent interactions, subsequently an irreversible covalent bond formation at a proximal residue on the enzyme surface. Upon the non-covalent binding step, one part of the agent is in the active site and the other part freely swing in/outside (depends on the structure) the active site pocket. At this point the active moiety on the agents (typically an electrophile) and a target residue on the enzyme (typically a nucleophile) are brought up more closely. Holding two reactive groups closer and in the right conformation for the reaction is similar to increasing the concentration of both groups, facilitating the rate of reaction. The concentration of the 
reactant or catalytic group required to cause the intermolecular reaction to proceed at the observed rate of the intramolecular reaction was called Effective Molarity (EM), defined by Kirby in $1980.6,7$ Regarding the proximal acceleration, the EM of $E \cdot I$ complex increases, the rate of inactivation, which is dependent directly on the concentration of $E \cdot I$ complex, also increases (Figure 2.3). In contrast, the common nucleophiles and some enzymes in PTP family, who do not possess an active site or whose active sites are not complementary to the structure of the affinity labeling agent, will not be capable of binding to the agent with non-covalent interactions. Thus, a reactive group on those nucleophile or enzymes and the reactive group on the agent cannot be brought up more closely and the rate of inactivation will not be improved by EM. Therefore the rate will be relatively slower than the rate of inactivation between the target enzyme and the agent.

(Figure 2.4a, b, c)
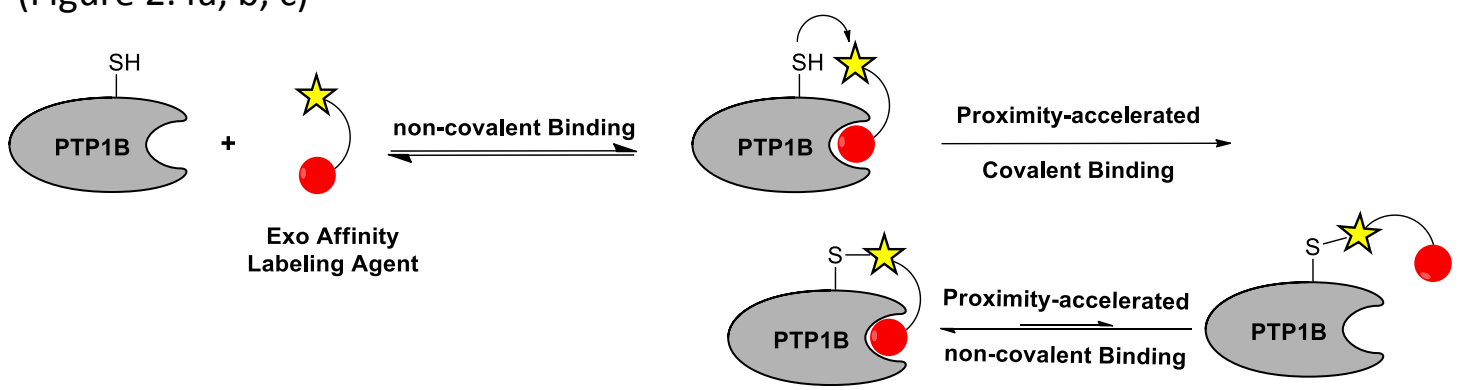

Inactivated PTP1B

Figure 2.3 Proximity-accelerated reaction of E-L-p $Y_{i}$. 
a)
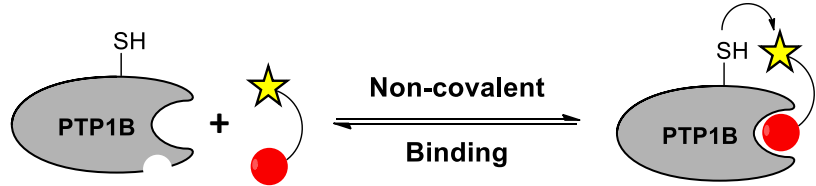

Proximity-accelerated

Covalent Binding

\section{Exo-affinity} Labeling Agent
Binding
Covalent Binding

Inactivated PTP1B (Irreversible Inhibition)

b)
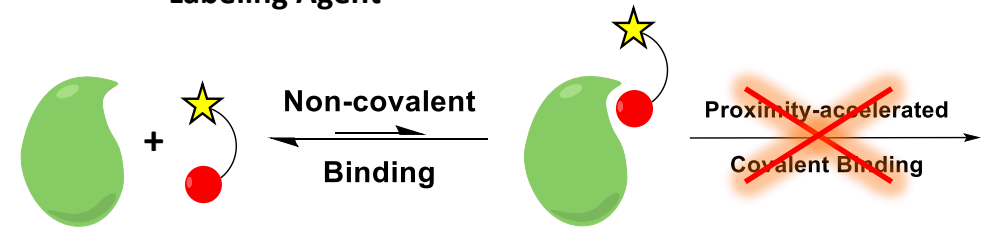

Inhibited enzyme

(Reversible Inhibition)

c)
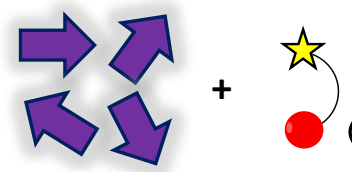

Relatively slow rate of covalent bond formation

(No proximity-accelerated reaction)

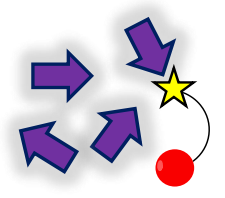

Common

Nucleophiles

d) $\mathrm{HS}$

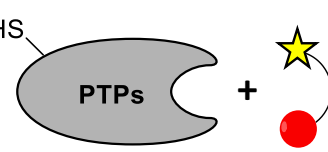

Homologous

Enzymes

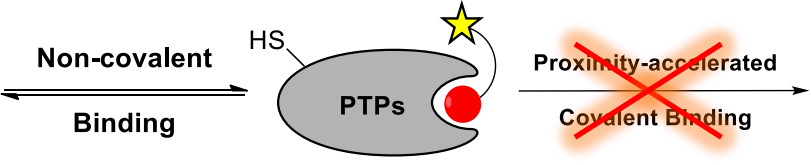

Transient Inactivation

Figure 2.4 Binding mode of an exo-affinity labeling agent to a) the target enzyme, b) other enzymes whose active sites are not complementary to the structure of the affinity labeling agent, c) common nucleophiles in physiological media and d) homologous enzyme without the reactive group or with the reactive group not located in the proper distance.

The other factor that contribute to greater selectivity over typical inhibitors is targeting a distinct reactive residue on the enzyme surface. Since the affinity labeling agents form covalent bond with a reactive amino acid in the active site or a certain distance away from the active site, if this amino acid is non-conserved (not found in other enzymes but PTP1B), the covalent bond formed will be exclusive to PTP1B. On the other hand, other PTPs that do not possess the reactive group or contain the reactive group but not the proper distance from the active site will not be able to form the covalent bond with the affinity labeling agents and the inhibition by the agents will be reversible like that 
of common inhibitors (Figure 2.4d). Therefore, the affinity labeling agents could be more selective than typical inhibitors due to proximity-accelerated reaction and targeting a distinct reactive residue.

With these advantages, we decided to develop exo-affinity labeling agents for PTP1B. The design of the agents will be described below.

\section{3) Design of Exo-Affinity Labeling Agent of PTP1B}

Our exo-affinity labeling $\left(E-L-p Y_{i}\right)$ design comprised of three parts; a phosphotyrosine isostere $\left(\mathrm{pY} \mathrm{Y}_{\mathrm{i}}\right)$, a linker (L), and an electrophile (E). (Figure 2.5)

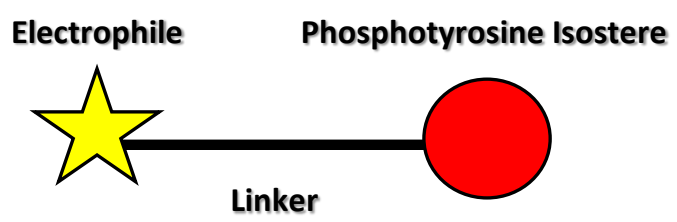

Figure 2.5 Design of the exo-affinity labeling agent, E-L-pYi

Phosphotyrosine Isostere $\left(\mathrm{pY}_{\mathrm{i}}\right)$ selection Current inhibitors, e.g. DFMP and carboxylic acid inhibitors were highly potent, but suffered from poor cell permeability and low cellular activity due to bis-anionic property. To overcome the cell permeability issue, study and synthesis of a minimal charged compound that was capable of mimicking $\mathrm{pY}$ substrate was undertaken. In 2005, Black and co-workers reported o-methoxy TDZ 8 with improved $\mathrm{IC}_{50}=2.5 \mu \mathrm{M} .{ }^{8}$ The inhibitor had only one negative charge $(\mathrm{N}$ atom at position 2 has pKa of 2 approximately, measured by Parsons, Z.D. my colleague), low molecular weight, and the structure was in the range of drug-like compound, offering an opportunity 
to modify its structure as the ideal covalent drug of PTP1B. Moreover, revealed by X-ray structure, the compound occupied the active site pocket with the phenyl ring pointing toward two nucleophilic amino acid residues, i.e. Cys32 and Asp48 with the distance of 14.2 $\dot{A}$ and $5.2 \dot{A}$ (measuring from the end p-carbon), respectively (Figure 2.6). This offered an opportunity to develop a selective exo-affinity labeling agent by targeting residue proximal to the active site of the enzyme.

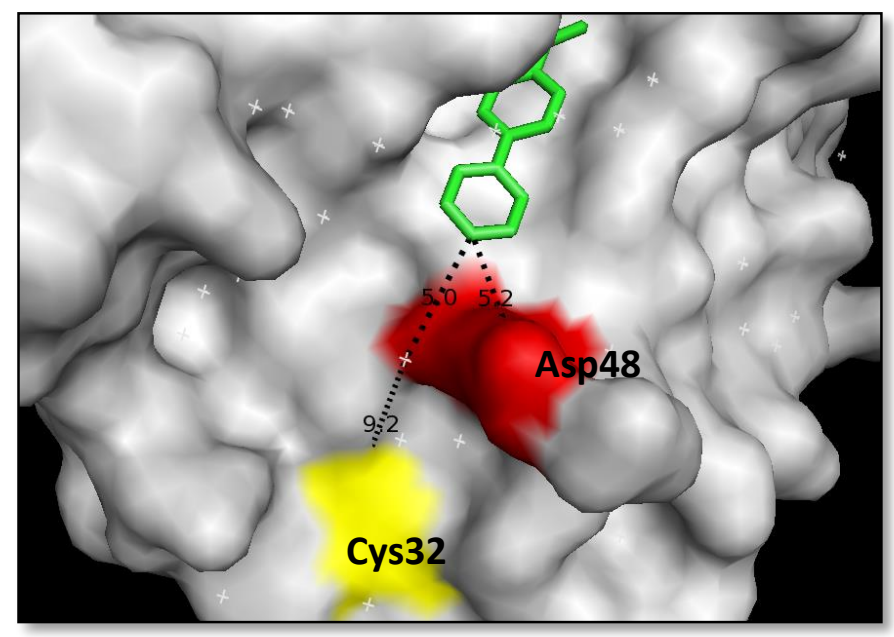

Figure 2.6 Pymol co-structure of $\mathbf{8}$ and PTP1B. The distances from $p$-carbon at the end of $\mathbf{8}$ to Asp48 and Cys32 are $5.2 \dot{\mathrm{A}}$ and $14.2 \dot{\mathrm{A}}$, respectively.

Electrophile I selection As far as the advantages of covalent inhibitors over noncovalent inhibitors were concerned, adding an electrophile moiety targeting a nucleophilic residue on the exo-affinity labeling agent could improve its potency and selectivity if the target amino acid on PTP1B surface is non-conserved. Based on crystal structure of PTP1B from protein data bank (the structure in PDB entry $2 \mathrm{HNP}^{9}$ is used as a reference), there are several reactive amino acids proximal to the PTP1B active site, i.e. Ser118, Tyr46, Asp48, Glu115, and Ser32, and Cys32. (Figure 2.7) Targeting these amino acids could be the key to selectivity to PTP1B over other PTPs. 
The electrophile of choice needs to be complementary or susceptible to the target residue on the surface of PTP1B and also inert toward common cellular nucleophiles, such as glutathione, albumin. Thioester and $\alpha$-halo carbonyl groups have been reported to be reactive toward several nucleophilic amino acids, ${ }^{10}$ but tolerate biological nucleophiles. 11,12 In this thesis, the thioesters are incorporated into our agent molecules.

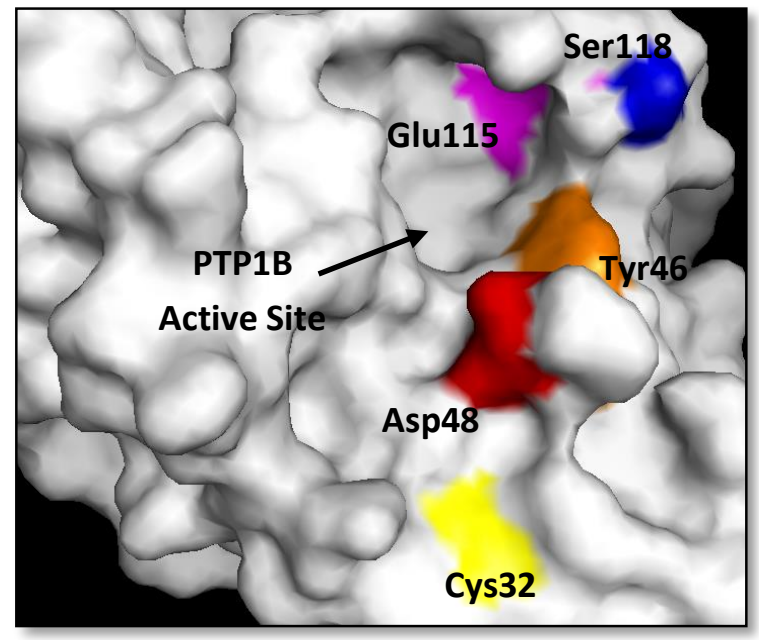

Figure 2.7 Positions of nucleophilic residues in PTP1B proximal to the active site.

Linker Selection (L) Characteristics of an ideal linker comprised of availability of functional groups, water solubility, and flexibility of dimensions. ${ }^{13}$ However, in the first generation of our exo-affinity agent, we utilized several C-C bonds to link the electrophile and $p Y_{i}$ moiety together.

\section{4) Synthetic Route to First Generation of E-L-pYi}

TDZ as the $\mathrm{pY} i$ was obtained by Black's method. (Scheme 2.2$)^{8}$ This route was first brought into our lab by my colleague, Hillebrand, R. The synthetic route started with brominated anilines $\mathbf{1 2}$ undergoing alkylation with methyl $\alpha$-bromoacetate to yield an 
adduct 13, followed by sulfonylation of Boc-protected chlorosulfonamide. The resulting boc-protected product 14 was deprotected with TFA and cyclized by NaH to form monoaryl TDZs 16. Another phenyl ring carrying various functional groups was added to the mono-aryl TDZs 16 via Suzuki coupling, giving bi-aryl TDZ derivatives 17-18. Finally, BOP ((Benzotriazol-1-yloxy)tris(dimethylamino)phosphonium hexafluorophosphate) was used to couple biphenyl TDZ bearing a carboxylic group 18 with different nucleophiles to access the first generation of E-L-pYi. (Scheme 2.3)
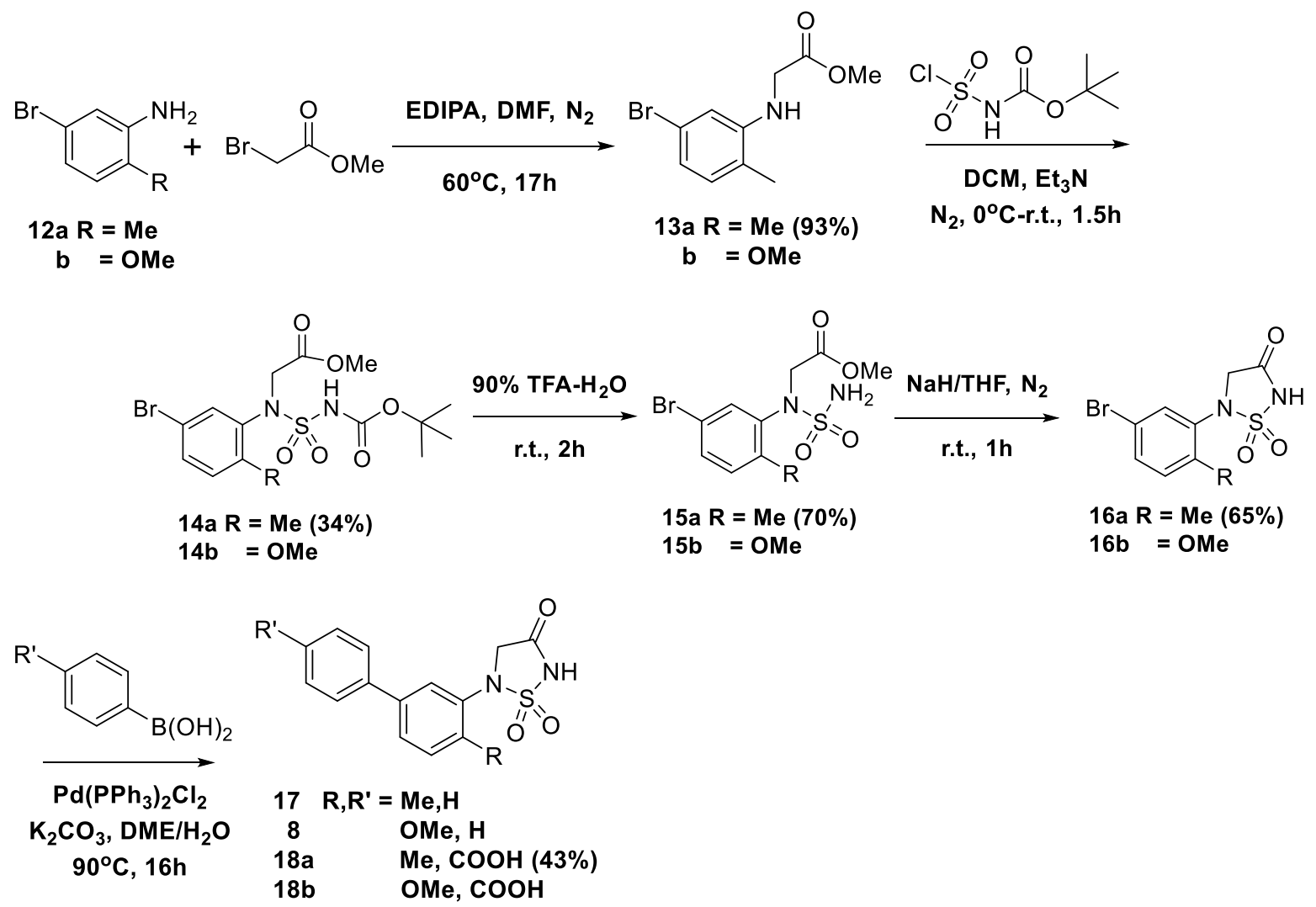

Scheme 2.2 Synthesis of bi-aryl TDZ by Black's method. ${ }^{8}$ (17a and all OMe analogs were synthesized by my colleague Ruddraraju, K. V. R.) 

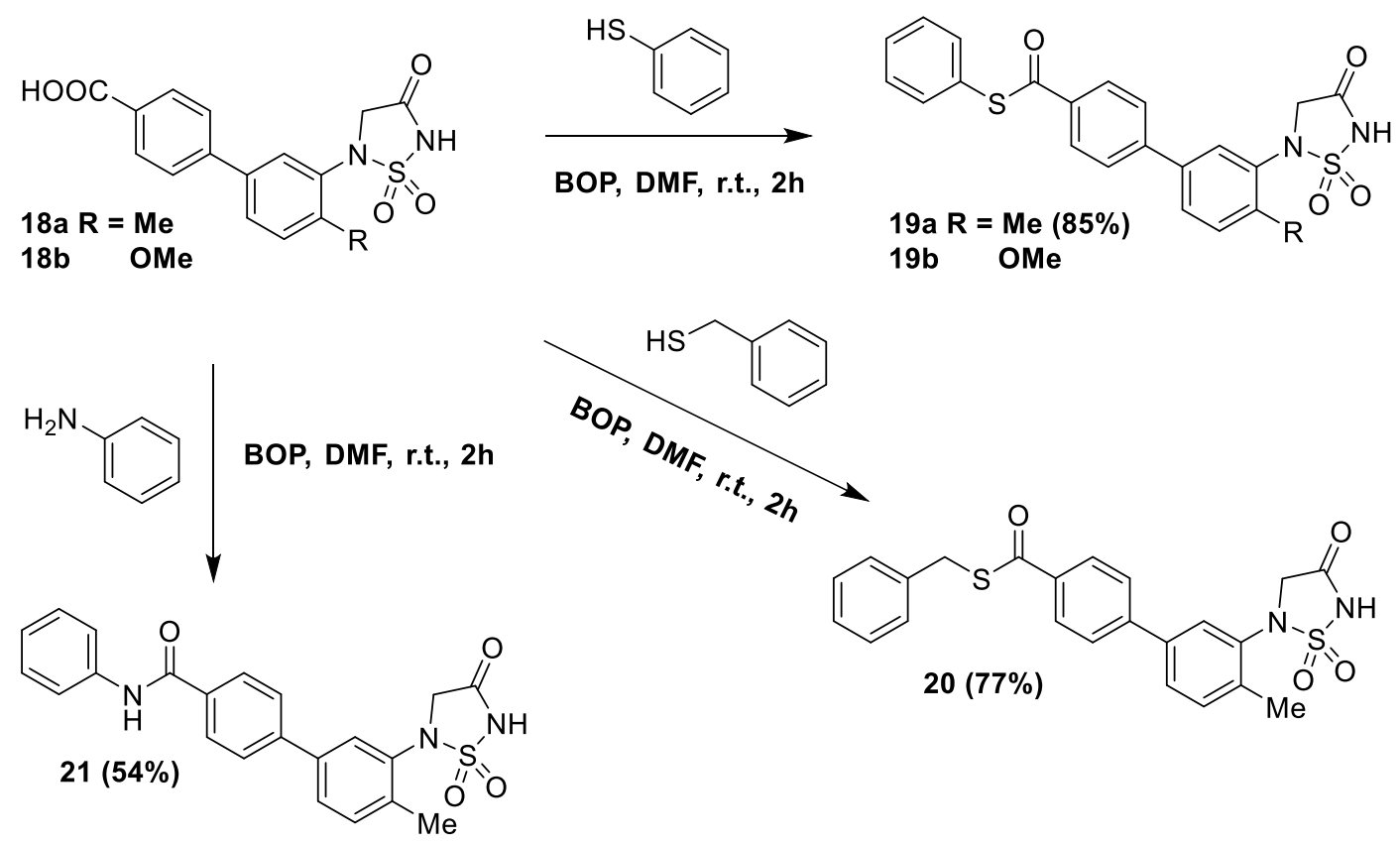

Scheme 2.3 Synthesis of E-L-pYi. Variety of functional groups offers different reactivity of the electrophile part which targets a reactive groups on the enzyme surface. (19a family was synthesized by my colleague Ruddraraju, K. V. R.)

\section{5) $I C_{50}$ Determination for compound 8, 19-21}

Potency of an inhibitor is typically measured by determining an $\mathrm{IC}_{50}$ value, the concentration of an inhibitor where $50 \%$ of target activity was inhibited under some specified conditions. The $\mathrm{IC}_{50}$ value of a given inhibitor against its target is obtained by examining an effect of different inhibitor concentrations on the target activity and plotting the activity versus the concentrations. In this thesis, we employed phosphatase assays using $p$-nitrophenyl phosphate ( $p$ NPP) which was dephosphorylated by an active PTP1B affording $p$-nitrophenolate $\left(\lambda_{\max }=410 \mathrm{~nm}\right.$, Scheme 2.4$)$ to evaluate PTP1B activity on different concentrations of our first generation of E-L-pY. Plotting PTP1B activity versus the concentrations and fitting the data to does response equation (Scheme 2.5a) 
gave $\mathrm{IC}_{50}$ values of each compound at the concentration that gave $50 \%$ activity. (Figure

2.8a, b, c and Table 2.1)
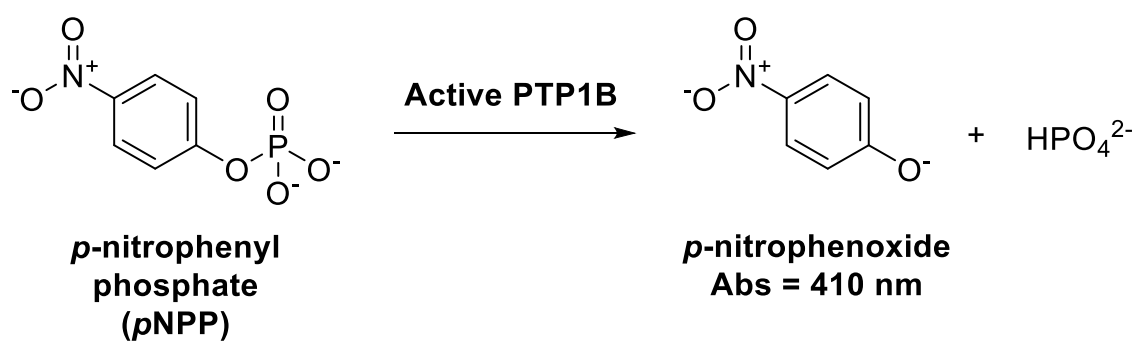

Scheme 2.4 Reaction of $p$ NPP and PTP1B yielding $p$-nitrophenoxide $\left(\lambda_{\max }=410 \mathrm{~nm}\right)$.
a) $\quad y=\min +\frac{(\max -\min )}{1+10^{\left[\left(\log I C_{50}-\log [x]\right)\left(n_{H}\right)\right]}}$
b) $\quad K_{i}=\frac{I C_{50}}{1+\frac{[S]}{K_{m}}}$

Scheme 2.5 a) Dose-Response Equation, where min is minimum enzyme activity, max is maximum enzyme activity, IC $\mathrm{C}_{50}$ is concentration of an inhibitor where $50 \%$ of its target activity is inhibited, $[x]$ is the inhibitor concentration, and $n_{H}$ is Hill's coefficient. b) Cheng-Prusoff equation, where $K_{l}$ is the binding affinity of the inhibitor, $[\mathrm{S}]$ is fixed substrate concentration and $\mathrm{Km}$ is the concentration of substrate at which enzyme activity is at half maximal $\left(\mathrm{K}_{\mathrm{m}}=0.4 \mathrm{mM} p \mathrm{NPP}^{8}\right)$. 
a)

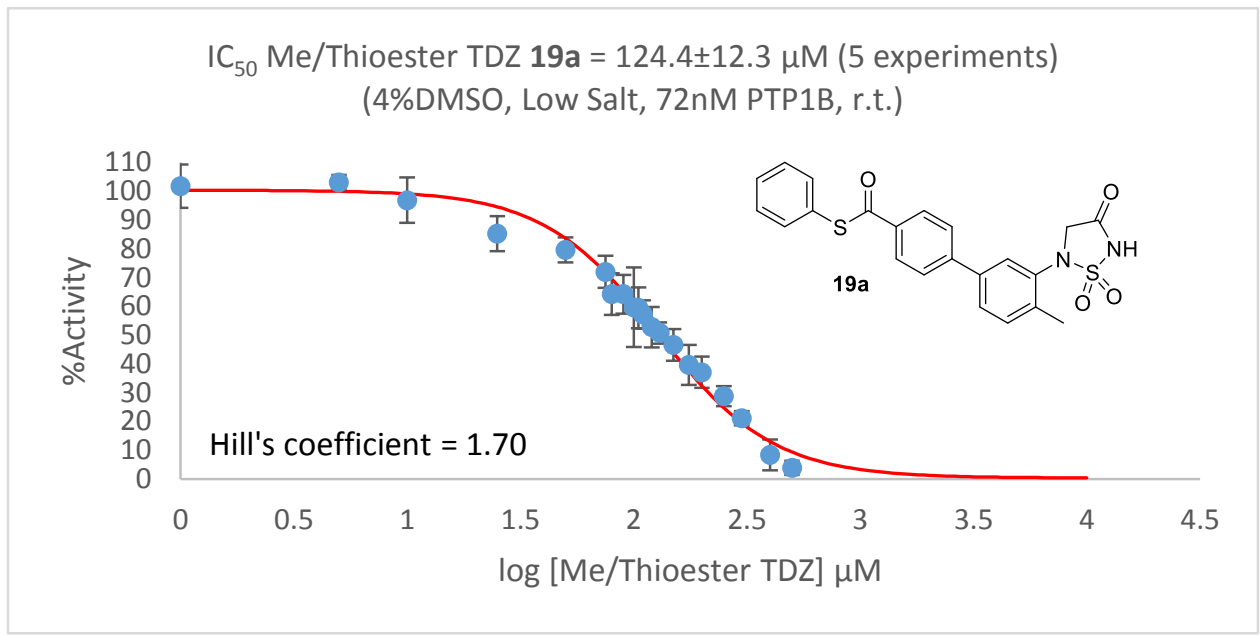

b)

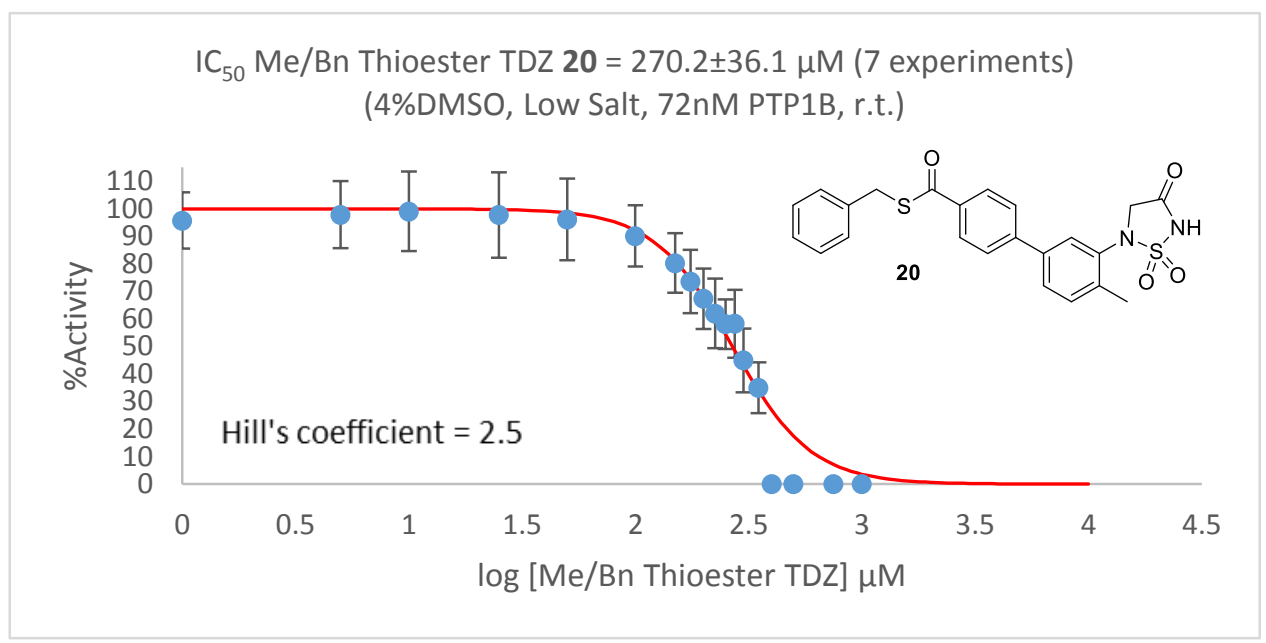

c)

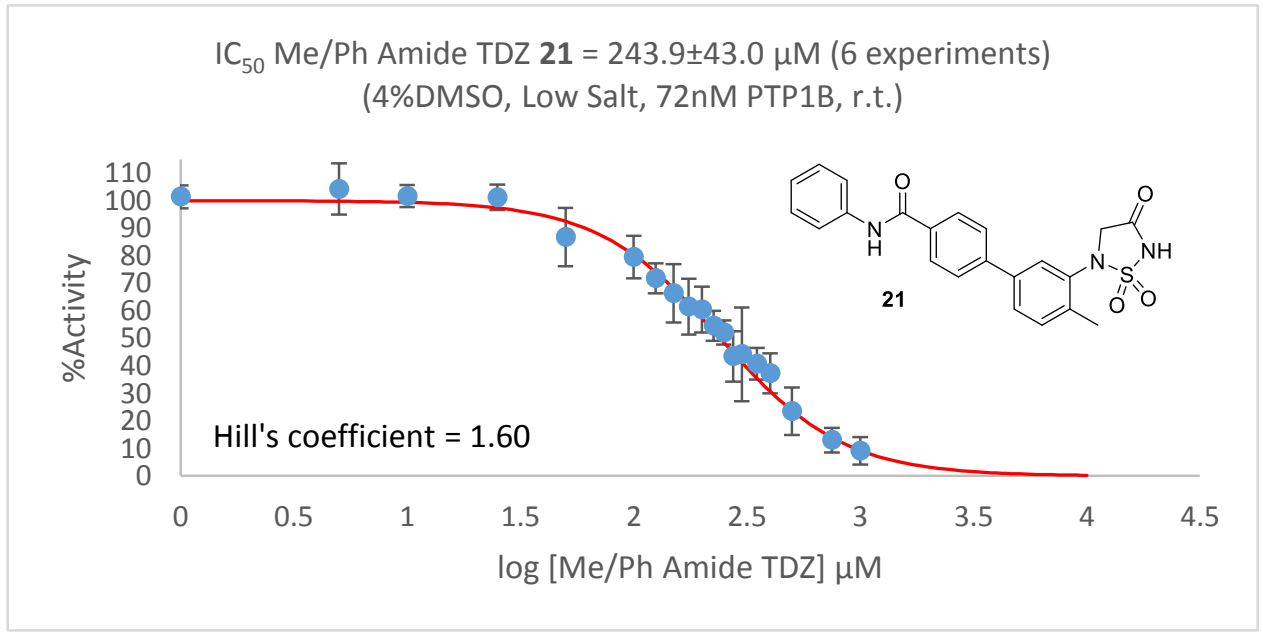

Figure 2.8 Plots of \% PTP1B Activity versus concentration of a) Me/Ph Thioester TDZ 19a and b) Me/Bn Thioester TDZ 20 and c) Me/Ph Amide TDZ 21. IC 50 with error bars (from $\geq 5$ experiment) of the compounds were $124 \pm 12 \mu \mathrm{M}, 270 \pm 36 \mu \mathrm{M}$, and $244 \pm 43 \mu \mathrm{M}$, respectively. 


\begin{tabular}{|c|c|c|c|c|c|}
\hline \multirow[b]{3}{*}{ TDZ } & \multicolumn{4}{|c|}{${ }^{I} C_{50}(\mu \mathrm{M})$} & \multirow{3}{*}{$\begin{array}{l}\text { Estimated } K_{l} \\
(\mu \mathrm{M})^{\mathrm{f}}\end{array}$} \\
\hline & \multicolumn{2}{|c|}{ 20\%DMSO } & \multicolumn{2}{|c|}{ 4\%DMSO } & \\
\hline & High Saltc & Low Salt ${ }^{d}$ & Low Salt ${ }^{d}$ & Low Salt ${ }^{\mathrm{e}}$ & \\
\hline 17 & $>300$ & $2167.1^{\mathrm{g}}$ & 283.0 & - & - \\
\hline 8 & 65.3 & $15.2 \pm 1.7^{\mathrm{a}}$ & 4.3 & - & - \\
\hline $19 a$ & $>300$ & $1100.1^{\mathrm{g}}$ & $114.7 \pm 6.4^{b}$ & $124.4 \pm 12.3^{a}$ & 62.2 \\
\hline $19 b$ & 182.8 & 47.6 & 10.3 & - & - \\
\hline 20 & $>300$ & 631.0 & - & $270.2 \pm 36.1^{\mathrm{a}}$ & 135.1 \\
\hline 21 & $>400$ & $1349.0^{\mathrm{g}}$ & 216.3 & $243.9 \pm 43.0^{a}$ & 121.9 \\
\hline
\end{tabular}

a triplicate experiments $(n \geq 3)$

${ }^{\mathrm{b}}$ duplicate experiments $(\mathrm{n}=2)$

c High Salt condition: 50 mM Tris, 50 mM Bis-Tris, 50 mM DTPA, 80 mM NaOAc, $100 \mu M$ DTT, 0.05\%v/v Tween80, 2 mM pNPP, room temperature, 24 nM PTP1B.

d Low Salt condition: 2 mM EDTA, $50 \mathrm{mM}$ Bis-Tris, $5 \mathrm{mM}$ DTT, 0.05\%v/v Tween80, $0.4 \mathrm{mM} p \mathrm{NPP}$, room temperature, 48 nM PTP1B.

e Low Salt condition: 2 mM EDTA, 50 mM Bis-Tris, $5 \mathrm{mM} \mathrm{DTT,} \mathrm{0.05 \% v/v} \mathrm{Tween80,} 0.4 \mathrm{mM}$ pNPP, room temperature, 72 nM PTP1B.

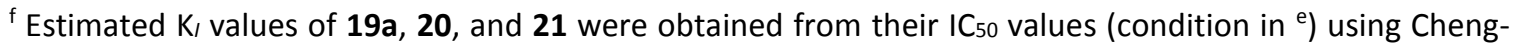
Prusoff equation (Scheme 2.5b)

g Plot \%Enzyme Activity vs TDZ concentration was extrapolated to $\mathrm{IC}_{50}$ value by curve fitting to does response equation (Scheme 2.5a)

Table $2.1 \mathrm{IC}_{50}$ values in $4 \%$ and $20 \%$ DMSO, and low and high salt condition.

As mentioned earlier that E-L-pY was designed to bind to PTP1B at its active site pocket with TDZ moiety. Thus, the compound possessed a certain affinity which was measured by dissociation constant $\left(\mathrm{K}_{l}\right)$. However, $I \mathrm{C}_{50}$ value was typically reported as a measurement of affinity of a giving inhibitor instead. Although $\mathrm{IC}_{50}$ was not a direct measurement of $K_{l}$, both values related by the Cheng-Prusoff equation. ${ }^{14}$ (Scheme $2.5 b$ ) Using the equation, estimated K/ values of 19a, 20, and 21 were obtained. (Table 2.1)

According to the $\mathrm{IC}_{50}$ values, we discovered that an ionic strength of a buffer (Salt effect) and an amount of DMSO (DMSO effect) had an effect on the interaction between the enzyme and $E-L-p Y_{i}$. lonic strength of a buffer is typically referred to salt concentration. Salt is capable of screening charge-charge interaction between the 
enzyme and the inhibitor resulting in weaker binding. In other words, if the inhibitor binds to its target via charge-charge interactions, high concentration of salt, or high ionic strength buffer, is expected to decrease binding affinity of the compound and increase $\mathrm{IC}_{50}$ value. TDZ moiety contained acidic $\mathrm{N}-\mathrm{H}$ group with $\mathrm{pK}_{\mathrm{a}}$ of 2 approximately (measured by one of my colleague, Parsons, Z.D.). The buffers that we used for $\mathrm{IC}_{50}$ assay was neutral $(\mathrm{pH} 7)$, that meant more than $99 \%$ of TDZ was negatively charged in the condition and bound to PTP1B active site pocket with charge-charge interaction. Therefore, $\mathrm{IC}_{50}$ of $\mathbf{1 7 b}$ and $19 \mathrm{~b}$ in higher ionic strength buffer (ionic strength $\mathrm{High-Salt}=0.580 \mathrm{M}$ ) was greater than that in low ionic strength buffer (ionic strength Low-Salt $=0.0144 \mathrm{M}$ ). This observation was corresponding to the salt effect study by Zhang and team in $2001 .{ }^{15}$ In their study, the most potent PTP1B inhibitor, DFMP 1, was synthesized and the affinity of the inhibitor, reported as $\mathrm{K}_{\mathrm{i}}$ (dissociation constant), in different buffers with different ionic strengths was investigated. Due to the highly ionic property (five negatively charged at pH 7), this compound was susceptible to changes in ionic strength. Increasing ionic strength from 25 $\mathrm{mM}$ to $42.5 \mathrm{mM}$ and $0.15 \mathrm{M}$, the charged-charged interaction was weakened and $\mathrm{IC}_{50}$ increased from $0.14 \mathrm{nM}$ to $0.69 \mathrm{nM}$ and $2.4 \mathrm{nM}$, respectively. ${ }^{15}$

DMSO could also potentially influence $\mathrm{IC}_{50}$. We observed that higher amount of DMSO in $p$ NPP assay increased IC $\mathrm{C}_{50}$ up to 10 -fold. The explanation of the DMSO effect on protein-ligand was still unknown because there were few attentions on the effect to date. However, this observation was complementary to the very recent work by Cubrilovic and Zenobi. ${ }^{16}$ Studied by nano ESI-MS, $\mathrm{K}_{d}$ (dissociation constant) of three different proteinligand systems were determined. They found that varying proportion of DMSO as a co- 
solvent from $0 \%$ to $8 \%$ in a buffer increased $\mathrm{K}_{d}$ value up to 10 -fold in the case of tight binding carbonic anhydrase-chlorothiazide. However, the causes of this solvent effect remained unclear.

In 2006, Shoichet reported interpretation of steep does-response curves, defined by Hill's coefficient of above $1.5 .{ }^{17}$ According to the study, the steepness of the curves suggested three mechanism, i.e. multi-site binding, inhibitor phase transition, and stoichiometric inhibition caused by a high enzyme to $K_{d}$ ratio. The first mechanism is a result of several inhibitor molecules binding to one enzyme molecule. The slope of the dose-response curve becomes steeper (higher Hill's coefficient) as the number of binding site increases. The second mechanism could be observed when the inhibitors undergoing physical phase transition (precipitation or colloid formation) as increasing its concentration. If the phase transition associated with its target inhibition, a steep doseresponse curve was observed. Finally, the steep dose-response curves would also take place if the enzyme concentration exceeded the $K_{\mathrm{d}}$ value of the inhibitor (usually in the case of high affinity inhibitor) and inhibition in this manner would be stoichiometric. In addition to the second mechanism, Coan and team ${ }^{18}$ studied the inhibitory mechanism of some compounds that could aggregate, so called "aggregate-based inhibitor" as its concentration was increased. The study showed that the aggregation inhibited its target by unfolding enzyme molecules and that could lead to false positives in $\mathrm{IC}_{50}$ interpretation. Regarding the Hill's coefficients of 19a, 20, and 21 of 1.70, 2.50, and 1.60, respectively (Figure $2.8 \mathrm{a}, \mathrm{b}, \mathrm{c}$ ), these exo-affinity labeling agents could be aggregatebased inhibitor. To identify the inhibitor type, further investigation are needed. 


\section{6) Kinetics of the Inactivation of PTP1B by Thioester TDZ}

Stated above, our E-L-pY $\mathrm{i}_{\mathrm{i}}$ a designed to bind to PTP1B in two steps, non-covalent interaction and covalent modification. The non-covalent interactions, such as hydrogen bonds, charge-charge interactions, hydrophobic interactions, and etc., occur when TDZ reversibly binds to PTP1B by the rate constant $k_{1}$, rapidly forming an enzyme-inactivator $(E \cdot I)$ complex (scheme 2.1$)$. Simultaneously, some of $E \cdot I$ complex can collapse and become free enzyme molecules and free inactivator molecules with the rate constant $k_{-1}$. As a result, an equilibrium is established by a dissociation equilibrium constant $K_{l}$, defined

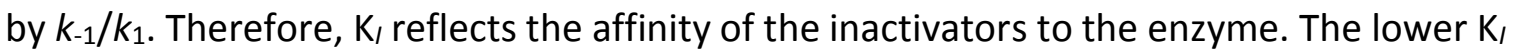
value, the relatively larger $k_{1}$ comparing to $k_{-1}$, and the inactivators bind to the target more tightly. Note that this is only true if $k_{\text {inact }}$ is slower relative to $k_{1}$ and $k_{-1}$. The second step is covalent modification of an electrophile moiety of E-L-pY $\mathrm{F}_{i}$ to a nucleophilic residue on PTP1B. This chemical step occurs by first-order rate constant $k_{\text {inact, }}$ represented by

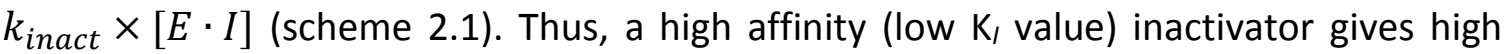
concentration of $E \cdot I$ complex and enhanced observed rate of inactivation. Note that this

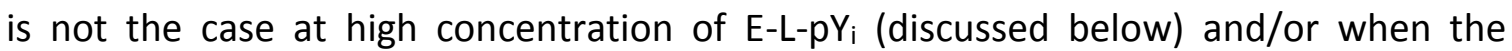
concentration of the inactivator exceeding solubility limit. Due to this irreversible attachment, an E-L-pY $Y_{i}$ interacts with PTP1B in time-dependent manner and the reaction proceeds to completion rather than equilibrium. ${ }^{19}$

To determine the kinetic constants $K_{/}$and $k_{\text {inact, }}$ we utilized conventional $p$ NPP assays to follow decrease of PTP1B activity over time course of the inactivation process at different $\mathrm{E}-\mathrm{L}-\mathrm{pY} \mathrm{Y}_{\mathrm{i}}$ concentrations. The observed rate constant of inactivation $\left(k_{\mathrm{obs}}\right)$ at 
each concentration was determined from slope of semi-logarithmic plot of enzyme activity against time (Figure $2.9 a$ ). Then, the $k_{\text {obs }}$ values are re-plotted against E-L-pY concentration (Figure 2.9b) and fitted data to a hyperbolic equation (Scheme 2.6). ${ }^{19} \mathrm{~K}$ I was obtained as the concentration that gives half $k_{\text {obs }}$ and $k_{\text {inact }}$ was obtained as maximum $k_{\text {obs. }}$

a)

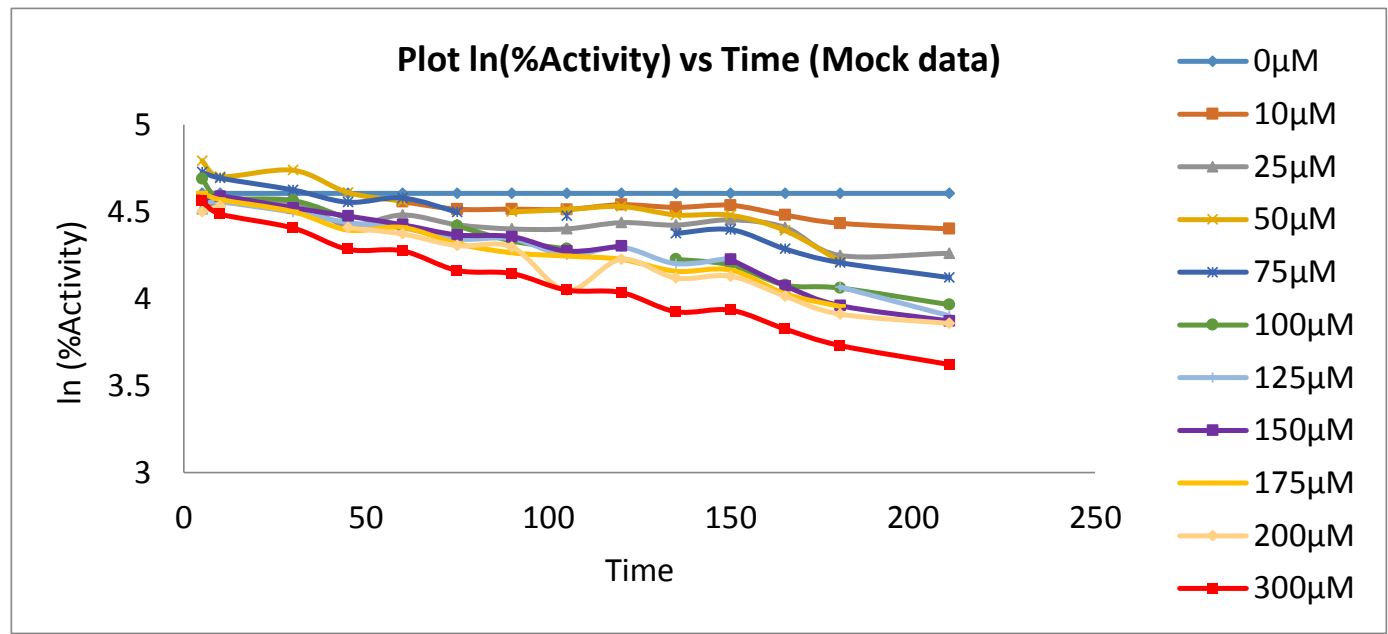

b)

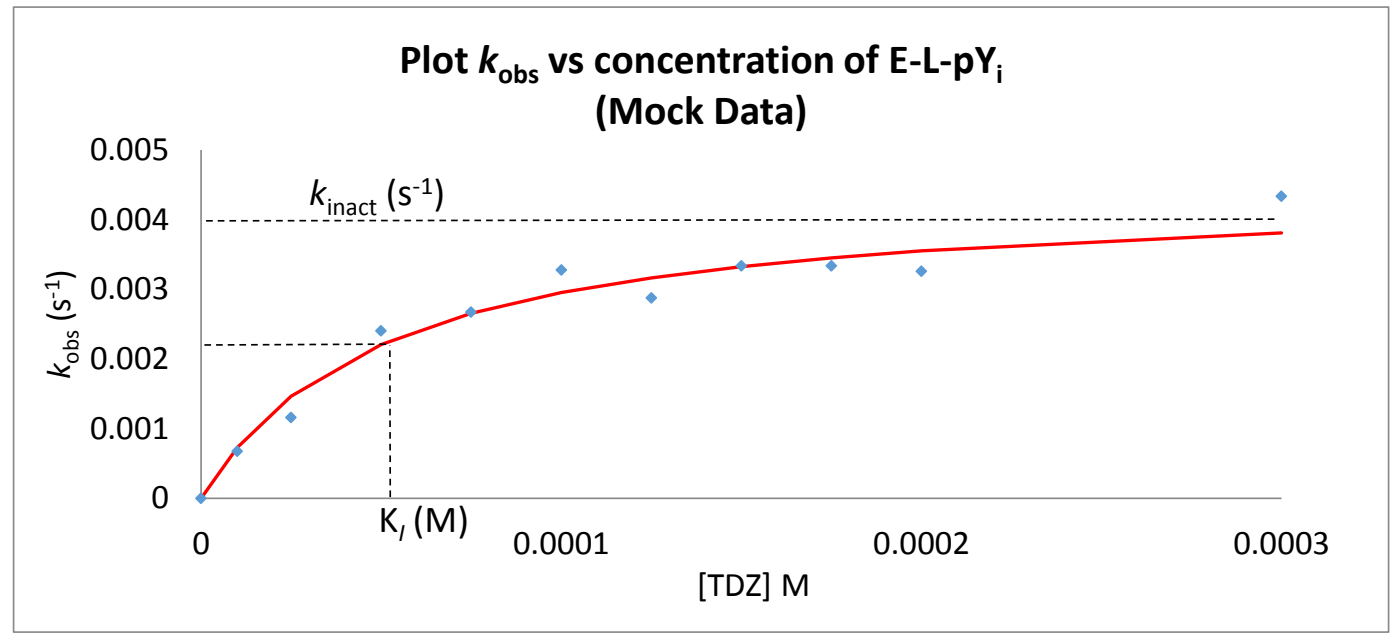

Figure 2.9 a) A semi-logarithmic of \%enzyme activity against time plot for each concentration of an exoaffinity labeling agent (E-L-pY $Y_{i}$ ). b) Re-plot $k_{\text {obs }}$ (slope from a)) vs concentration of the exo-affinity labeling agent and fit the data to the hyperbolic equation (Scheme 2.6). K/ was obtained as the concentration that gives half $k_{\text {obs }}$ and $k_{\text {inact }}$ was obtained as the maximum $k_{\mathrm{obs}}$, respectively. 


$$
k_{o b s}=\frac{k_{\text {inact }}}{1+\frac{K_{I}}{[I]}}
$$

Scheme 2.6 A hyperbolic equation to obtain values of $K_{\text {। }}$ and $k_{\text {inact. }}$. where $k_{\text {obs }}=$ observed $1^{\text {st }}$-order rate of inactivation, $k_{\text {inact }}=1^{\text {st }}$-order rate of inactivation, $\mathrm{K}_{l}=$ dissociation constant, $[\mathrm{I}]=$ concentration of an inactivator.

Regarding scheme 2.1 , the rate of covalent formation/inactivation is directly proportional to the concentration of $E \cdot I$ complex, represented by $k_{\text {inact }} \times[E \cdot I]$. Increasing concentration of the inactivator drives the equilibrium forward, more $E \cdot I$ complex is formed, and subsequently the rate of inactivation becomes faster. However, this is the case only at low concentration of the exo-affinity labeling agent. At high concentration, the enzyme becomes saturated by the labeling agent molecules. In other words, all PTP1B active sites were occupied by the inactivator, there was no further $E \cdot I$ complex can be formed. At this point, the rate of inactivation was at maximum and independent on the inactivator concentration resulting in plateau in the $k_{\text {obs }^{-}}$ concentration plot. (Figure 2.9b)

Among exo-affinity labeling agents that we synthesized, 19a, 20, and 21 were subjected to inactivation assays against PTP1B. 19a was expected to be the most susceptible to nucleophilic attack and has relatively high $k_{\text {inact }}$ since $\mathrm{pK}_{\mathrm{a}}$ of an aryl thioester $\left(\mathrm{pK}_{\mathrm{a}} \sim 7\right)$ was lower than those of an alkyl thioester $\left(\mathrm{pK}_{\mathrm{a}} \sim 10\right)$ and an aryl amine $\left(\mathrm{pK}_{\mathrm{a}} \sim\right.$ 30). On the other hand, the aryl amine analogue $\mathbf{2 1}$ should be inert toward a nucleophile on PTP1B and $k_{\text {obs }}$ would be zero. Additionally, these three molecules were expected to bind to the enzyme with the relatively similar affinity (similar K/ values) because they all possessed the same TDZ moiety which interacts with the enzyme with the same binding 
mode. (Figure 2.10a) Furthermore, as mentioned earlier, DMSO was presumed to have negative influence on the inactivation process, according to study by Cubrilovic and Zenobi. ${ }^{16}$ Therefore, high concentration of DMSO could weaken the interaction between the exo-affinity labeling and the enzyme, lowering the concentration of $E \cdot I$ complex, and could decrease the rate of inactivation. In this thesis, 19a was subjected to assays in $5 \%$ and $20 \%$ DMSO, expecting that the compound in 20\% DMSO exhibited slower inactivation

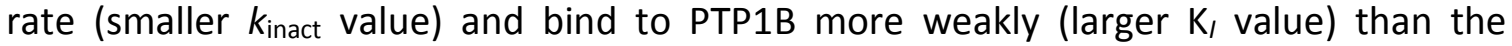
compound does in 5\%DMSO. (Figure 2.10a)

a)

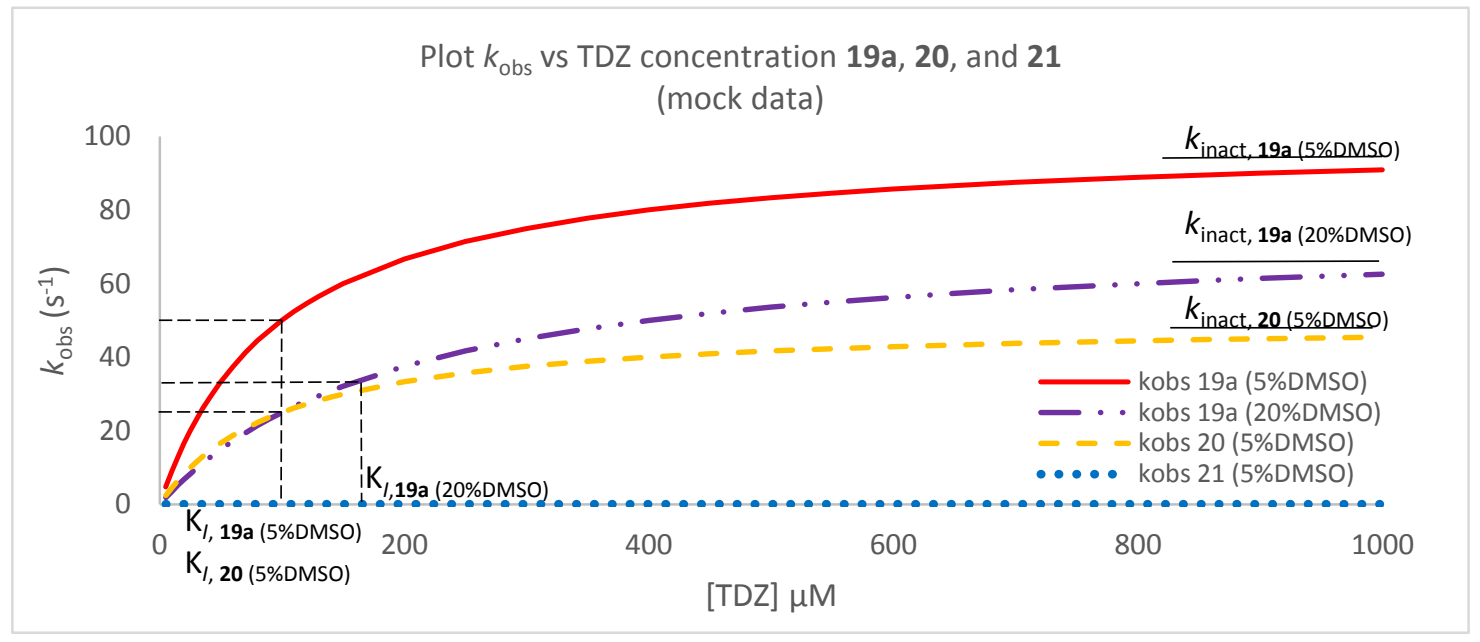

b)

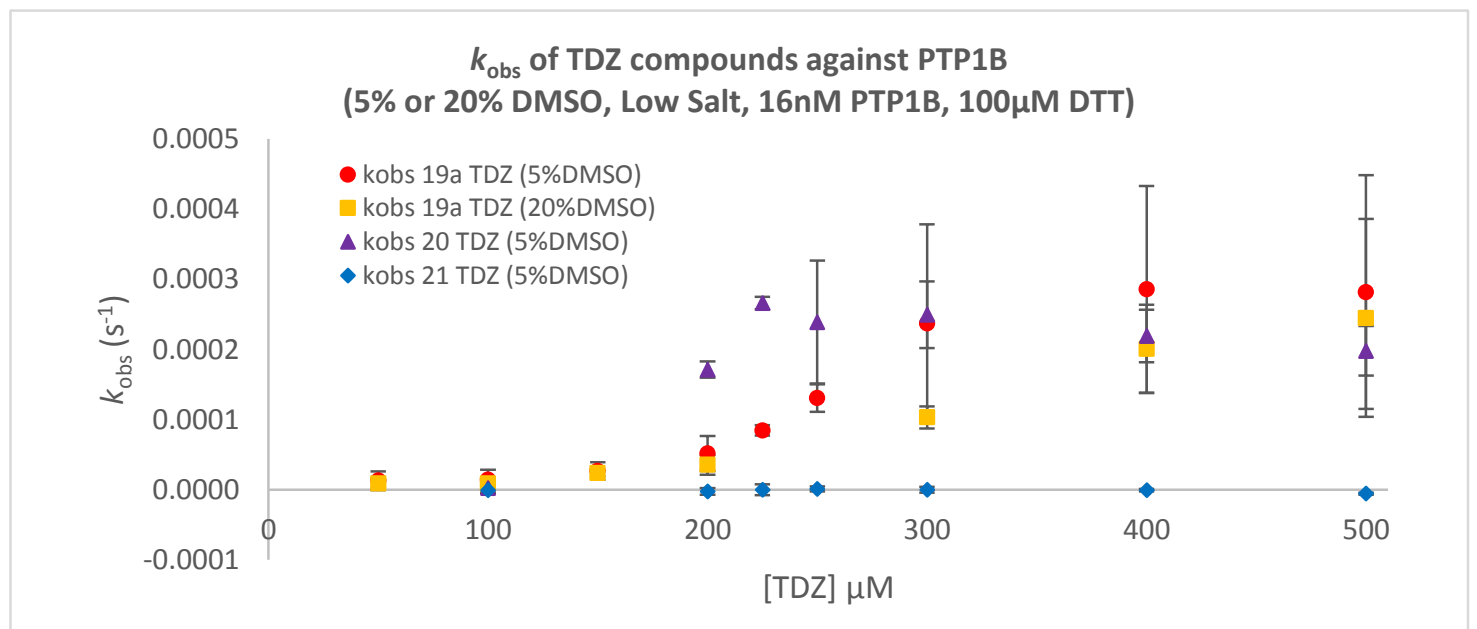

Figure 2.10 Plot $k_{\text {obs }}$ vs concentration of $19 a, 20$, and $\mathbf{2 1}$ in 5\%DMSO and 20\%DMSO a) mock data b) observed data $(n \geq 3)$. 
a)

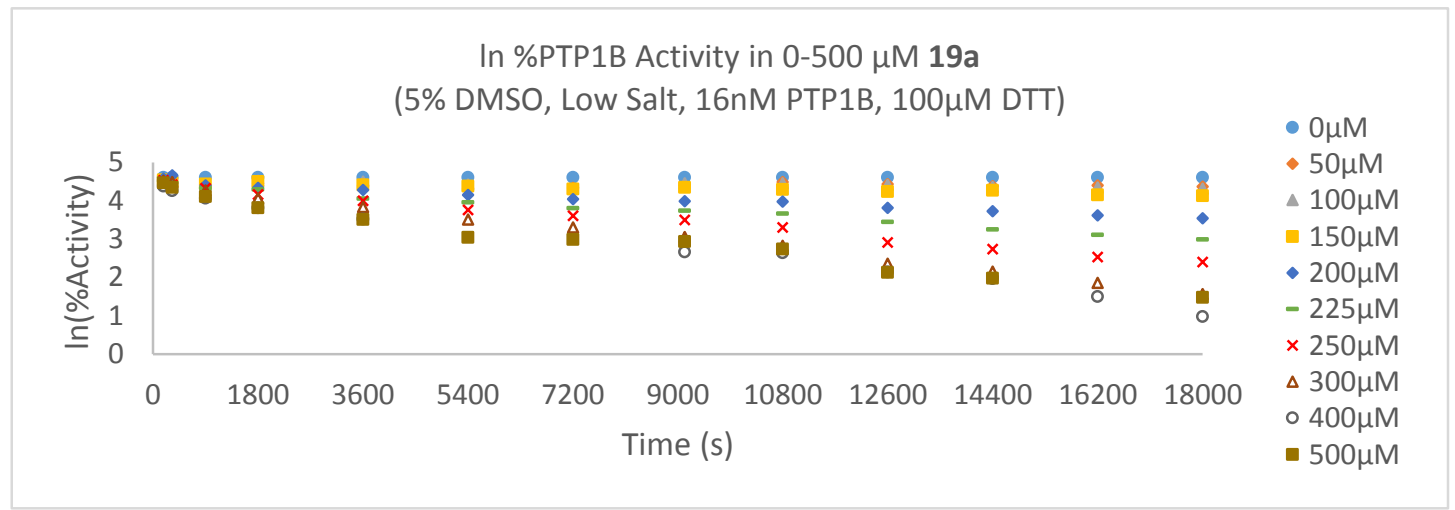

b)

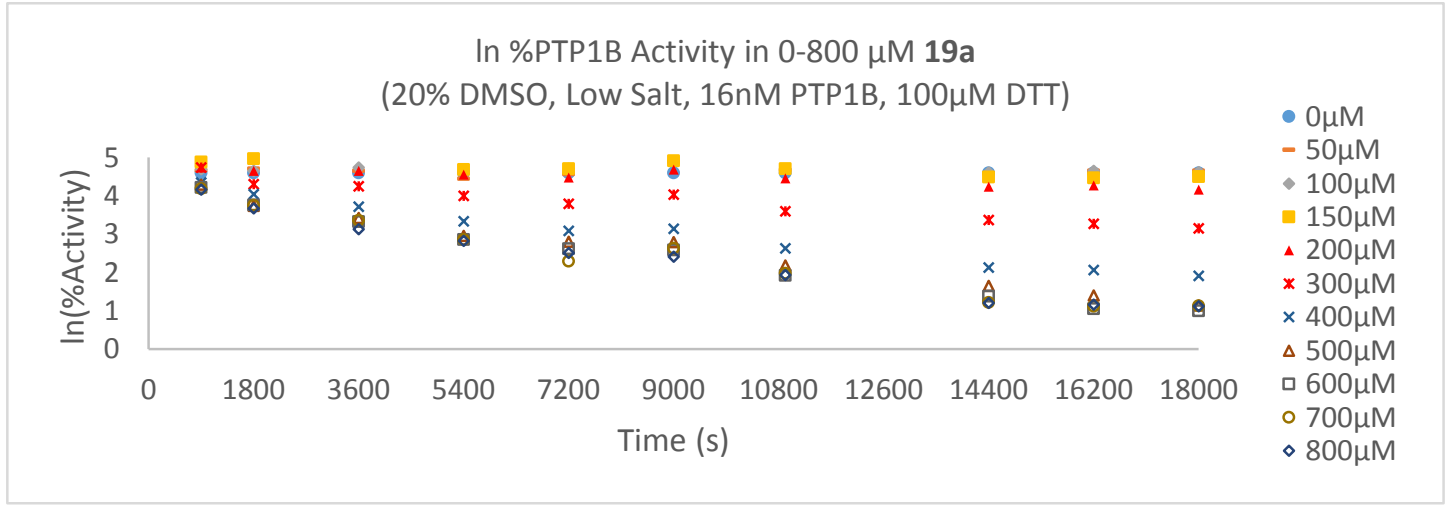

c)

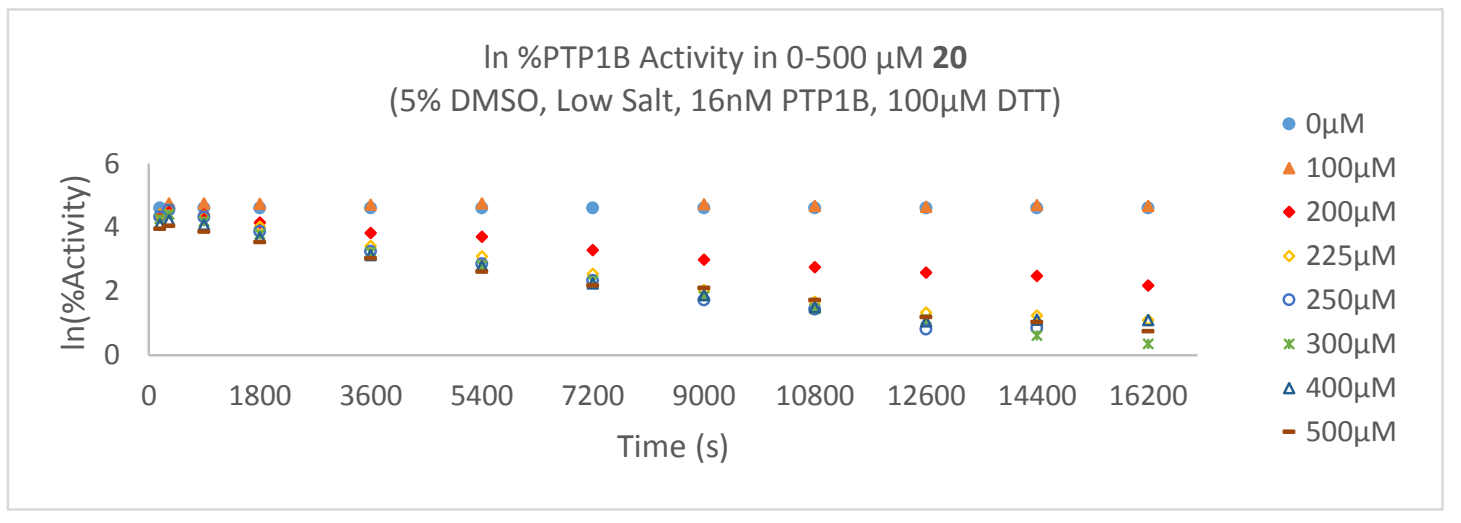

d)

In \%PTP1B Activity in 0-500 $\mu \mathrm{M} 21$

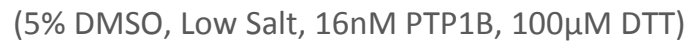

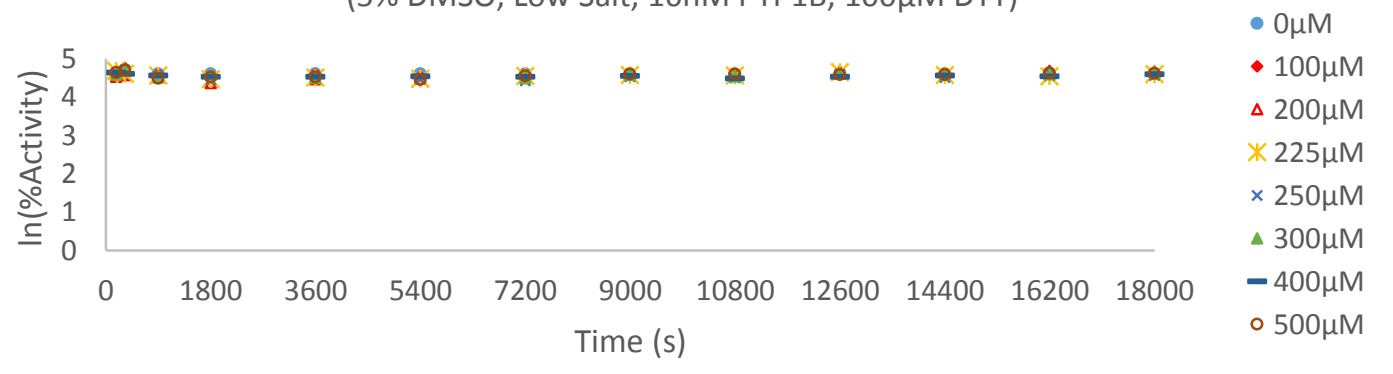

Figure 2.11 Plot In (\%Activity) vs time of a) 19a (5\%DMSO), b) 19a (20\%DMSO), c) 20 (5\%DMSO) and d) 21 $(5 \% \mathrm{DMSO})(n \geq 3)$. 
a)

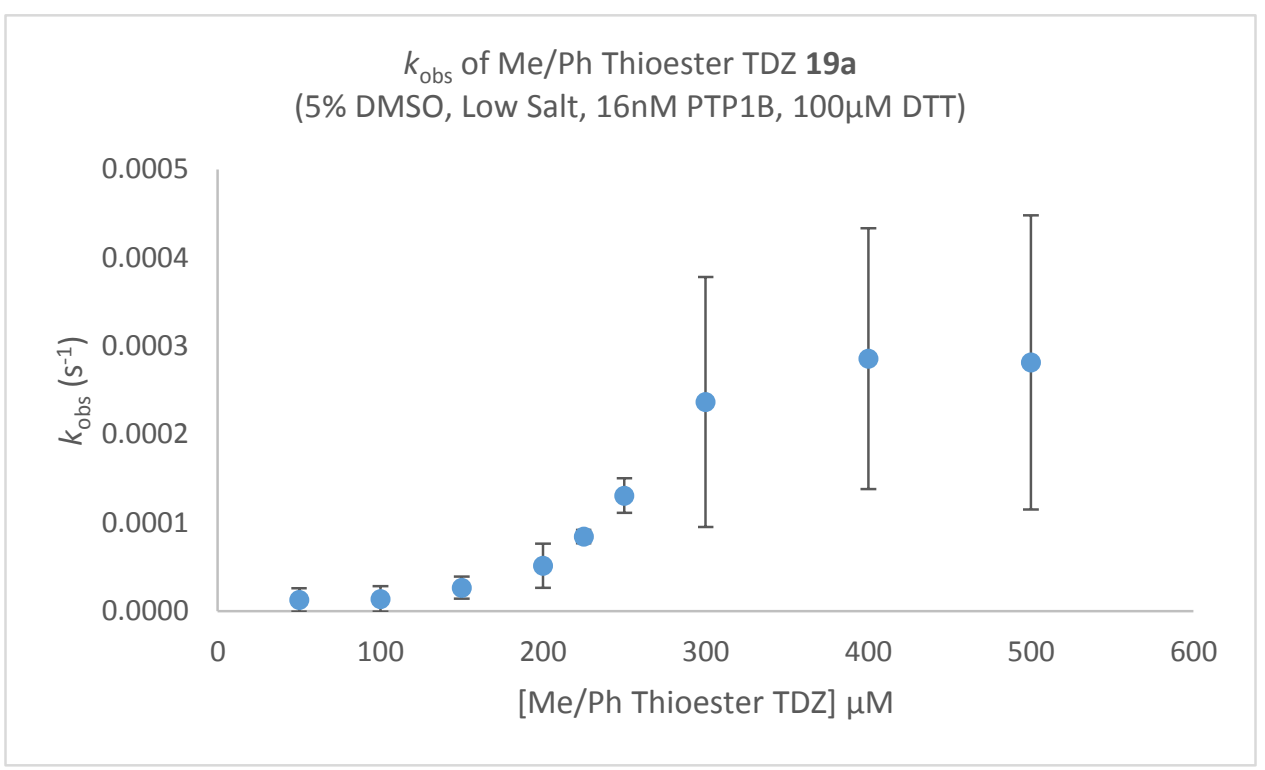

b)

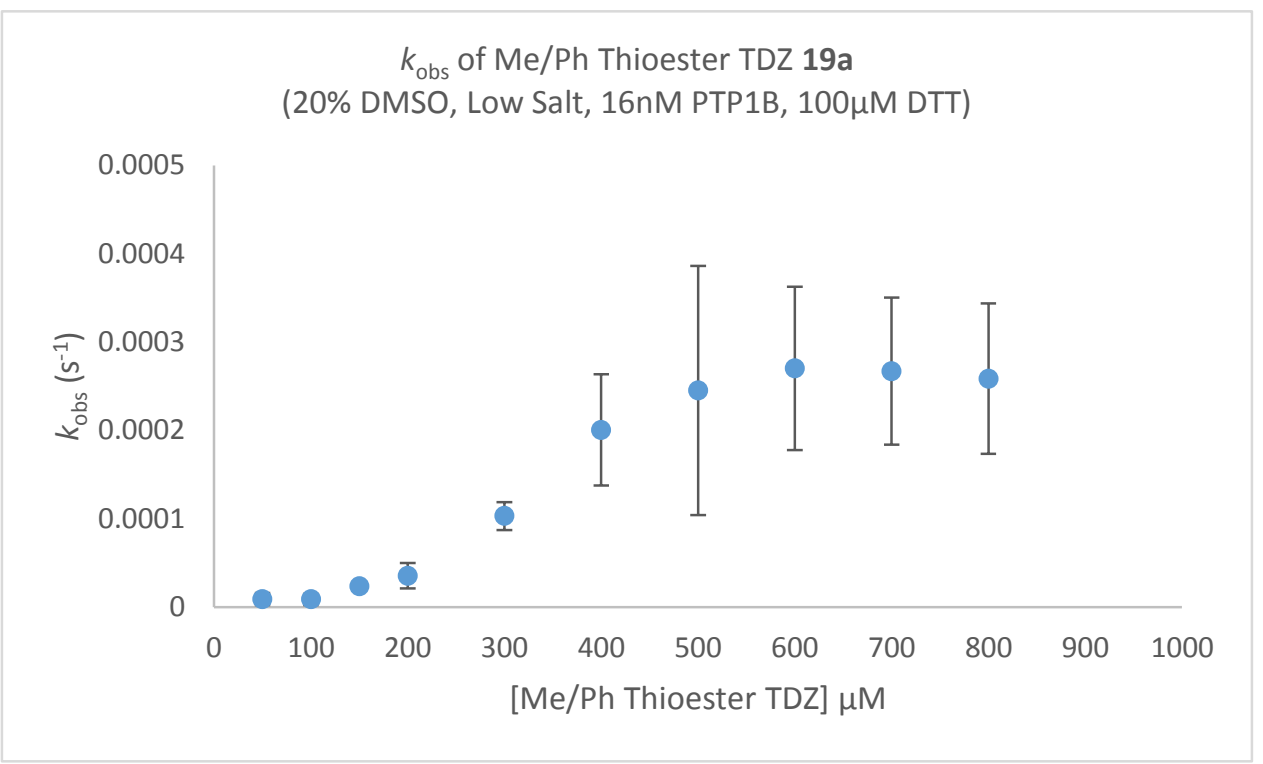


c)

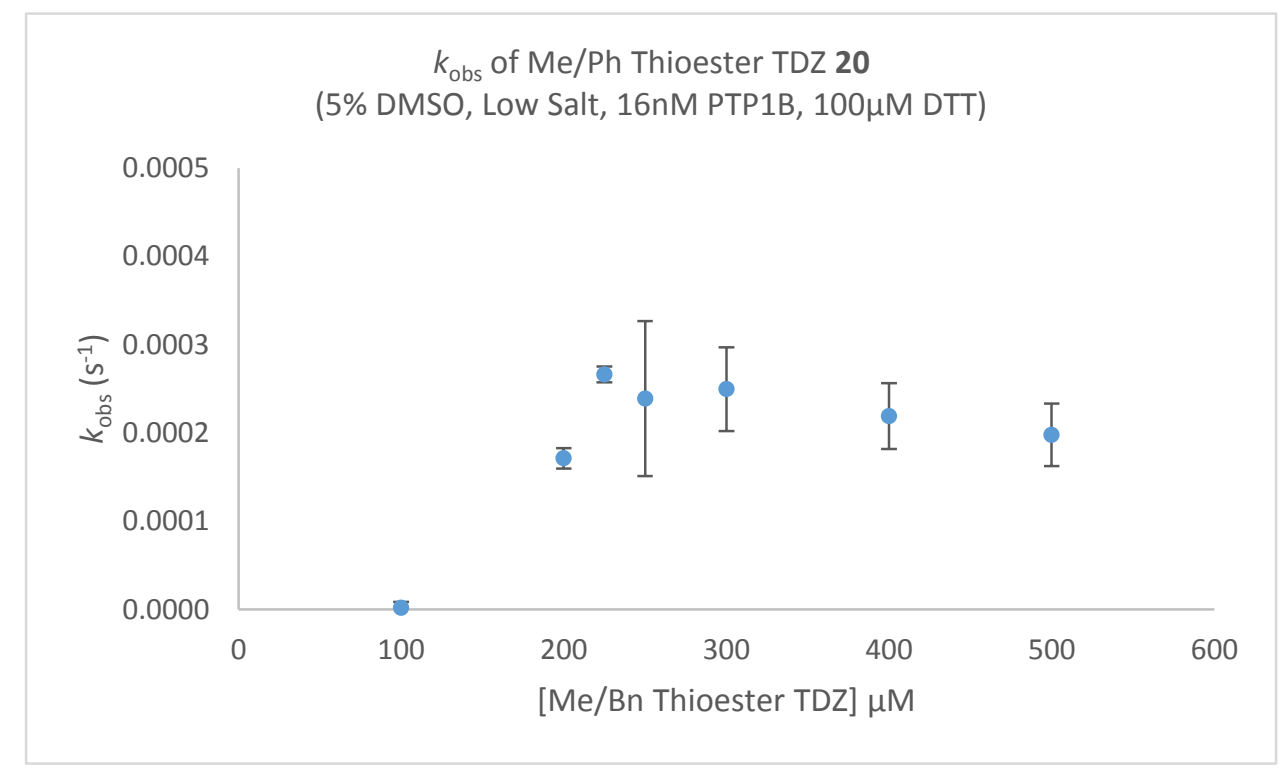

d)

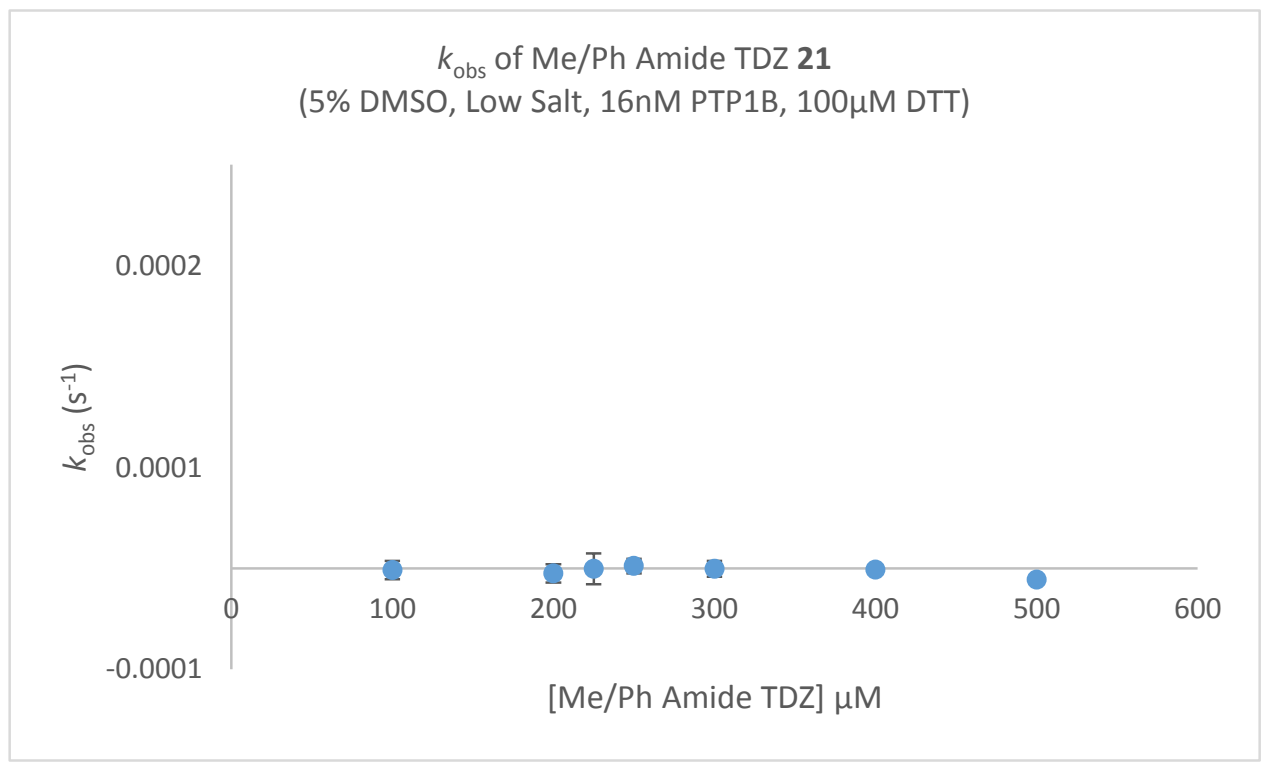

Figure 2.12 Plot $k_{\text {obs }}$ vs concentration of 19a, 20, and 21. a) 19a (5\%DMSO), b) 19a (20\%DMSO), c) 20 (5\%DMSO) and d) 21 (5\%DMSO) ( $\geq 3$ ).

Interestingly, the observed data was different from the expectation (Figure 2.10b).

First of all, $k_{\mathrm{obs}}$ vs concentration plots of $19 \mathrm{a}$ and $\mathbf{2 0}$ were not fit the hyperbolic equation

(Figure $2.12 \mathrm{a}, \mathrm{b})$. At low concentration $(0-100 \mu \mathrm{M}), k_{\mathrm{obs}}$ increased very slowly, but dramatically at moderate concentration (200-300 $\mu \mathrm{M})$, and reached plateau at high 
concentration (300-500 $\mu \mathrm{M})$. The plateau occurred presumably because all PTP1B active sites were occupied at this concentration range and no faster rate of inactivation could be achieved. The unexpected plots might suggest that the molecules inhibited or inactivated the enzyme with different mechanism from a typical exo-affinity labeling agents. Second, the amide analog 21 did not inactivate PTP1B as expected, since $k_{\text {obs }}$ remained relatively unchanged as increasing concentration (Figure 2.12d, Figure 2.13d). This data possibly showed that the amide bond could tolerate nucleophilic attack by a reactive residue on the enzyme. Third, 19a in 20\%DMSO seemed to bind to PTP1B more loosely and inactivated the enzyme as quickly as in 5\%DMSO. Forth, the benzyl TDZ analog 20 in 5\% DMSO was likely to bind to PTP1B relatively more tightly (lower $\mathrm{K}_{\mathrm{I}}$ ) and inactivate the enzyme with relatively similar rate (similar $k_{\text {inact }}$ ) than $19 a$ in 5\% DMSO, although 20 was expected to possess similar affinity and lower inactivation rate than those of 19a.

An alternative hypothesis is that these three compounds were aggregate-based inhibitor. Based on studies by Shoichet ${ }^{17}$ mentioned earlier, the Hill's coefficient from dose-response curves of $\mathbf{1 9 a}$ and $\mathbf{2 0}$ were more than 1.5 which was considered steep. One possible inactivation mechanism of compounds that showed steep dose-response curves was that the compounds at a certain concentration range aggregated and the aggregation associated to enzyme inhibition, according to study by Coan. ${ }^{18}$ Surprisingly, some of our data supported this hypothesis. Firstly, re-plotting $k_{\mathrm{obs}}$ vs low concentrations of 19a (below $100 \mu \mathrm{M}$ ) fitted the hyperbolic equation in Scheme 2.6, with $R^{2}$ value of 0.986845194 , but deviated at concentration above $100 \mu \mathrm{M}$, with $\mathrm{R}^{2}$ of 0.611790504 
(Figure 2.13a). This could suggest that the compound behaved like a typical inactivator at concentrations below $100 \mu \mathrm{M}$ and aggregated at concentrations above $100 \mu \mathrm{M}$.

a)

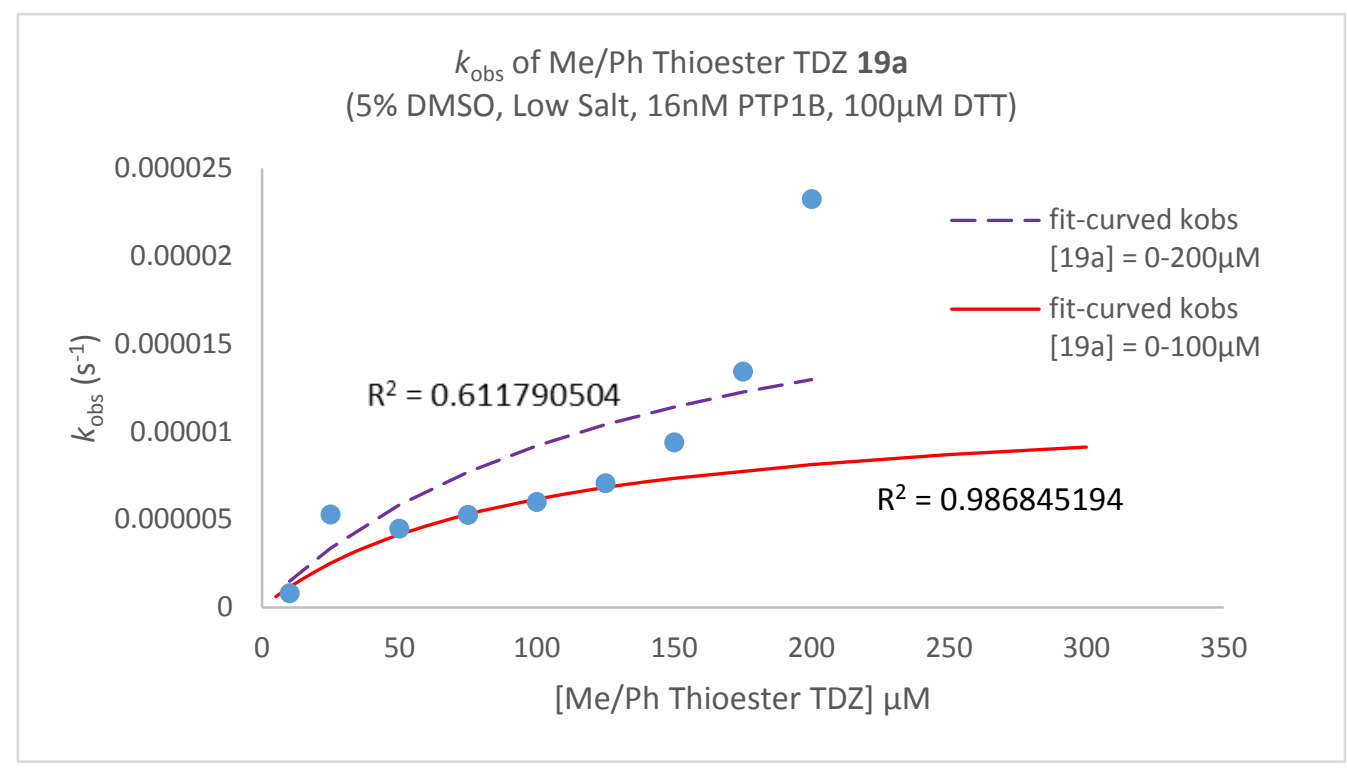

b)

$k_{\text {obs }}$ of 0-800 $\mu \mathrm{M}$ Me/Ph Thioester TDZ 21

(5\% DMSO, Low Salt, 16nM PTP1B, 100 $\mu$ M DTT)

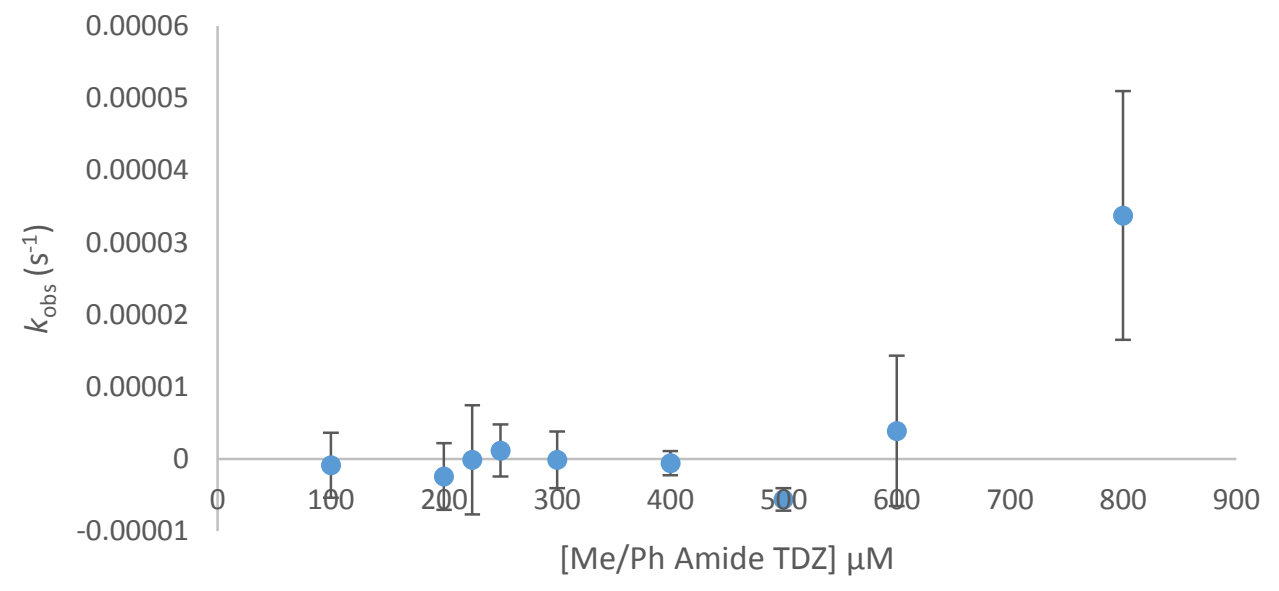

Figure 2.13 a) Plot $k_{\text {obs }}$ vs concentration of $19 a$ in $5 \%$ DMSO $(n=1)$; Fitting $k_{\text {obs }}$ values of $10,50,75$, and 100 $\mu \mathrm{M}$ to the hyperbolic equation gave $\mathrm{R}^{2}$ of 0.986845194 . However, fitting all $k_{\mathrm{obs}}$ values to the equation gave $\mathrm{R}^{2}$ of 0.611790504 . b) Plot $k_{\text {obs }}$ vs concentration of $\mathbf{2 1}$ in $5 \%$ DMSO $(n=3)$ showed that $k_{\text {obs }}$ values of the concentrations above $500 \mu \mathrm{M}>0 \mathrm{~s}^{-1}$. 
Secondly, $k_{\text {obs }}$ values of Me/Ph Amide TDZ 21 increased at concentration above $500 \mu \mathrm{M}$ (Figure 2.13b). Ideally, $\mathbf{2 1}$ was not expected to inactivate the enzyme due to high $\mathrm{pK}_{\mathrm{a}}$ of the amide group, thus $k_{\mathrm{obs}}$ should be $0 \mathrm{~s}^{-1}$ at all compound concentrations. However, the compound showed enzyme inactivation at high concentration. This also could suggest that the compound aggregated and the resulting aggregates associate with inhibition of PTP1B activity.

\section{7) Conclusion}

Based on our data, we developed Me/Ph Thioester TDZ 19a, Me/Bn Thioester TDZ 20, and Me/Ph Amide TDZ 21 which could be potential exo-affinity labeling agents targeting PTP1B. The design of these molecules were composed of three parts; an electrophile (E), a linker (L), and a phosphotyrosine isostere $\left(p Y_{i}\right), E-L-p Y_{i}$. Thioesters (phenyl analog 19a and benzyl analog 20) were chosen as the electrophiles as they were susceptible to nucleophilic attack according to literatures. The linker was several C-C bonds long connecting the electrophile part with $\mathrm{pY}_{\mathrm{i}}$. Lastly, TDZ as $\mathrm{pY}_{\mathrm{i}}$ moiety was included in our compounds due to mode of binding and cell permeability reason. The compounds were designed to interact with a few amino acids in PTP1B active site using TDZ moiety and subsequently to modify a nucleophilic residue proximal to the active site pocket via an electrophilic counterpart forming a covalent bond. Further study was needed to identify the target residue. Moreover, the affinity of our E-L-pY $\mathrm{s}$ were reported

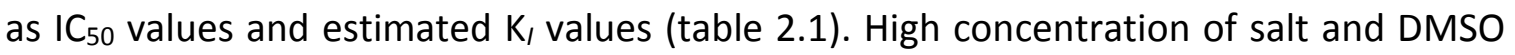
seemed to have negative effect on enzyme-inactivator binding resulting in increased $\mathrm{IC}_{50}$. 
Inactivation kinetics of the three compounds were also investigated. 19a and 20 interacted with PTP1B in time-dependent manner, suggesting that the compounds possibly inactivated the enzyme target rather than inhibited which was timeindependent. Unlikely, the amide analogue $\mathbf{2 1}$ as expected interacted with the enzyme in time-independent manner which suggested that the compound was not capable of forming the covalent bond and therefore inhibited the target enzyme rather than inactivated. However, several evidence suggested that these compounds could be aggregate-based inhibitor at high concentration. Nonetheless, further investigation was necessary to identify the mechanism of inactivation.

\section{8) Material and Method}

Chemicals and Reagents Reagents were purchased from the following suppliers: 5-bromo-2-methyl aniline, 5-bromo-2-methoxy aniline, methyl bromoactate, ethyldiisopropylamine, triethylamine, dimethyl formamide, chlorosulfonyl isocyanate, dichloromethane, triethyl amine, trifluoroacetic acid, sodium hydride, 1,2dimethoxyethane, bis(trisphenyl phosphine)palladium (II) dichloride, thiophenol, benzyl mercaptane, alanine, (benzotriazol-1-yloxy) tris(dimethylamino)phosphate (BOP), tris(hydroxymethyl)aminomethane $\quad$ (Tris), 2-[bis-(2-hydroxyethyl)-amino]-2hydroxymethyl-propane-1,3-diol (Bis-tris), 4-nitrophenyl phosphate disodium salt hexahydrate ( $p N P P)$, DL-dithiothreitol (DTT), diethylenediamine tetraacetic acid disodium

(EDTA), 2-[4-(2-hydroxyethyl)piperazin-1-yl]ethanesulfonic acid (HEPES), 
diethylenetriaminepentaacetic acid (DTPA), sodium hydroxide, and sodium acetate $(99+\%)$ were obtained from Sigma-Aldrich. potassium carbonate and sodium chloride were purchased from Fischer Chemical. 4-carboxybenzene boronic acid was obtained from Boron Molecular. Zeba mini centrifugal buffer exchange column was purchased from Thermoscientific, and Tween-80 were purchased from Pierce Biotechnology. Amicon Ultra centrifugal filter devices were purchased from Millipore. The enzyme consisting of amino acids 1-322 of human PTP1B was expressed and purified as described previously ${ }^{20}$ and the concentration of active enzyme in stock solutions was determined as described by Prege ${ }^{21}$ et. al. Thiol-free PTP1B was prepared by a Zeba mini centrifugal desalting column buffer exchange column according to manufacturer protocol. The buffer exchange columns were equilibrated before use in sodium acetate (100 mM), Tris (50 $\mathrm{mM})$, Bis-tris (50 mM, pH 7), DTPA (10 mM), and Tween 80 (0.05\%). The thiol-free enzyme was further diluted, if necessary, with sodium acetate (100 mM), Tris (50 mM), Bis-tris (50 $\mathrm{mM}, \mathrm{pH} 7)$, DTPA $(10 \mathrm{mM})$, and Tween 80 (0.05\%). NMR spectra were recorded using Bruker DRX 500 or DRX $300 \mathrm{MHz}$ instruments at University of Missouri-Columbia. HRMS data were recorded on LC/ESI TOF mass spectrometer by Mass Spectrometry Laboratory, University of Illinois at Urbana-Champaign. MS data of 16a was recorded on direct infusion ESI/APCI mass spectrometer, University of Missouri-Columbia. IR experiments were recorded on a Perkin-Elmer Spectrum 100 FT-IR spectrometer.

Expression and Purification of PTP1B (1-298 domain) The enzyme was prepared by Lewis, S.M., my colleague, using a protocol reported by Zhou ${ }^{22}$ et. al. The PTP1B (1298) plasmid was transformed into E. coli BL21Al cells and plated on LB Agar containing 
ampicillin $(50 \mu \mathrm{g} / \mathrm{mL})$. The plate was incubated at $37{ }^{\circ} \mathrm{C}$ overnight and a single colony of the transformant was picked to inoculate $10 \mathrm{~mL}$ starter culture made of $1 \%$ tryptone and $0.5 \%$ yeast extract. This was incubated at $37^{\circ} \mathrm{C}$ with constant shaking at $250 \mathrm{rpm}$, overnight. The starter culture was used to inoculate $1 \mathrm{~L}$ of auto-induction media, ${ }^{23}$ and the cells were allowed to shake constantly for two hours at $37^{\circ} \mathrm{C}$ and $250 \mathrm{rpm}$. After two hours of cell growth, the temperature was reduced to $25{ }^{\circ} \mathrm{C}$, and $0.2 \%$ arabinose was added to the media. Cells were harvested after $20-21$ hours by centrifugation at $4{ }^{\circ} \mathrm{C}$ and $3500 \mathrm{rpm}$ and resuspended in Buffer A (20 mM Tris, $150 \mathrm{mM} \mathrm{NaCl}, 10 \%$ glycerol pH 7.5). The cell pellet was quick-frozen into liquid nitrogen for later use. Frozen cells were thawed at $4{ }^{\circ} \mathrm{C}$ in the presence of the following protease inhibitors: $10 \mu \mathrm{M}$ leupeptin, $1 \mu \mathrm{M}$ pepstatin A, $1 \mathrm{mM}$ PMSF. Cells were stirred for $15-20$ minutes at $4{ }^{\circ} \mathrm{C}$ followed by disruption using sonication. Unbroken cells and debris were removed by centrifugation for $60 \mathrm{~min}$ at 17,000 rpm. The supernatant was collected and subjected to a second centrifugation step for $30 \mathrm{~min}$ at $17,000 \mathrm{rpm}$. The resulting supernatant was used for further purification by immobilized metal-ion affinity chromatography $\left(\mathrm{Ni}^{2+}-\right.$ charged HiTRAP; GE Healthcare). The fractions were eluted using buffer B (Buffer A supplemented with $1 \mathrm{M}$ imidazole). Fractions containing PTP1B were pooled and mixed with TEVP (1 mg of TEVP per $40 \mathrm{mg}$ of PTP1B) and $1 \mathrm{mM}$ THP. The sample was incubated for $8 \mathrm{~h}$ at $20^{\circ} \mathrm{C}$ and then dialyzed against buffer $\mathrm{A}$. The dialyzed protein was again loaded onto the $\mathrm{Ni}^{2+}$ charged column using buffer A. Tag-free PTP1B was collected in both the flow-through and by elution in $3 \%$ buffer $B$. The purified protein was dialyzed into $10 \mathrm{mM}$ Tris, $25 \mathrm{mM}$ 
$\mathrm{NaCl}, 1 \mathrm{mM}$ EDTA, $1 \mathrm{mM}$ THP pH 7.5. Finally, the protein was distributed into thin-walled PCR tubes, quickfrozen in liquid nitrogen, and stored at $-80^{\circ} \mathrm{C}$.

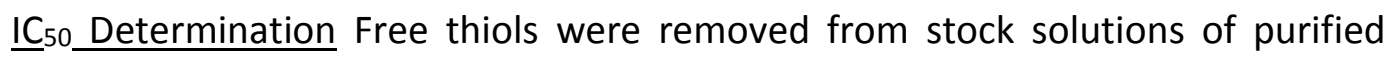
PTP1B using Zeba mini centrifugal exchange columns according to the manufacturer's protocol. The exchange buffer contained $50 \mathrm{mM}$ Bis-Tris, 2mM EDTA and 0.05\% Tween 80 at $\mathrm{pH}$ 7.0. PTP1B was adding to an assay mixture $p$ NPP, different concentrations of compounds (19a, 20, or $\mathbf{2 1}), 4 \%$ or $20 \%$ DMSO in a buffer (50 mM Bis-Tris, 2 mM EDTA, 5 $\mathrm{mM}$ DTT, $0.05 \%$ Tween80) to achieve a final PTP1B concentration of $48 \mathrm{nM}, 60 \mathrm{nM}$, or 72 $\mathrm{nM}$ and a final $p$ NPP concentration of $2 \mathrm{mM}$ or $0.4 \mathrm{mM}$. Absorbance at $410 \mathrm{~nm}$ of the mixture was measured every $5 \mathrm{~s}$ for $1 \mathrm{~min}$. Activity of PTP1B in the presence of each compound concentration was a slope of a plot of absorbance $(410 \mathrm{~nm})$ against time $(\mathrm{s})$. The activities relative to the uninhibited activity were used to calculate the relative activity which were re-plotted against the compound concentrations. $\mathrm{IC}_{50}$ was the concentration that gave $50 \%$ PTP1B relative activity.

Time-Dependent Inactivation of PTP1B Free thiols were removed from a stock solution of concentrated PTP1B by gel filtration/buffer exchange into buffer A (50 mM Bis-Tris, $50 \mathrm{mM}$ Tris, $1.0 \mathrm{mM}$ DTPA, $100 \mathrm{mM} \mathrm{NaOAc}$, and $0.05 \%$ Tween 80 at pH 7.0) or buffer B (50 mM Bis-Tris, 2mM EDTA and 0.05\% Tween 80 at pH 7.0) using a Zeba mini centrifugal desalting column. Upon inactivation process, $10 \mu \mathrm{L}$ of concentrated PTP1B stock was added into a $90 \mu \mathrm{L}$ inactivation mixture (various concentration of $19 \mathrm{a}, \mathbf{2 0}$, or 21, DMSO, DTT, buffer A or buffer B) at $25^{\circ} \mathrm{C}$ to the final concentration of $0.8 \mu \mathrm{M}, 5 \%$ or 20\% DMSO, and $100 \mu \mathrm{M}$ DTT. A $10 \mu \mathrm{L}$ aliquot of the inactivation mixture was removed 
every $30 \mathrm{~min}$ and placed into $490 \mu \mathrm{L}$ in an activity assay buffer (50 mM Bis-Tris, $100 \mathrm{mM}$ $\mathrm{NaCl}, 10 \mathrm{mM}$ DTPA, and $20 \mathrm{mM} p \mathrm{NPP} \mathrm{pH} 6.0$ ) at $30^{\circ} \mathrm{C}$ and incubated for additional 10 minutes (Final concentration of 8 nM PTP1B). The enzymatic reaction was quenched with the addition of $500 \mu \mathrm{L} 2 \mathrm{M} \mathrm{NaOH}$. The amount of $\mathrm{p}$-nitro phenolate released during the reaction was determined by UV-vis measurement of the absorbance at $25^{\circ} \mathrm{C}$ and $410 \mathrm{~nm}$.

\section{9) Synthesis}

Methyl N-(4-bromo-2-methylphenyl) amino acetate (13a) To a

stirred solution of 5-bromo-2-methylaniline (5.0 g, $27 \mathrm{mmol})$ in

DMF (6 mL) was added methyl bromoacetate $(2.4 \mathrm{~mL}, 26 \mathrm{mmol})$

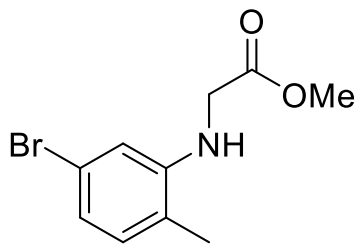

and diisopropylethylamine $(23.6 \mathrm{~mL}, 136 \mathrm{mmol})$. The reaction mixture was stirred for 18 $\mathrm{h}$ at $60^{\circ} \mathrm{C}$ and cooled down to room temperature. The solution was poured in cold ice water and refrigerated for $1.5 \mathrm{~h}$. The precipitate was filtered, washed with cold water, and dried in vacuo to obtain an off-white solid. If necessary, the title compound was purified by column chromatography (10\% EtOAc/Hexane) on silica gel to obtain $13 a$ (6.5 g, $93 \%)$ as a white solid ( $\left.\mathrm{mp} 71-73^{\circ} \mathrm{C}\right) . \mathrm{R}_{\mathrm{f}}\left(10 \%\right.$ EtOAc/Hexane) $0.32 .{ }^{1} \mathrm{H}-\mathrm{NMR}(500 \mathrm{MHz}$, $\left.\mathrm{CDCl}_{3}\right): \delta 6.90(1 \mathrm{H}, \mathrm{d}, J=2.1 \mathrm{~Hz}), 6.72(1 \mathrm{H}, \mathrm{dd}, J=8,2 \mathrm{~Hz}), 6.53(1 \mathrm{H}, \mathrm{d}, J=2 \mathrm{~Hz}), 3.97(2 \mathrm{H}$, s), $3.06(3 \mathrm{H}, \mathrm{s}), 2.12(3 \mathrm{H}, \mathrm{s}) .{ }^{13} \mathrm{C}-\mathrm{NMR}\left(500 \mathrm{MHz}, \mathrm{CDCl}_{3}\right): \delta$ 173.59, 148.49, 132.33, 122.77, 121.33, $120.81,113.29,52.58,45.93,17.15$. HRMS (ESI-TOF): $\mathrm{m} / \mathrm{z}$ calcd for $\mathrm{C}_{10} \mathrm{H}_{13} \mathrm{NO}_{2} \mathrm{Br}$ 258.0130 $\left[\mathrm{M}^{+}+\mathrm{H}\right]$; Found 258.0131. IR (neat): 3416, 3003, 2957, 1750, $1222 \mathrm{~cm}^{-1}$. 


\section{Methyl 2-((5-bromo-2-methylphenyl) (N-(tert- \\ butoxycarbonyl) sulfonyl) amino) acetate (14a) To a}

stirred solution of chlorosulfonyl isocyanate $(2.81 \mathrm{~mL}$,

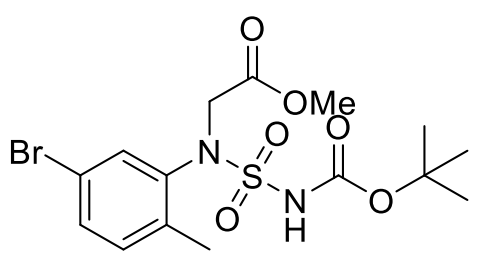

$32.1 \mathrm{mmol})$ in dry $\mathrm{DCM}(50.0 \mathrm{~mL})$ was cooled to $0{ }^{\circ} \mathrm{C}$, slowly added t-BuOH $(3.34 \mathrm{~mL}, 35.1$

$\mathrm{mmol})$. The solution mixture was stirred for $15 \mathrm{~min}$ at room temperature to obtain $\mathrm{t}$ butylchlorosulfony carbamate solution and used without purification.

To a solution of $13 \mathrm{a}(0.51 \mathrm{~g}, 1.9 \mathrm{mmol})$ in $\mathrm{DCM}(10.0 \mathrm{~mL})$ was cooled to $0{ }^{\circ} \mathrm{C}$ and added the solution of t-butylchlorosulfonyl carbamate, followed by addition of Triethylamine $(0.81 \mathrm{~mL}, 5.8 \mathrm{mmol})$. The reaction solution, then, was warmed to room temperature and stirred for $2 \mathrm{~h}$. After stirring, the solution was washed with Three times with $\mathrm{H}_{2} \mathrm{O}(10.0 \mathrm{~mL})$. The organic layer was dried over $\mathrm{Na}_{2} \mathrm{SO}_{4}$, filtered, concentrated by rotary evaporation, and purified by column chromatography (10\%EtOAc:Hexane) on silica gel to give $14 a(0.86 \mathrm{~g}, 34 \%)$ as a white solid (mp $\left.131-132{ }^{\circ} \mathrm{C}\right) . \mathrm{R}_{\mathrm{f}}(10 \%$ EtOAc/Hexane) 0.17. ${ }^{1} \mathrm{H}-\mathrm{NMR}\left(300 \mathrm{MHz}, \mathrm{CDCl}_{3}\right): \delta 7.61(1 \mathrm{H}, \mathrm{d}, J=2.1 \mathrm{~Hz}), 7.39(1 \mathrm{H}, \mathrm{dd}, J=8.4,2 \mathrm{~Hz}), 7.16$ $(1 \mathrm{H}, \mathrm{d}, J=8.4 \mathrm{~Hz}), 4.56(2 \mathrm{H}, \mathrm{s}), 3.74(3 \mathrm{H}, \mathrm{s}), 2.42(3 \mathrm{H}, \mathrm{s}), 1.53(9 \mathrm{H}, \mathrm{s}) .{ }^{13} \mathrm{C}-\mathrm{NMR}(500 \mathrm{MHz}$, $\left.\mathrm{CDCl}_{3}\right): \delta 169.53,149.94,149.21,139.21,138.40,133.10,132.61,132.53,119.40,84.18$ 77.41, 77.16, 76.90, 55.06, 52.56, 28.13, 17.80. HRMS (ESI-TOF): $\mathrm{m} / \mathrm{z}$ calcd for $\mathrm{C}_{15} \mathrm{H}_{21} \mathrm{~N}_{2} \mathrm{O}_{6} \mathrm{BrNa} 459.0201$ [ $\left.\mathrm{M}^{+}+\mathrm{Na}\right] ;$ Found 459.0206. IR (neat): 3249, 2982, 1734, 1368, $1150,1139 \mathrm{~cm}^{-1}$. 
<smiles>COC(=O)CN(c1cc(Br)ccc1C)S(N)(=O)=O</smiles>
Methyl 2-((5-bromo-2-methylphenyl) (sulfonyl) amino) acetate

(15a) To a stirred solution of $14 \mathrm{a}$ in $(3.4 \mathrm{~g}, 7.7 \mathrm{mmol})$ was slowly added TFA (5.9 mL, $77 \mathrm{mmol}$ ) under $\mathrm{N}_{2}$ atmosphere. The reaction solution was stirred for $3 \mathrm{~h}$ at room temperature. Monitoring the progress of the reaction by TLC (EtOAc:Hexane)stained with ninhydrin, more TFA was added if necessary. The solvent was evaporated in vacuo and azeotroped with toluene to remove trace TFA and dried overnight to obtain $15 \mathrm{a}(1.8 \mathrm{~g}, 70 \%)$ as a brown oil (mp $\left.112-114{ }^{\circ} \mathrm{C}\right) .{ }^{1} \mathrm{H}-\mathrm{NMR}(500$ $\left.\mathrm{MHz}, \mathrm{CDCl}_{3}\right): \delta 7.72(1 \mathrm{H}, \mathrm{D}, J=0.9 \mathrm{HZ}), 7.40(1 \mathrm{H}, \mathrm{DD}, J=4.8,1.2 \mathrm{HZ}), 7.18(1 \mathrm{H}, \mathrm{d}, J=4.8 \mathrm{~Hz})$, $5.26(2 \mathrm{H}, \mathrm{s}), 3.78(3 \mathrm{H}, \mathrm{s}), 2.33(3 \mathrm{H}, \mathrm{s}) .{ }^{13} \mathrm{C}-\mathrm{NMR}\left(500 \mathrm{MHz}, \mathrm{CDCl}_{3}\right): \delta 171.79,140.31,138.52$, 133.10, 132.51, 131.98, 119.44, 77.41, 77.16, 76.90, 54.45, 52.91, 17.92. HRMS (ESI-TOF): m/z calcd for $\mathrm{C}_{10} \mathrm{H}_{14} \mathrm{~N}_{2} \mathrm{O}_{4} \mathrm{SBr} 336.9858\left[\mathrm{M}^{+}+\mathrm{H}\right]$; Found 336.9858. IR (neat): 3381, 3279, $2955,1739,1358 \mathrm{~cm}^{-1}$.

\section{5-(2-methyl-4-bromophenyl)-1,2,5-thiadiazolidin-3-one-1,1-}

dioxide (16a) To a solution of $15 \mathrm{a}(1.13 \mathrm{~g}, 0.263 \mathrm{mmol})$ in anhydrous THF $(5.0 \mathrm{~mL})$ was purged with $\mathrm{N}_{2}$. In a separate flask, $\mathrm{NaH}(60 \%$

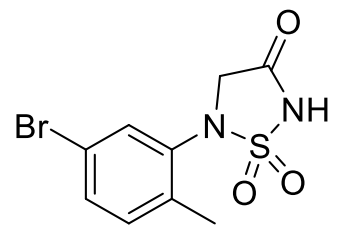
dispersion in mineral oil) $(0.263 \mathrm{~g}, 10.9 \mathrm{mmol})$ was dissolved in anhydrous THF $(2.0 \mathrm{~mL})$ and purged with $\mathrm{N}_{2}$. The suspension of $\mathrm{NaH} / \mathrm{THF}$ was slowly added to the solution of 15a under $\mathrm{N}_{2}$ and the reaction mixture was stirred for $1 \mathrm{~h}$ at room temperature. The reaction mixture was quenched via slow addition of $\mathrm{H}_{2} \mathrm{O}(2.0 \mathrm{~mL})$, basified with $10 \% \mathrm{NaOH}(\mathrm{pH} 14)$, and EtOAc $(10.0 \mathrm{~mL})$ was added. The aqueous layer was washed three times with Hexane (10.0 $\mathrm{mL}$ ) to remove mineral oil, maintaining $\mathrm{pH} 14$ to prevent product loss. The aqueous 
layer was separated and acidified $(\mathrm{pH} \sim 1)$ with $10 \% \mathrm{HCl}$, and extracted three times with EtOAc $(10.0 \mathrm{~mL})$, dried over $\mathrm{Na}_{2} \mathrm{SO}_{4}$, concentrated by rotary evaporator, and purified by column chromatography (10\% EtOAc:PET Ether) on silica gel to give $16 \mathrm{a}(0.73 \mathrm{~g}, 65 \%)$ as an off-white solid (mp 196-198 $\left.{ }^{\circ} \mathrm{C}\right) \cdot \mathrm{R}_{\mathrm{f}}(10 \% \mathrm{EtOAc} / \mathrm{PE})$ 0.22. ${ }^{1} \mathrm{H}-\mathrm{NMR}\left(300 \mathrm{MHz},\left(\mathrm{CD}_{3}\right)_{2} \mathrm{CO}\right)$ : $\delta 7.69(1 \mathrm{H}, \mathrm{d}, J=2.1 \mathrm{~Hz}), 7.48(1 \mathrm{H}, \mathrm{dd}, J=8.1,2.1 \mathrm{~Hz}), 7.27(1 \mathrm{H}, \mathrm{d}, J=8.1 \mathrm{~Hz}), 4.48(2 \mathrm{H}, \mathrm{s})$, $2.38(3 \mathrm{H}, \mathrm{s}) .{ }^{13} \mathrm{C}-\mathrm{NMR}\left(500 \mathrm{MHz},\left(\mathrm{CD}_{3}\right)_{2} \mathrm{CO}\right): \delta 166.33,139.98,136.20,133.79,133.30$. 119.87, 57.45, 17.77. MS (ESI-APCI): $\mathrm{m} / \mathrm{z}$ calcd for $\mathrm{C}_{9} \mathrm{H}_{9} \mathrm{~N}_{2} \mathrm{O}_{3} \mathrm{SBr} 302.94\left[\mathrm{M}^{+}-\mathrm{H}\right]$; Found 303.24. IR (neat): $3422,1739,1326,1169 \mathrm{~cm}^{-1}$.

5-(2-methyl-4-(4-carboxyphenyl) phenyl)-1, 2, 5thiadiazolidin-3-one-1, 1-dioxide (18a) To a solution of $16 \mathrm{a}(1.0 \mathrm{~g}, 3.3 \mathrm{mmol}, 1 \mathrm{~g}), \mathrm{K}_{2} \mathrm{CO}_{3}(1.8 \mathrm{~g}, 13 \mathrm{mmol})$ and $4-$

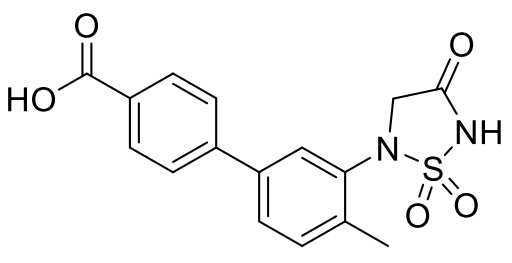
carboxyphenylboronic acid $(0.82 \mathrm{~g}, 4.9 \mathrm{mmol})$ in $3: 1 \mathrm{DME} / \mathrm{H}_{2} \mathrm{O}(40.0 \mathrm{~mL})$ in a seal tube was degassed for $10-15 \mathrm{~min}$ at room temperature. The mixture was added $5 \mathrm{~mol} \%$ of $\mathrm{Pd}\left(\mathrm{PPh}_{3}\right)_{2} \mathrm{Cl}_{2}(0.12 \mathrm{~g}, 0.16 \mathrm{mmol})$ and degassed for another 10-15 min. The reaction mixture was stirred for $10 \mathrm{~h}$ at $100{ }^{\circ} \mathrm{C}$, monitoring the progress of reaction by TLC $(10 \%$ AcOH:EtOAc). The used Pd catalyst and solid impurities were filtered and the filtrate was concentrated by rotary evaporation. The basic residue was washed with three times with EtOAc $(30.0 \mathrm{~mL})$, acidified with conc. $\mathrm{HCl}(\mathrm{pH} \sim 1)$, extracted three times with EtOAc (30.0 $\mathrm{mL}$ ), dried over $\mathrm{Na}_{2} \mathrm{SO}_{4}$, and filtered. The final filtrate was concentrated by rotary evaporation and purified by column chromatography (gradient elution 10-100\% EtOAc:Hexane $+5 \%$ AcOH $)$ on silica gel to obtain 18 a $(0.49 \mathrm{~g}, 43 \%)$ as a brown solid 
(decomposed $\left.223-225{ }^{\circ} \mathrm{C}\right) . \mathrm{R}_{\mathrm{f}}\left(10 \% \mathrm{AcOH}:\right.$ EtOAc) 0.2. ${ }^{1} \mathrm{H}-\mathrm{NMR}\left(500 \mathrm{MHz},\left(\mathrm{CD}_{3}\right)_{2} \mathrm{CO}\right): \delta$ $8.10(2 \mathrm{H}, \mathrm{d}, J=8.5 \mathrm{~Hz}), 7.85(1 \mathrm{H}, \mathrm{d}, J=2 \mathrm{~Hz}), 7.76(2 \mathrm{H}, \mathrm{d}, J=8.5 \mathrm{~Hz}), 7.68(1 \mathrm{H}, \mathrm{dd}, J=8,2 \mathrm{~Hz})$, $7.47(1 \mathrm{H}, \mathrm{d}, J=8 \mathrm{~Hz}), 4.55(2 \mathrm{H}, \mathrm{s}), 2.49(3 \mathrm{H}, \mathrm{s}) .{ }^{13} \mathrm{C}-\mathrm{NMR}\left(500 \mathrm{MHz},\left(\mathrm{CD}_{3}\right)_{2} \mathrm{CO}\right): \delta 175.20$ $169.61,145.56,140.63,140.47,136.17,133.02,131.42,130.89,128.90,128.83,127.87$ 58.46, 18.00. HRMS (ESI-TOF): $\mathrm{m} / \mathrm{z}$ calcd for $\mathrm{C}_{16} \mathrm{H}_{14} \mathrm{~N}_{2} \mathrm{O}_{5} \mathrm{NaS} 369.0521\left[\mathrm{M}^{+}+\mathrm{Na}\right]$; Found 369.0537. IR (neat): 3586, 3004, 2922, 1715, 1419, 1363, $1222 \mathrm{~cm}^{-1}$.

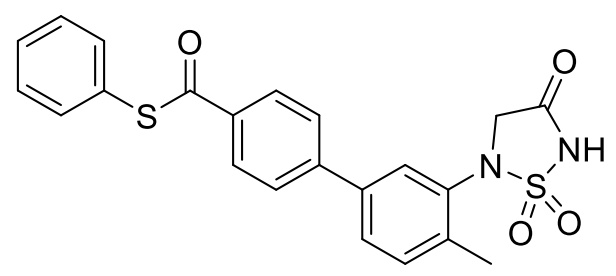

\section{5-(2-methyl-4-(4-(S-phenylthiocarbonyl) phenyl)} phenyl) -1, 2, 5-thiadiazolidin-3-one-1, 1-dioxide (19a) To a solution of $18 \mathrm{a}$ in $(53.3 \mathrm{mg}, 0.154 \mathrm{mmol})$

and BOP (136 mg, $0.308 \mathrm{mmol})$ in dry DMF $(5.0 \mathrm{~mL})$ was degassed and added diisopropylethylamine $(0.14 \mathrm{~mL}, 0.77 \mathrm{mmol})$. The solution mixture was stirred for $15 \mathrm{~min}$ at room temperature, followed by addition of thiophenol $(0.029 \mathrm{~mL}, 0.31 \mathrm{mmol})$. The reaction solution was stirred for $1-2 \mathrm{hr}$ at room temperature, monitoring by TLC (10\%AcOH/EtOAc). DMF was removed in vacuo, the resulting residue was added EtOAc $(5 \mathrm{~mL})$, and washed three to five times with water $(5 \mathrm{~mL})$. The organic layer was concentrated by rotary evaporation and purified by column chromatography (gradient elution from 10-100\% EtOAc:Hexane + 5\%AcOH) on silica gel to obtain 18a (57.4 mg, 85\%) as a white solid (decomposed $\left.146-148{ }^{\circ} \mathrm{C}\right) . \mathrm{R}_{\mathrm{f}}(10 \% \mathrm{AcOH} / \mathrm{EtOAC})$ 0.32. ${ }^{1} \mathrm{H}-\mathrm{NMR}(500 \mathrm{MHz}$, $\left.\left(\mathrm{CD}_{3}\right)_{2} \mathrm{CO}\right): \delta 8.10(2 \mathrm{H}, \mathrm{d}, J=8.5 \mathrm{~Hz}), 7.86(1 \mathrm{H}, \mathrm{d}, J=2 \mathrm{~Hz}), 7.82(2 \mathrm{H}, \mathrm{d}, J=8.5 \mathrm{~Hz}), 7.64(1 \mathrm{H}$, $\mathrm{dd}, J=8,2 \mathrm{~Hz}), 7.54-7.48(5 \mathrm{H}, \mathrm{m}), 7.44(1 \mathrm{H}, \mathrm{d}, J=8 \mathrm{~Hz}), 4.38(\mathrm{~s}, 1 \mathrm{H}), 2.49(3 \mathrm{H}, \mathrm{s}) .{ }^{13} \mathrm{C}-\mathrm{NMR}$ (500 MHz, $\left.\left(\mathrm{CD}_{3}\right)_{2} \mathrm{CO}\right): \delta$ 190.97, 174.81, 146.79, 140.84, 139.79, 137.69, 136.68, 136.29, 
132.92, 130.65, 130.33, 129.08, 128.74, 128.70, 128.30, 128.17, 59.80, 18.16. HRMS (ESI-

TOF): $\mathrm{m} / \mathrm{z}$ calcd for $\mathrm{C}_{22} \mathrm{H}_{19} \mathrm{~N}_{2} \mathrm{O}_{4} \mathrm{~S}_{2} 439.0786\left[\mathrm{M}^{+}+\mathrm{H}\right]$; Found 439.0792. IR (neat): 3445, $3059,2959,2959,1734,1700 \mathrm{~cm}^{-1}$.
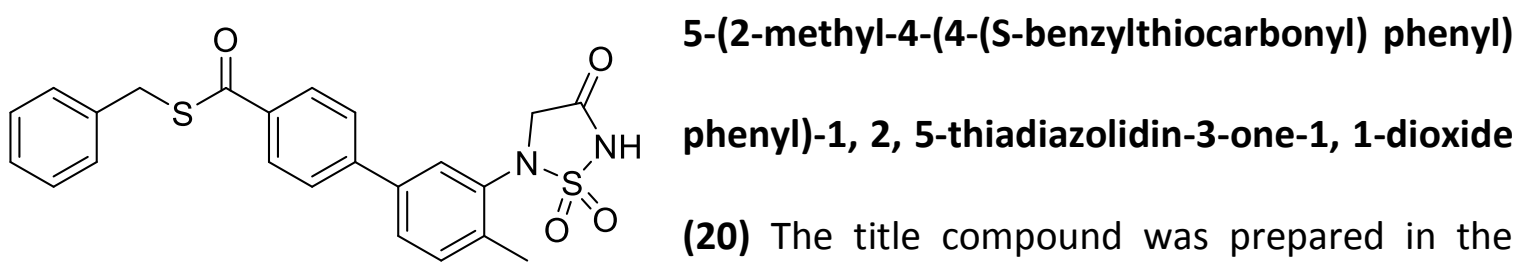

same manner as compound $19 \mathrm{a}$, benzylmercaptane $(0.037 \mathrm{~mL}, 0.28 \mathrm{mmol})$ was used instead of thiophenol to synthesize 20 (50.1 mg, 77\%) as a white solid (decomposed 85$\left.87^{\circ} \mathrm{C}\right) . \mathrm{R}_{\mathrm{f}}(10 \% \mathrm{AcOH} / \mathrm{EtOAC})$ 0.32. ${ }^{1} \mathrm{H}-\mathrm{NMR}\left(500 \mathrm{MHz},\left(\mathrm{CD}_{3}\right)_{2} \mathrm{CO}\right): \delta 8.02(2 \mathrm{H}, \mathrm{d}, J=8 \mathrm{~Hz})$, $7.99(1 \mathrm{H}, \mathrm{d}, J=1.5 \mathrm{~Hz}), 7.84(2 \mathrm{H}, \mathrm{d}, J=8.5 \mathrm{~Hz}), 7.67(1 \mathrm{H}, \mathrm{d}, J=6.5 \mathrm{~Hz}), 7.46-7.43(3 \mathrm{H}, \mathrm{m})$, $7.34(2 \mathrm{H}, \mathrm{t}, \mathrm{J}=7.5 \mathrm{~Hz}), 7.26(1 \mathrm{H}, \mathrm{t}, \mathrm{J}=7.5 \mathrm{~Hz}), 4.58(2 \mathrm{H}, \mathrm{s}), 4.37(2 \mathrm{H}, \mathrm{s}), 2.49(3 \mathrm{H}, \mathrm{s}) .{ }^{13} \mathrm{C}-\mathrm{NMR}$ (500 MHz, $\left.\left(\mathrm{CD}_{3}\right)_{2} \mathrm{CO}\right): \delta$ 190.74, 166.08, 145.45, 140.72, 139.54, 138.80, 136.62, 135.34, 132.93, 129.83, 129.44, 128.97, 128.86, 128.60, 128.10, 128.06, 57.57, 17.94. HRMS (ESITOF): $\mathrm{m} / \mathrm{z}$ calcd for $\mathrm{C}_{23} \mathrm{H}_{21} \mathrm{~N}_{2} \mathrm{O}_{4} \mathrm{~S}_{2} 453.0943\left[\mathrm{M}^{+}+\mathrm{H}\right]$; Found 453.0941. IR (neat): 3442, $3026,2952,1734,1652 \mathrm{~cm}^{-1}$.

\section{5-(2-methyl-4-(4-(S-phenylaminocarbonyl) phenyl)} phenyl)-1, 2, 5-thiadiazolidin-3-one-1, 1-dioxide (21) The title compound was prepared in the same<smiles>Cc1ccc(-c2ccc(C(=O)Nc3ccccc3)cc2)cc1N1CC(=O)NS1(=O)=O</smiles>
manner as compound 19a, aniline $(0.027 \mathrm{~mL}, 0.29 \mathrm{mmol})$ was used instead of thiophenol to give 21 (33.5 mg, 54\%) as a white solid (decomposed $\left.48-49{ }^{\circ} \mathrm{C}\right) . \mathrm{R}_{\mathrm{f}}(10 \%$ AcOH/EtOAc) 
0.32. ${ }^{1} \mathrm{H}-\mathrm{NMR}\left(500 \mathrm{MHz},\left(\mathrm{CD}_{3}\right){ }_{2} \mathrm{CO}\right): \delta 8.02(2 \mathrm{H}, \mathrm{d}, J=8 \mathrm{~Hz}), 7.85(1 \mathrm{H}, \mathrm{s}), 7.79(2 \mathrm{H}, \mathrm{d}, J=$ $8 \mathrm{~Hz}), 7.71(2 \mathrm{H}, \mathrm{d}, J=7.5 \mathrm{~Hz}), 7.64(1 \mathrm{H}, \mathrm{d}, J=8 \mathrm{~Hz}), 7.44(1 \mathrm{H}, \mathrm{d}, J=7.5 \mathrm{~Hz}), 7.37(3 \mathrm{H}, \mathrm{t}, \mathrm{J}=$ 7.5Hz), $7.16(3 \mathrm{H}, \mathrm{t}, \mathrm{J}=7.5 \mathrm{~Hz}), 4.43(2 \mathrm{H}, \mathrm{s}), 2.48(3 \mathrm{H}, \mathrm{s}) .{ }^{13} \mathrm{C}-\mathrm{NMR}\left(500 \mathrm{MHz},\left(\mathrm{CD}_{3}\right)_{2} \mathrm{CO}\right): \delta$ 168.51 (presumably two carbonyl carbons have equivalent chemical shift), 144.63, $140.44,140.32,139.90,137.01,135.10,132.93,129.81,129.33,128.73,128.40,127.96$ 125.62, 122.36, 59.81, 18.07. HRMS (ESI-TOF): $\mathrm{m} / \mathrm{z}$ calcd for $\mathrm{C}_{22} \mathrm{H}_{20} \mathrm{~N}_{3} \mathrm{O}_{4} \mathrm{~S} 422.1175\left[\mathrm{M}^{+}+\right.$ H]; Found 422.1174. IR (neat): 3392, 3955, 2956, 1734, $1652 \mathrm{~cm}^{-1}$. 


\subsection{0) Reference}

(1) De Munter, S.; Kohn, M.; Bollen, M. ACS Chem. Biol. 2013, 8, 36.

(2) Johnson, T. O.; Ermolieff, J.; Jirousek, M. R. Nat. Rev. Drug Discovery 2002, 1, 696.

(3) Combs, A. P. J. Med. Chem. 2010, 53, 2333.

(4) Silverman, R. B. The Organic Chemistry of Enzyme-catalyzed Reactions; illustrated, revised ed.; Academic Press, 2002.

(5) Guterman, L. Chemical \& Engineering News 2011, 89, 8.

(6) Kirby, A. J. Adv. Phys. Org. Chem. 1980, 17, 183.

(7) Silverman, R. B. The Organic Chemistry of Enzyme-catalyzed Reactions; illustrated, revised ed.; Academic Press, 2002.

(8) Black, E.; Breed, J.; Breeze, A. L.; Embrey, K.; Garcia, R.; Gero, T. W.; Godfrey, L.; Kenny, P. W.; Morley, A. D.; Minshull, C. A.; Pannifer, A. D.; Read, J.; Rees, A.; Russell, D. J.; Toader, D.; Tucker, J. Bioorg. Med. Chem. Lett. 2005, 15, 2503.

(9) Barford, D.; Flint, A. J.; Tonks, N. K. Science (Washington, D. C., 1883-) 1994, 263, 1397.

(10) Choi, S.; Connelly, S.; Reixach, N.; Wilson, I. A.; Kelly, J. W. Nat. Chem. Biol. 2010, 6, 133.

(11) Yeo, D. S. Y.; Srinivasan, R.; Uttamchandani, M.; Chen, G. Y. J.; Zhu, Q.; Yao, S. Q. Chem. Commun. (Cambridge, U. K.) 2003, 2870.

(12) Chmura, A. J.; Orton, M. S.; Meares, C. F. Proc. Natl. Acad. Sci. U. S. A. 2001, 98, 8480.

(13) Bertozzi, C. R.; Bednarski, M. D. J. Org. Chem. 1991, 56, 4326.

(14) Cheng, Y.; Prusoff, W. H. Biochem Pharmacol 1973, 22, 3099.

(15) Shen, K.; Keng, Y.-F.; Wu, L.; Guo, X.-L.; Lawrence, D. S.; Zhang, Z.-Y. J. Biol. Chem. 2001, $276,47311$.

(16) Cubrilovic, D.; Zenobi, R. Anal Chem 2013, 85, 2724.

(17) Shoichet, B. K. J. Med. Chem. 2006, 49, 7274.

(18) Coan, K. E. D.; Maltby, D. A.; Burlingame, A. L.; Shoichet, B. K. J. Med. Chem. 2009, 52, 2067.

(19) Singh, J.; Petter, R. C.; Baillie, T. A.; Whitty, A. Nat. Rev. Drug Discovery 2011, 10, 307. 
(20) Hoppe, E.; Berne, P.-F.; Stock, D.; Rasmussen, J. S.; Moeller, N. P. H.; Ullrich, A.; Huber, R. Eur. J. Biochem. 1994, 223, 1069.

(21) Pregel, M. J.; Storer, A. C. J. Biol. Chem. 1997, 272, 23552.

(22) Zhou, H.; Singh, H.; Parsons, Z. D.; Lewis, S. M.; Bhattacharya, S.; Seiner, D. R.; LaButti, J. N.; Reilly, T. J.; Tanner, J. J.; Gates, K. S. J. Am. Chem. Soc. 2011, 133, 15803.

(23) Studier, F. W. Protein Expression Purif. 2005, 41, 207. 
a)

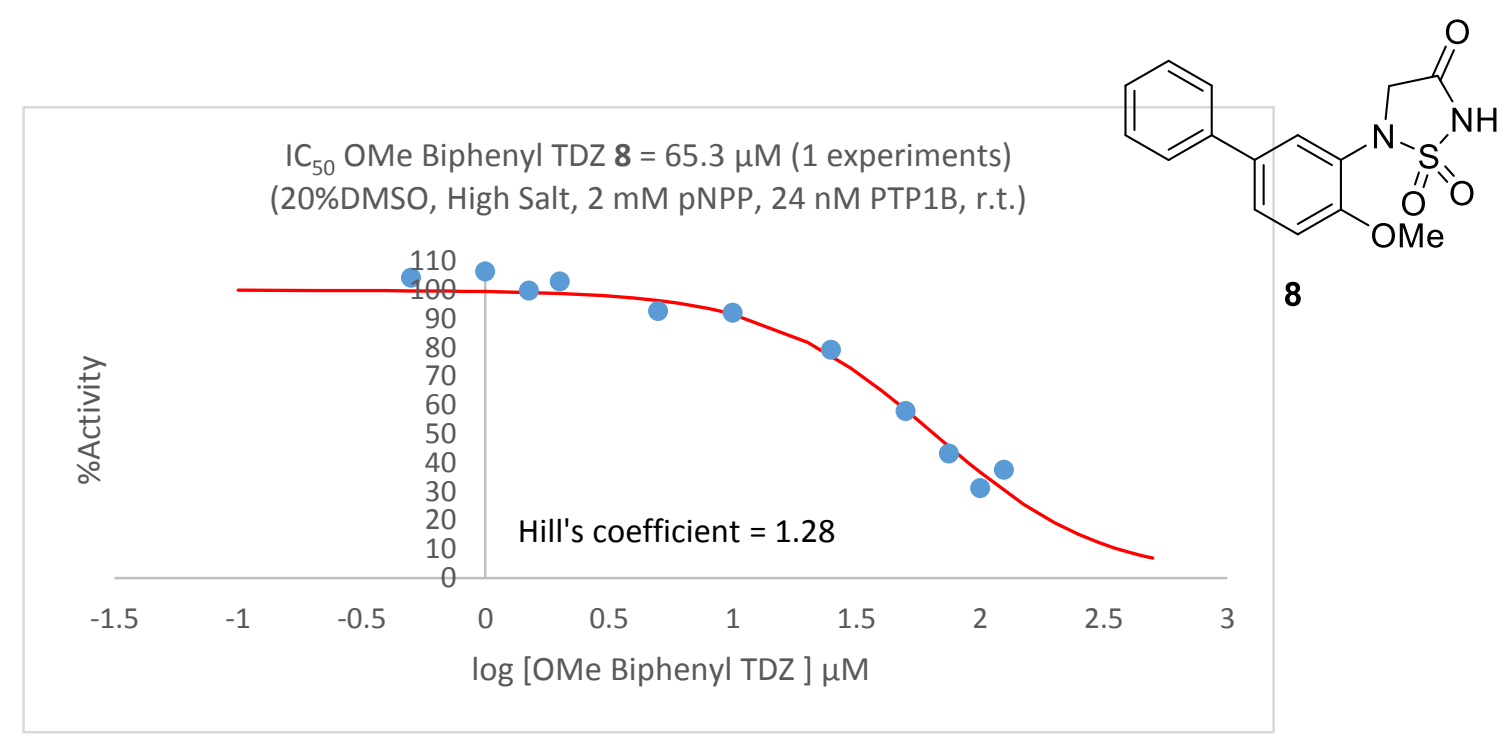

b)

$\mathrm{IC}_{50}$ OMe Biphenyl TZD $8=15.2 \pm 1.7 \mu \mathrm{M}$ (3 experiments)

(20\%DMSO, Low Salt, 0.4 mM pNPP, 24 nM PTP1B, r.t.)

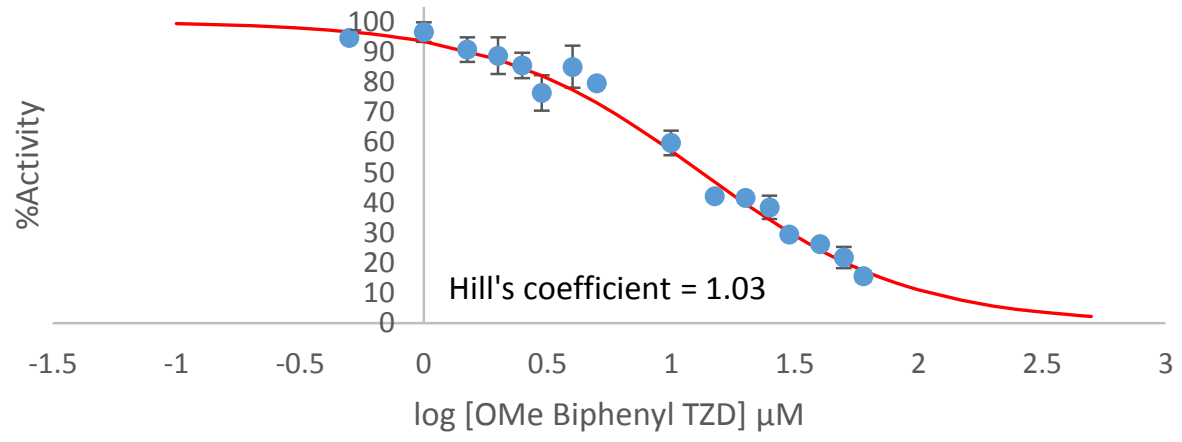

c)

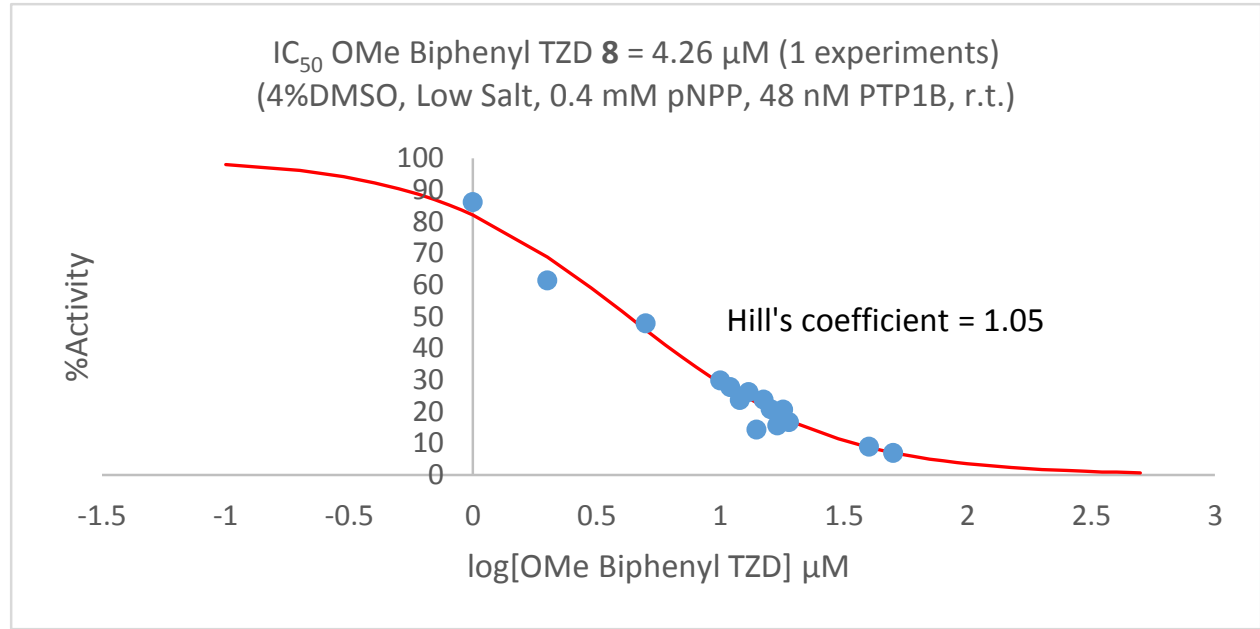

Figure 2.14 IC 50 of 8 in a) 20\%DMSO-high salt, b) 20\%DMSO-low salt, and c) 4\%DMSO-low salt. 
a)

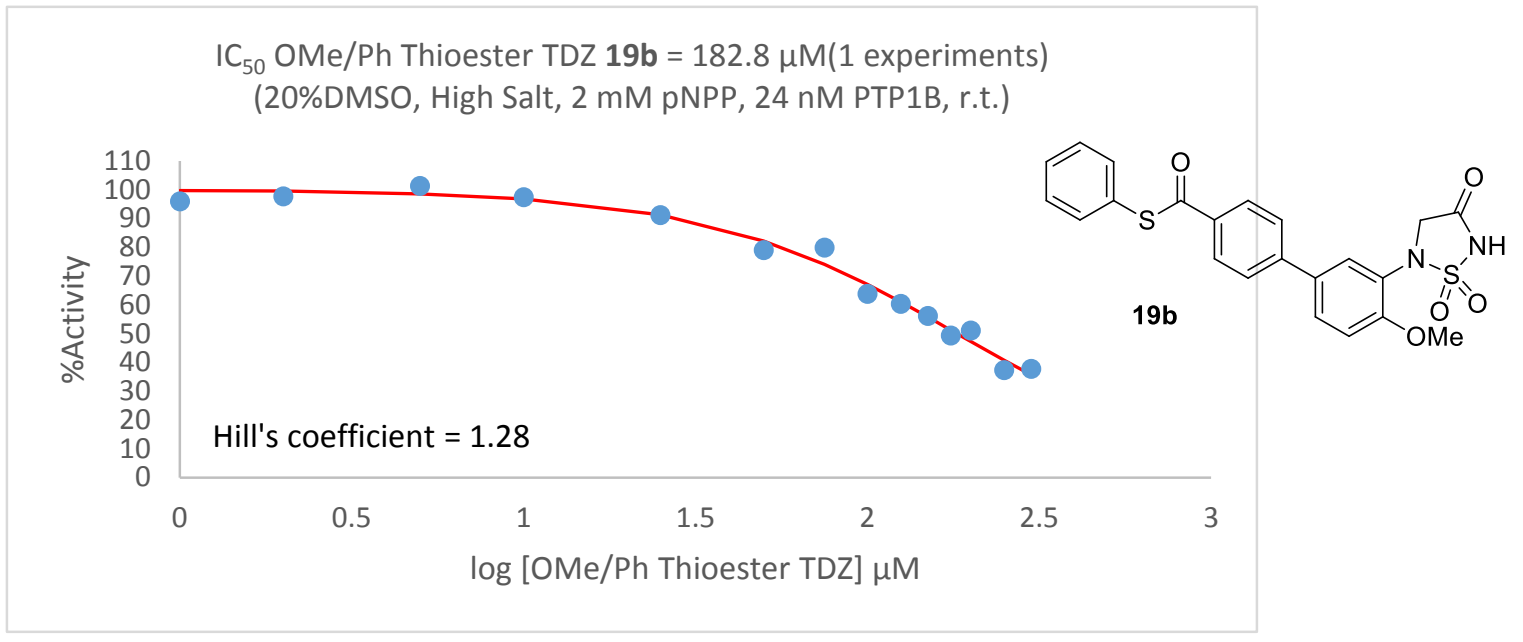

b)

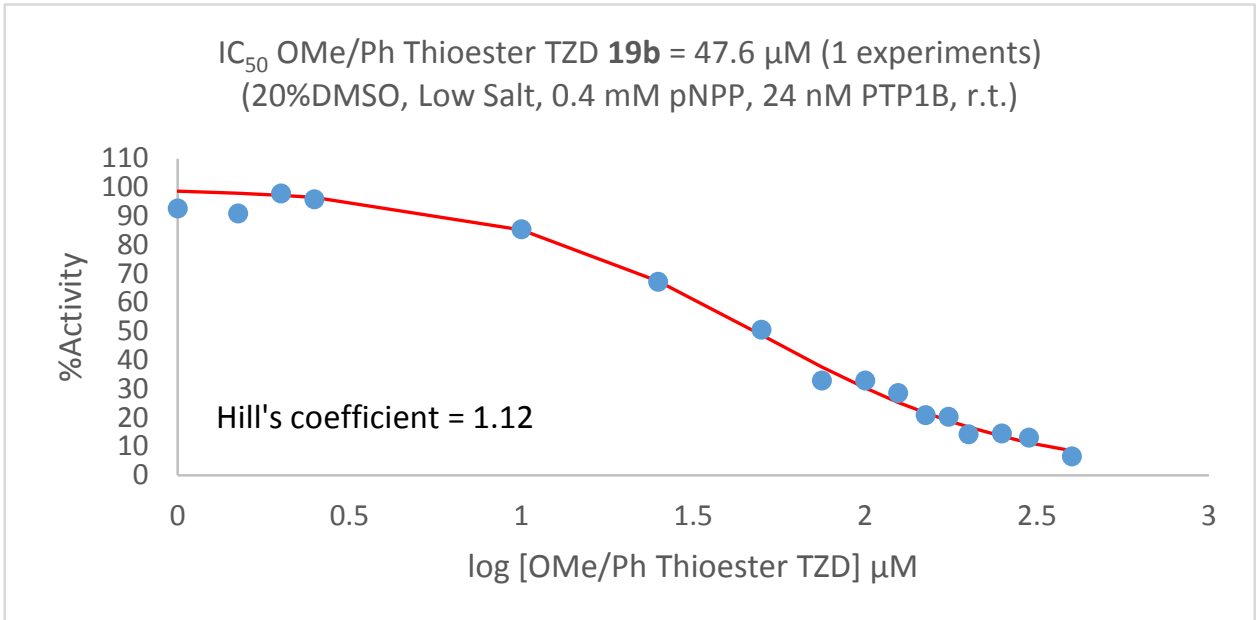

c)

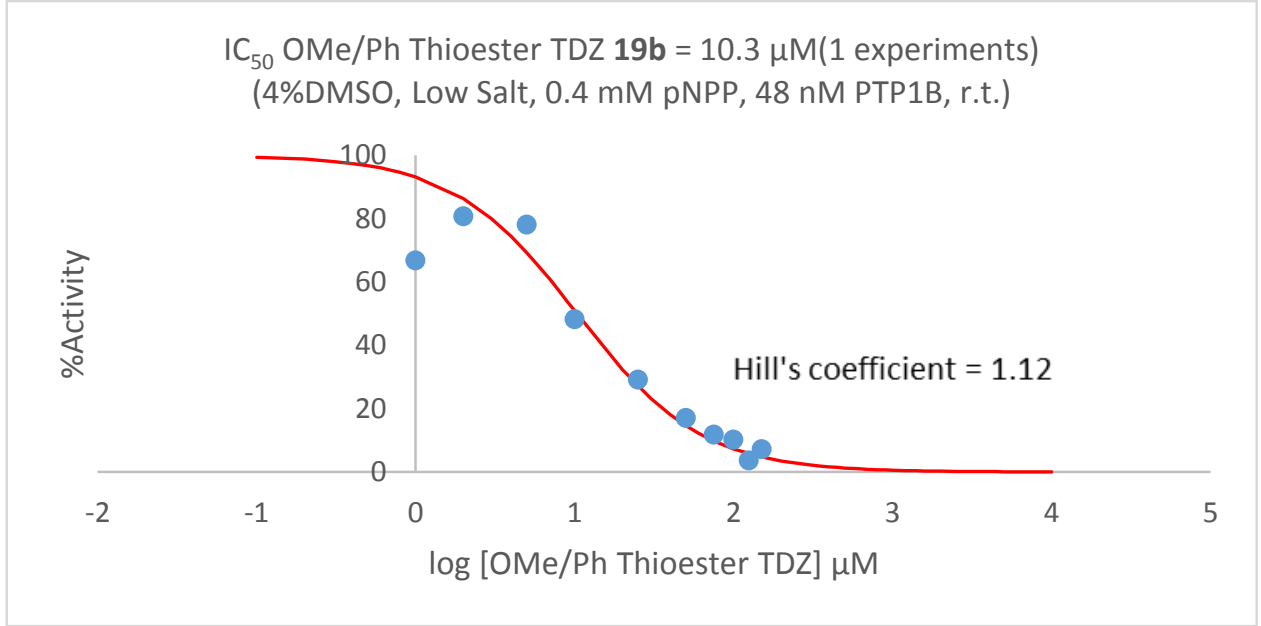

Figure $2.15 \mathrm{IC}_{50}$ of $19 \mathrm{~b}$ in a) $20 \% \mathrm{DMSO}-$ high salt, b) $20 \% \mathrm{DMSO}-$ low salt, and c) 4\%DMSO-low salt. 
a)

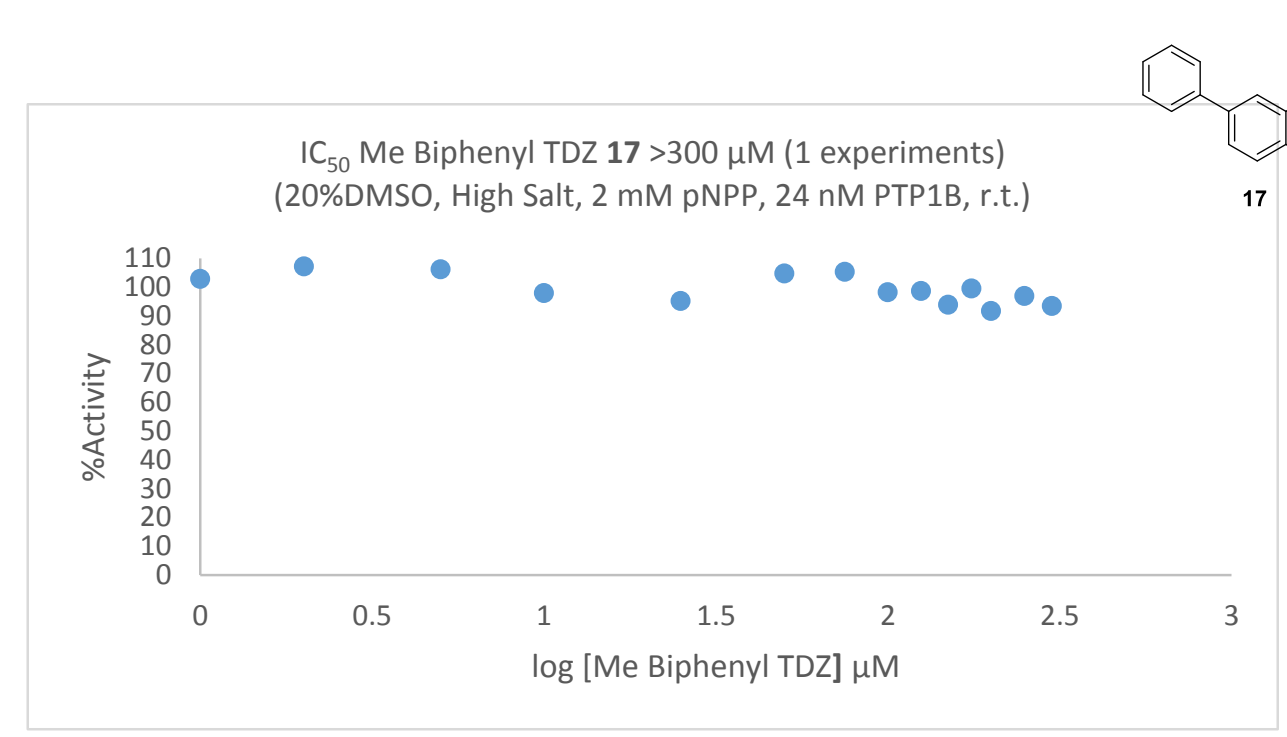

b)

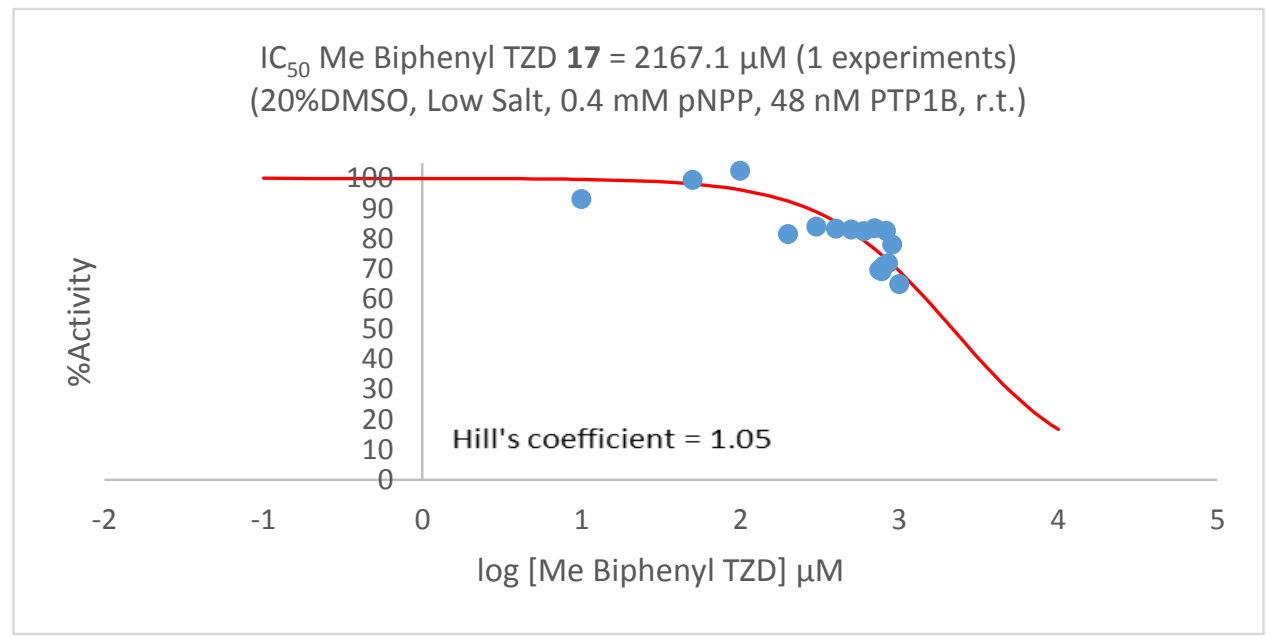

c)

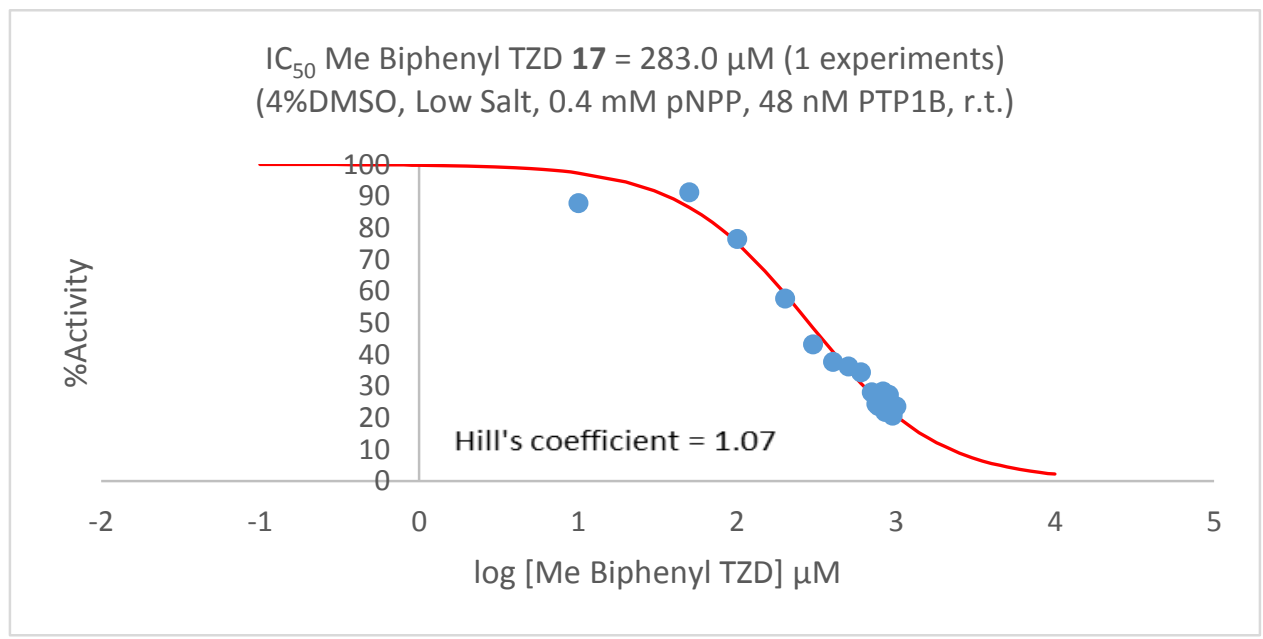

Figure $2.16 \mathrm{IC}_{50}$ of $\mathbf{1 7}$ in a) 20\%DMSO-high salt, b) 20\%DMSO-low salt, and c) 4\%DMSO-low salt. 
a)

$\mathrm{IC}_{50} \mathrm{Me} / \mathrm{Ph}$ Thioester TDZ 19a $>300 \mu \mathrm{M}$ (1 experiments)

(20\%DMSO, High Salt, 2 mM pNPP, 24 nM PTP1B, r.t.)

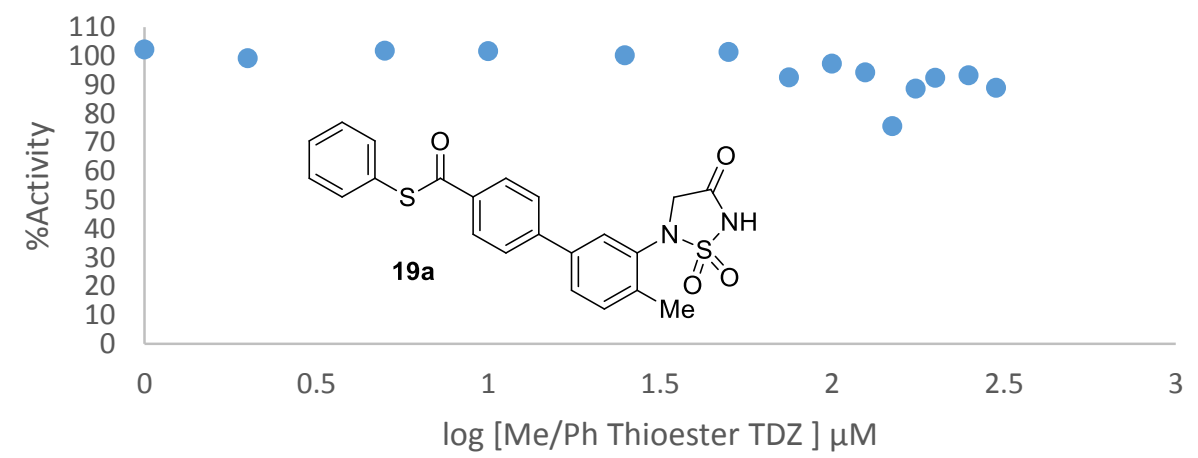

b)

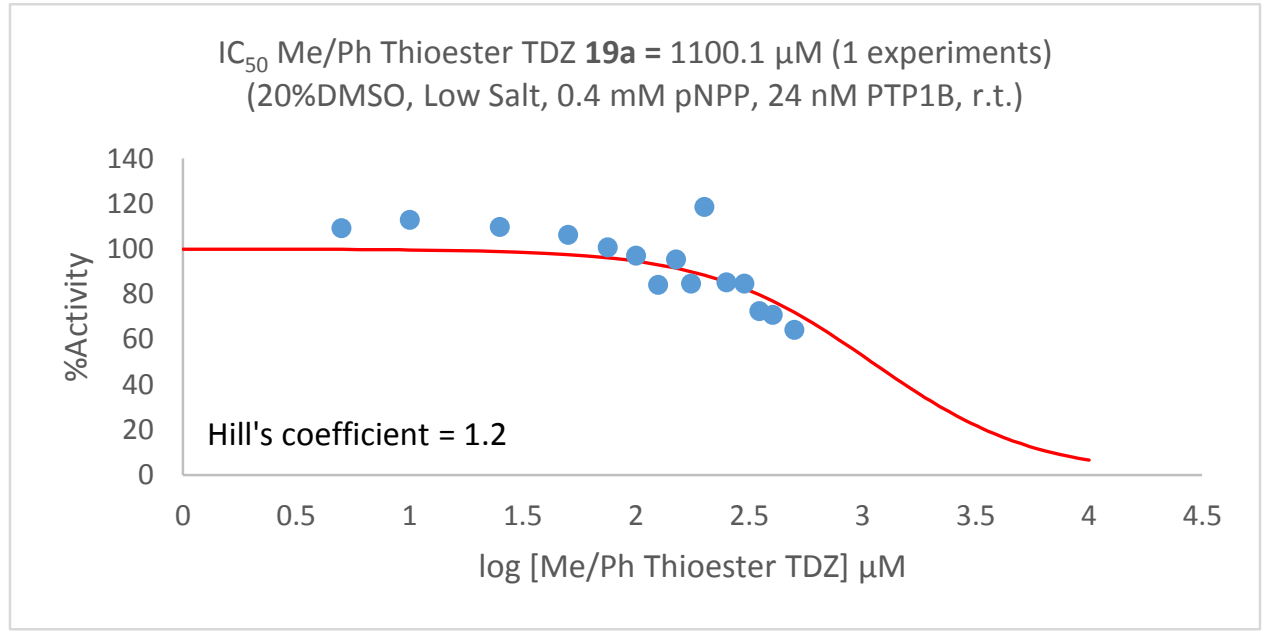

c)

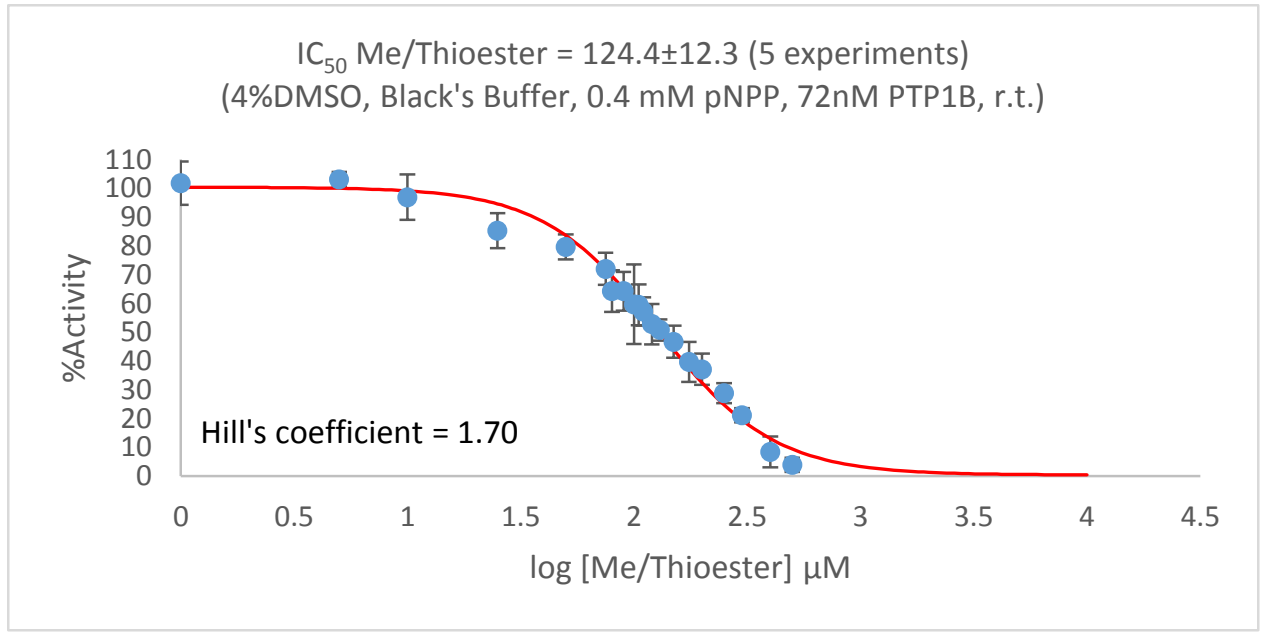

Figure 2.17 IC 50 of 19a in a) 20\%DMSO-high salt, b) 20\%DMSO-low salt, and c) 4\%DMSO-low salt. 
a)

$\mathrm{IC}_{50} \mathrm{Me} / \mathrm{Bn}$ Thioester TDZ $20>300 \mu \mathrm{M}$ (1 experiments)

(20\%DMSO, High Salt, 2 mM pNPP, 24 nM PTP1B, r.t.)

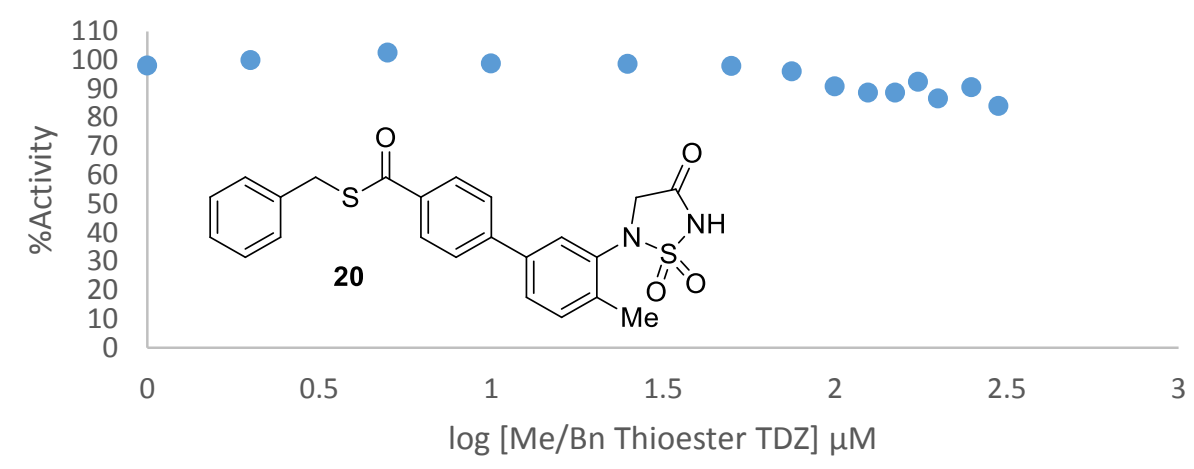

b)

$\mathrm{IC}_{50} \mathrm{Me} / \mathrm{Bn}$ Thioester TZD $20=631.0 \mu \mathrm{M}$ (1 experiments)

(20\%DMSO, Low Salt, 0.4 mM pNPP, 24 nM PTP1B, r.t.)

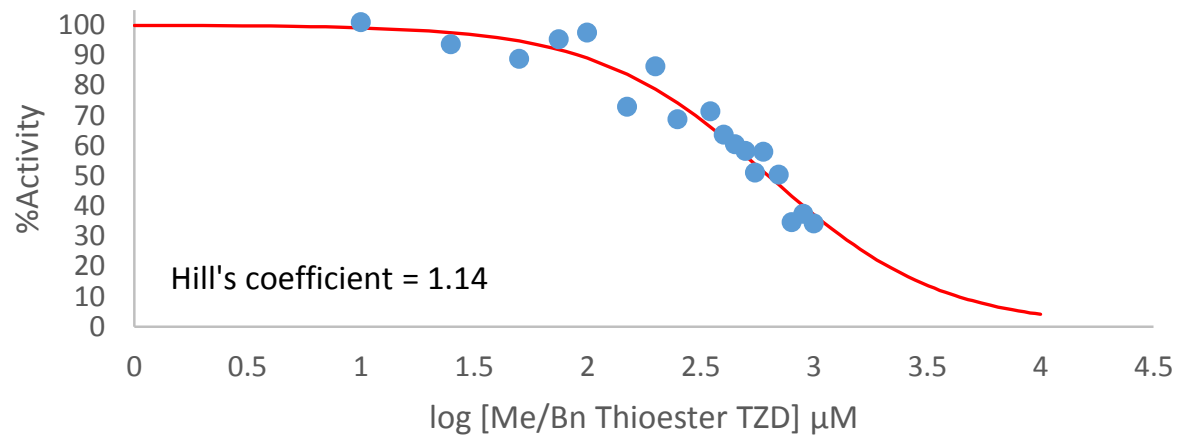

c)

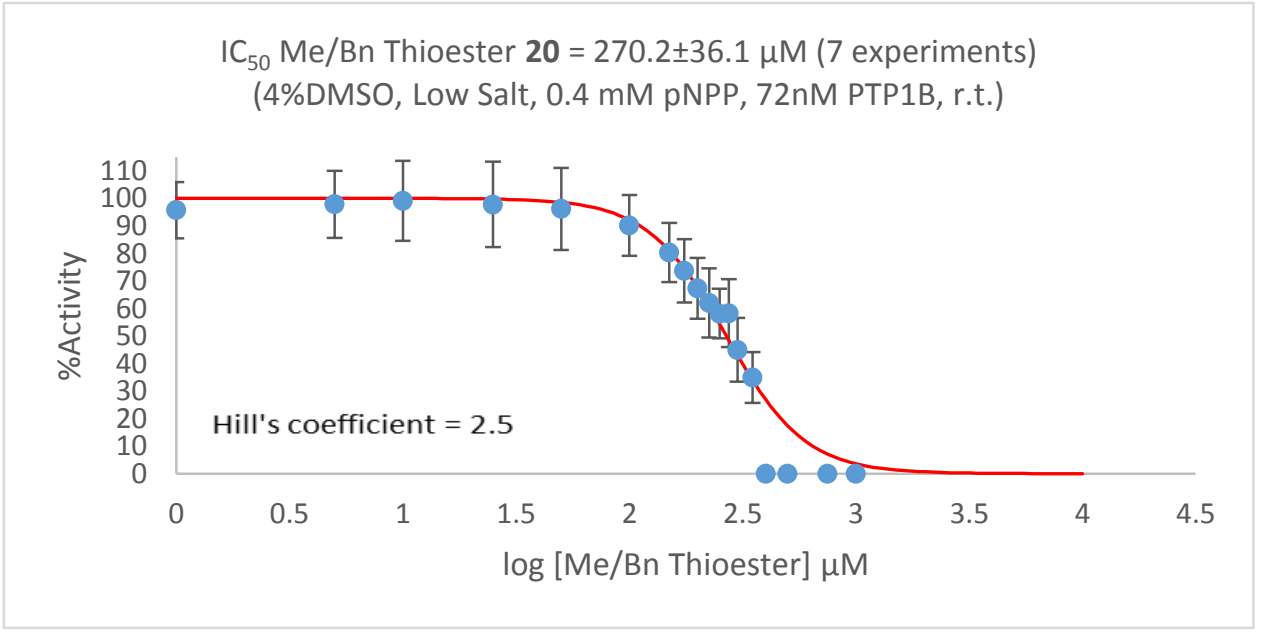

Figure 2.18 IC 50 of 20 in a) 20\%DMSO-high salt, b) 20\%DMSO-low salt, and c) 4\%DMSO-low salt. 
a)

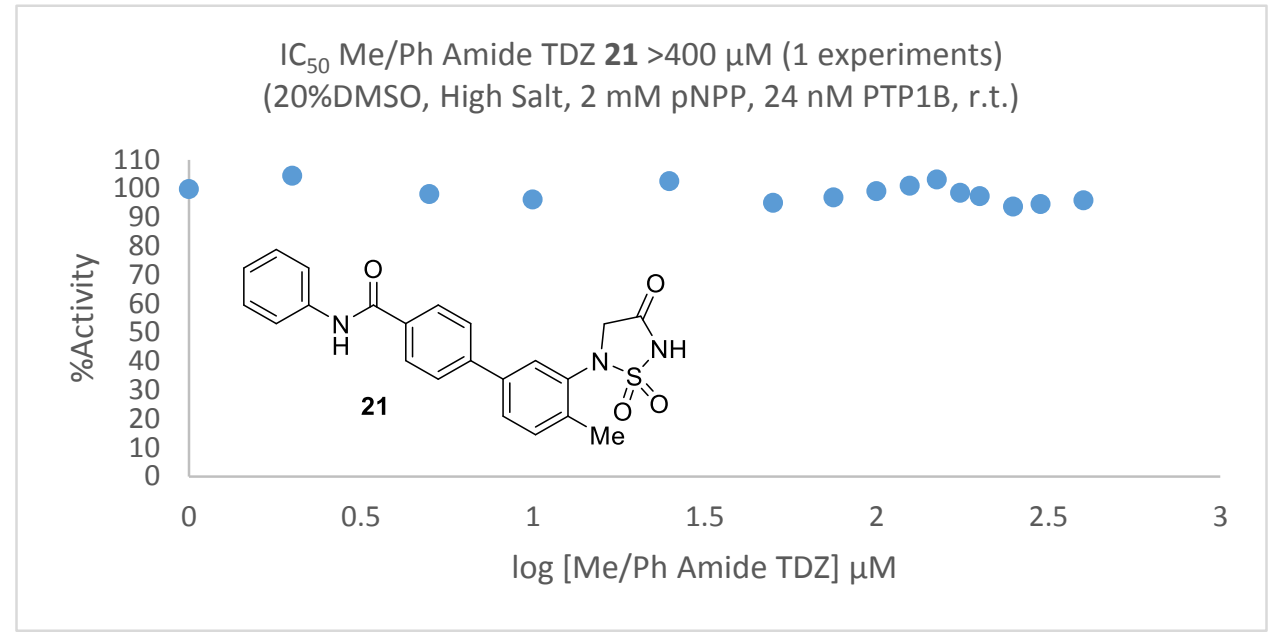

b)

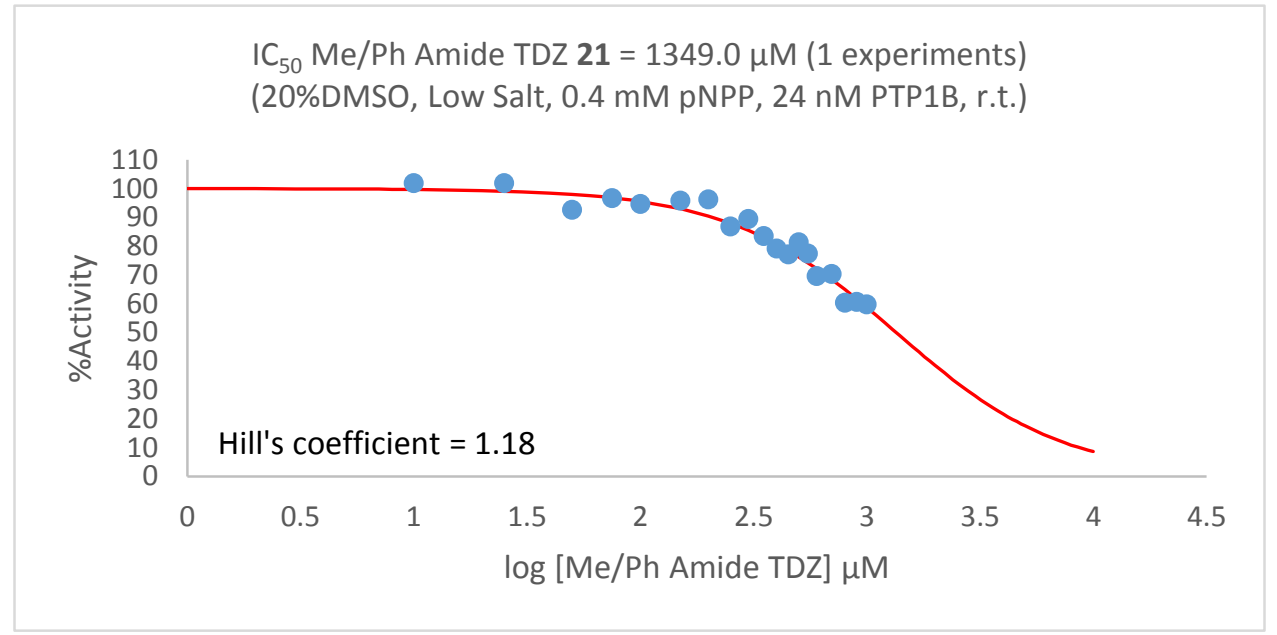

c)

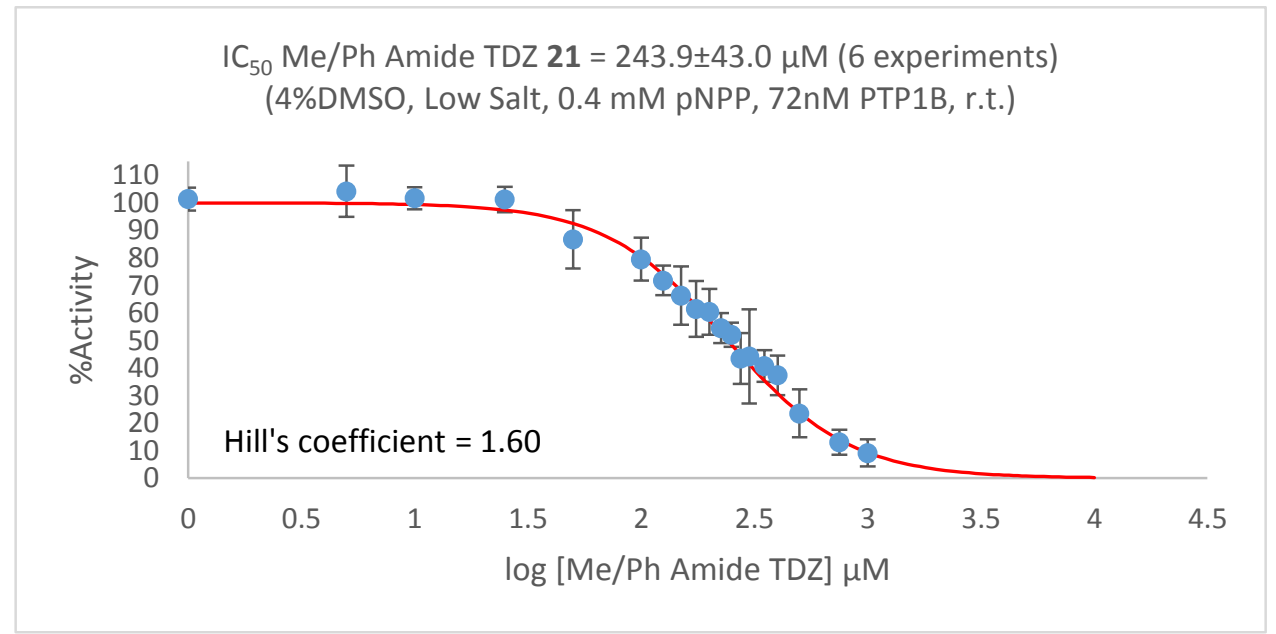

Figure $2.19 \mathrm{IC}$ (C) of 21 in a) 20\%DMSO-high salt, b) 20\%DMSO-low salt, and c) 4\%DMSO-low salt. 

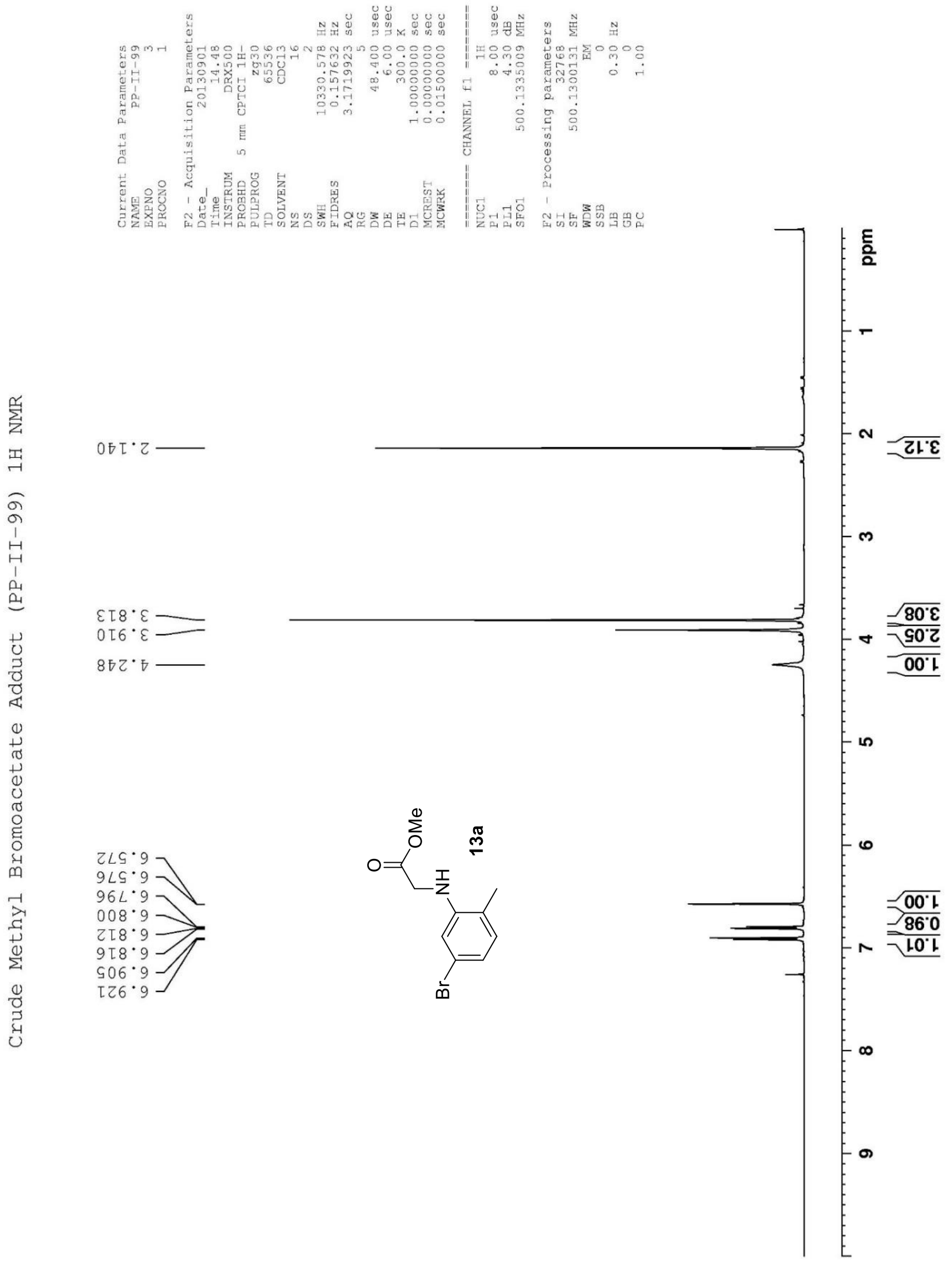


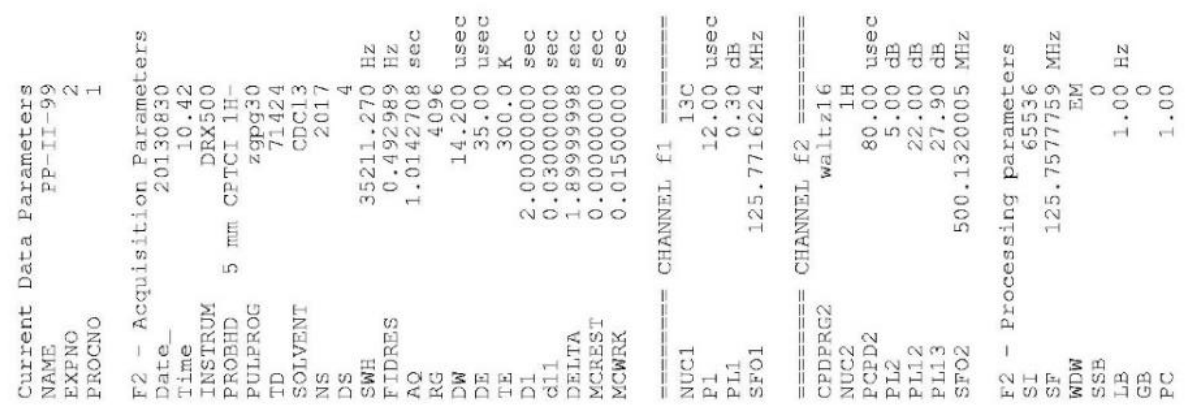

$\angle 0^{\circ} L I$
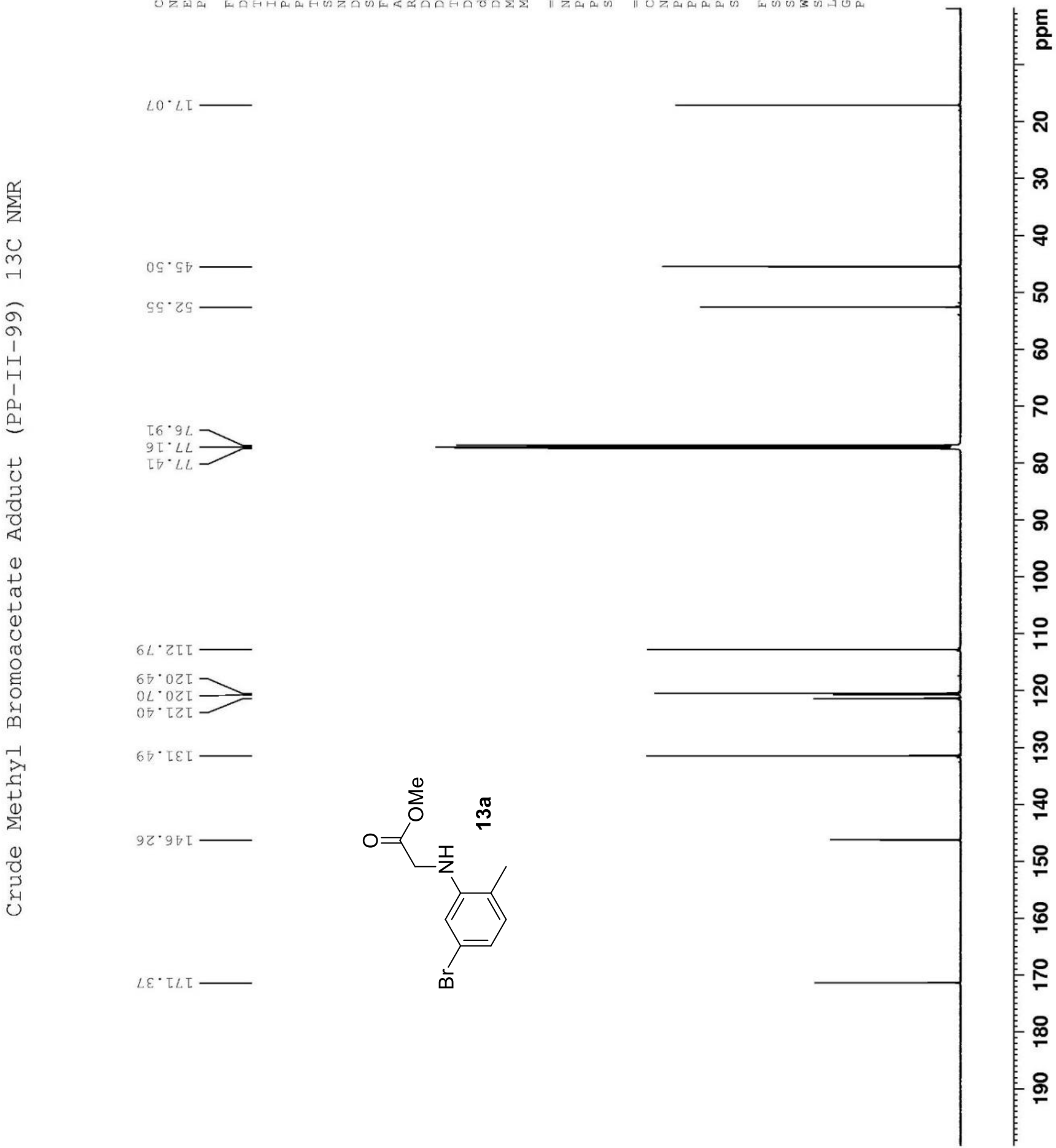

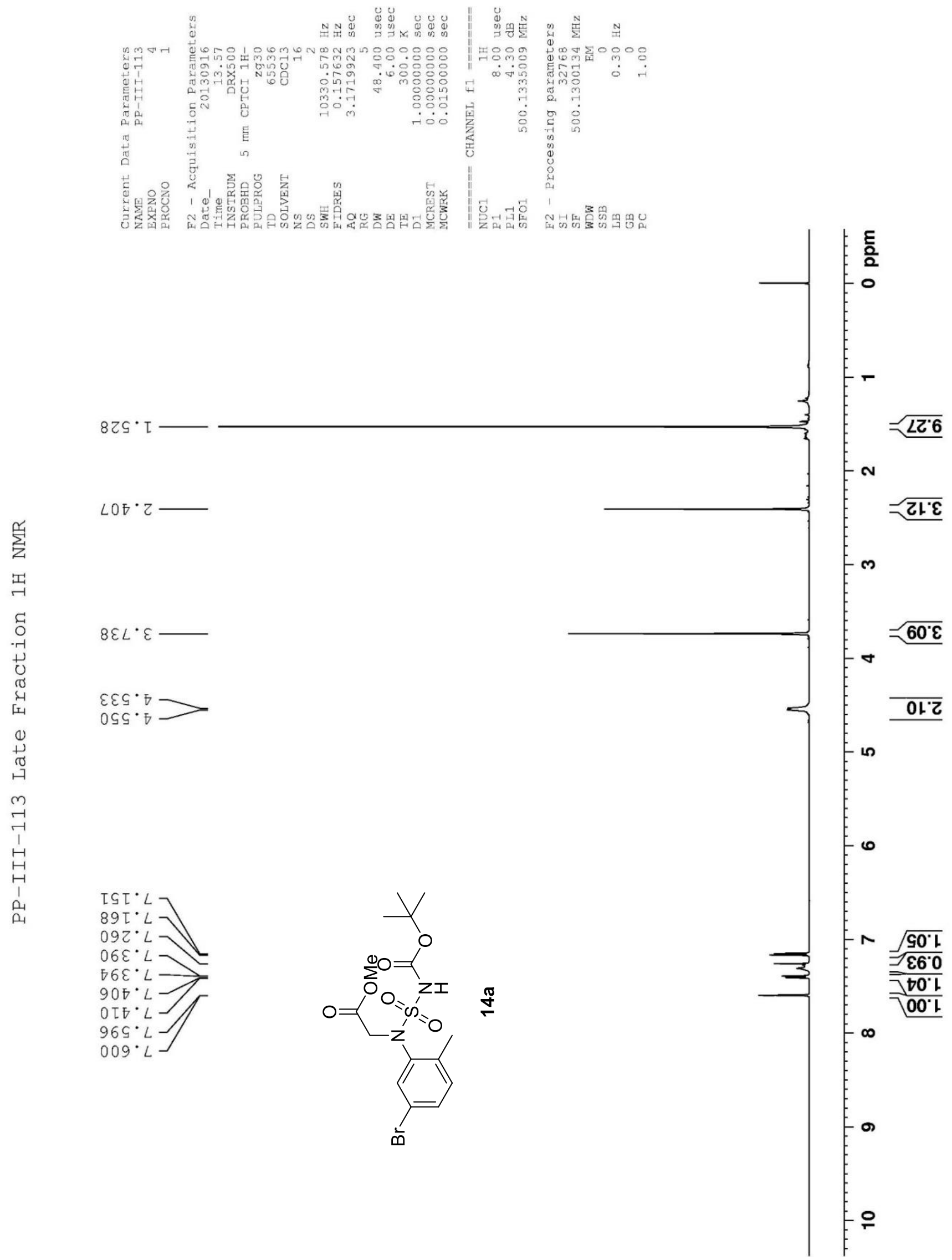

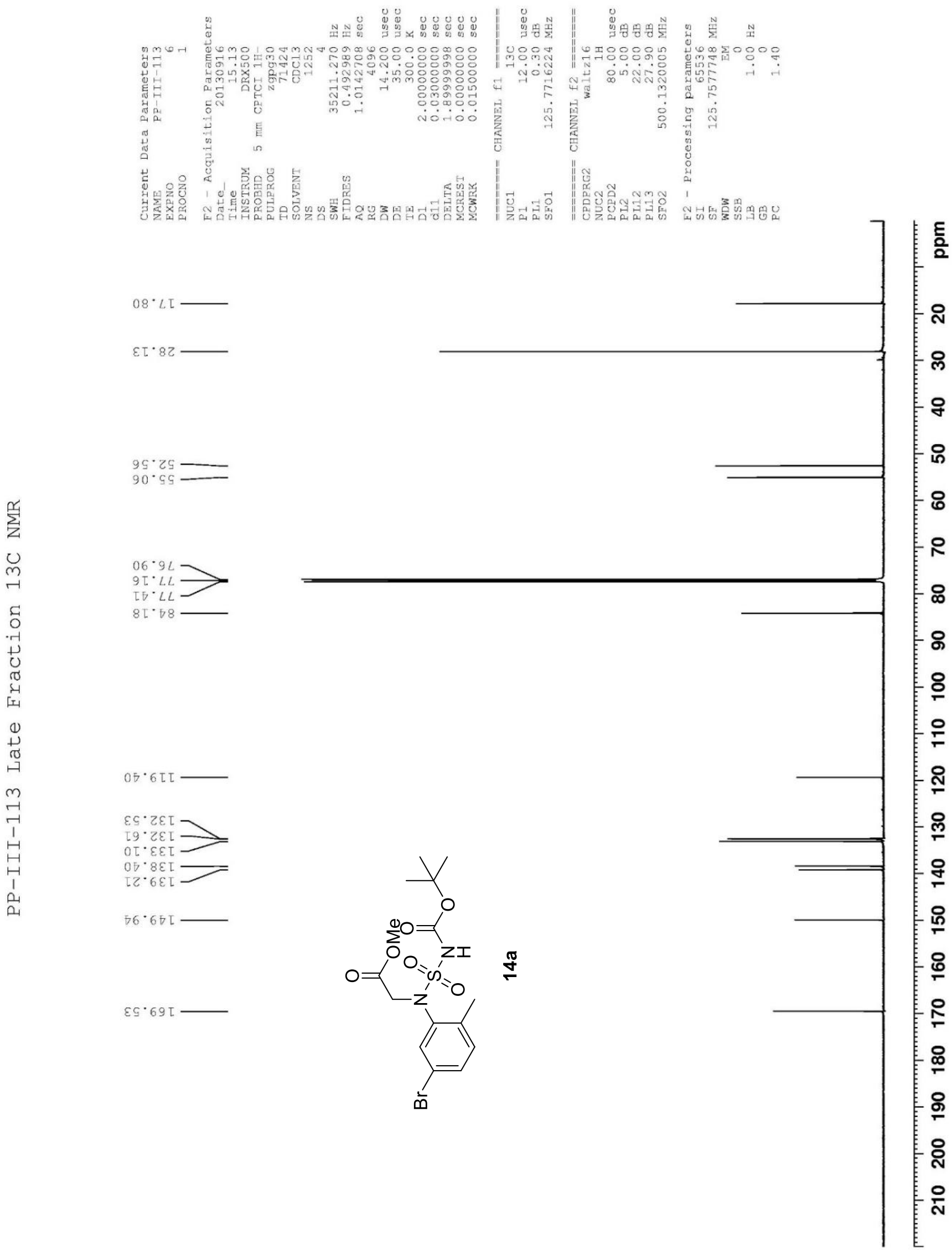


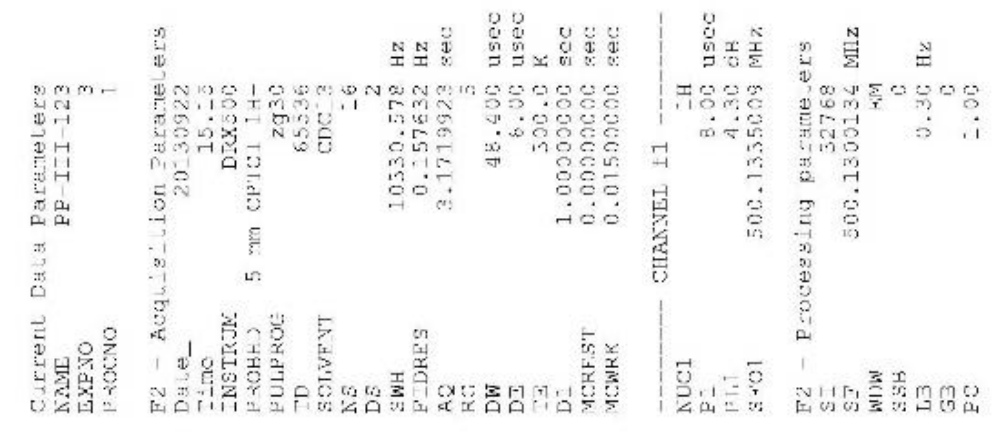

$9 \varepsilon \varepsilon \cdot z$

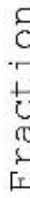

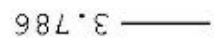

$90 z \cdot 9$

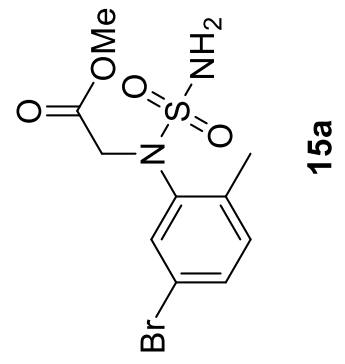

흥

$m$

$91^{\circ} \varepsilon$

点先

되 出
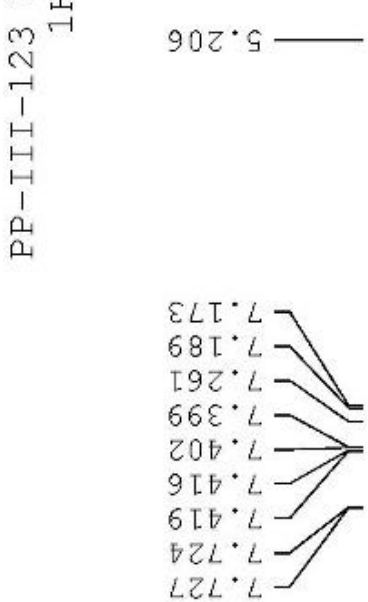

๓

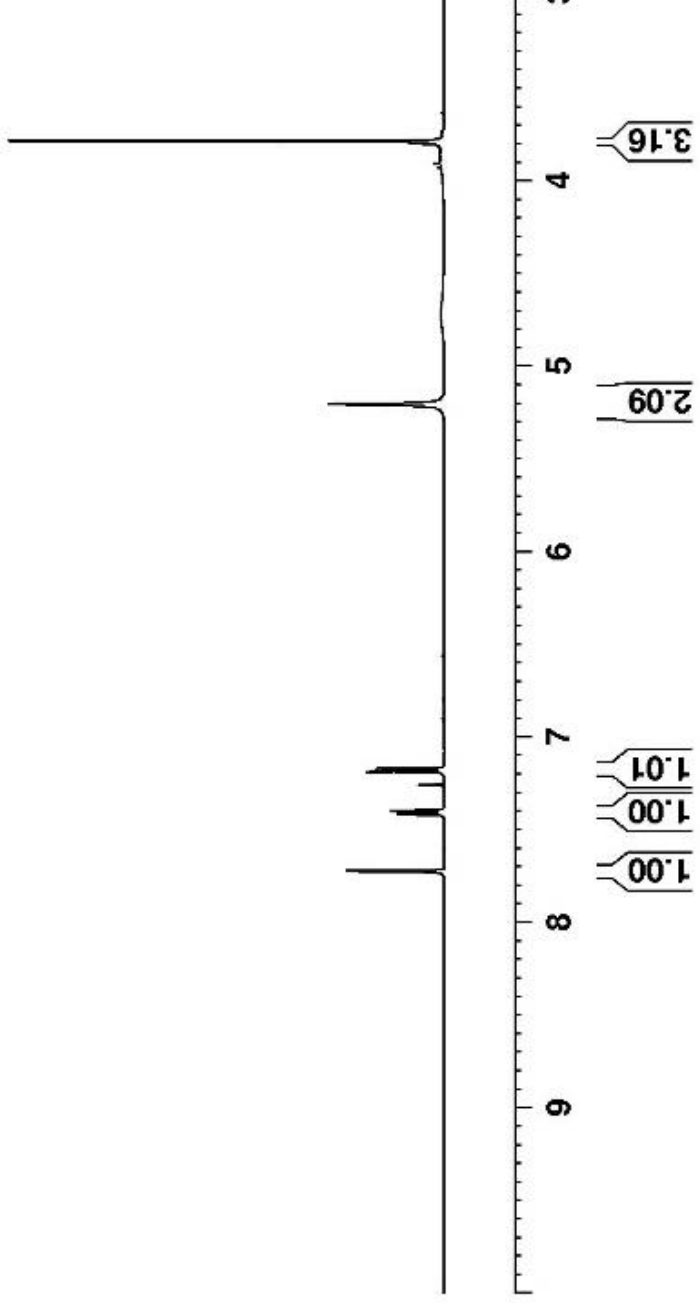



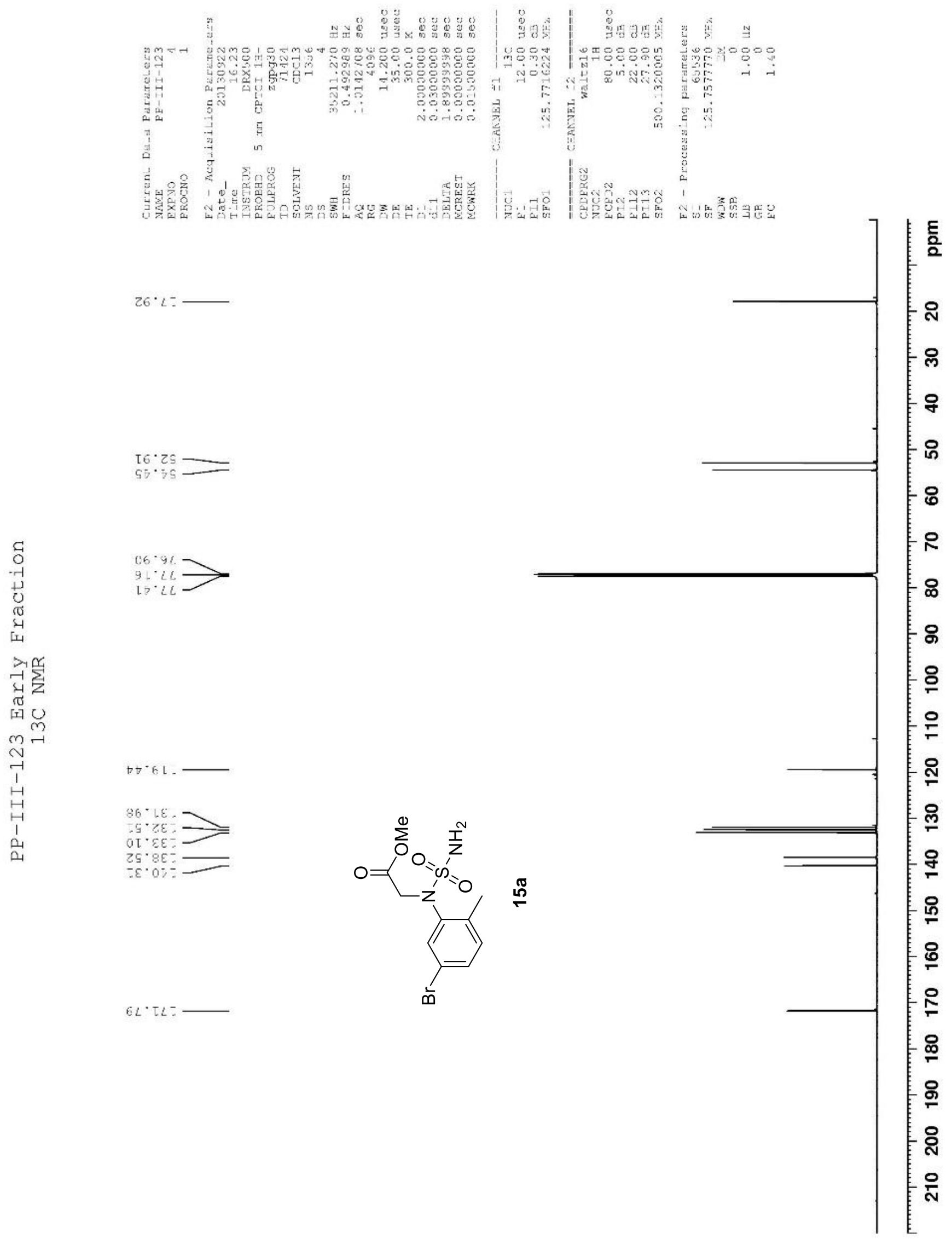

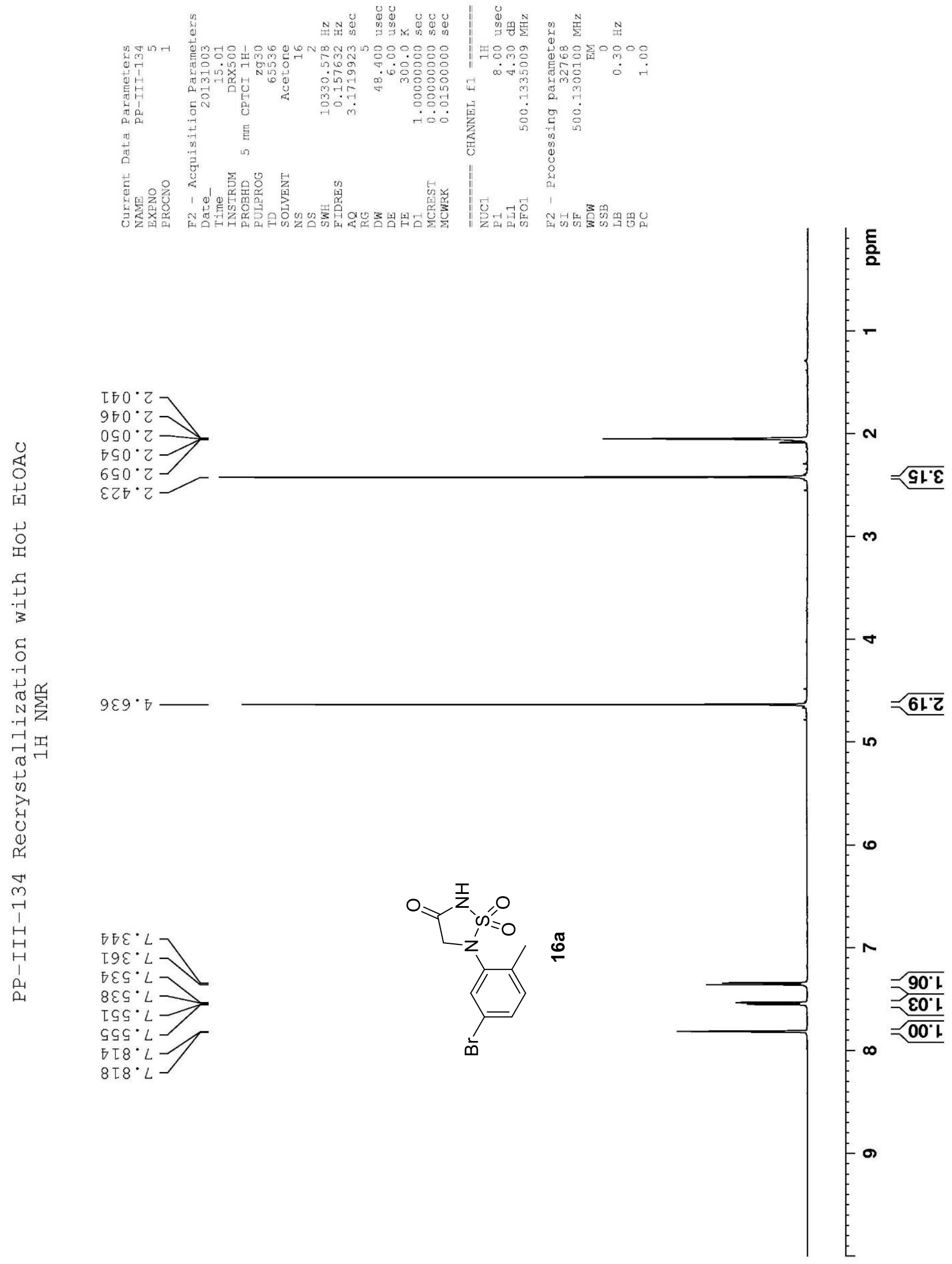


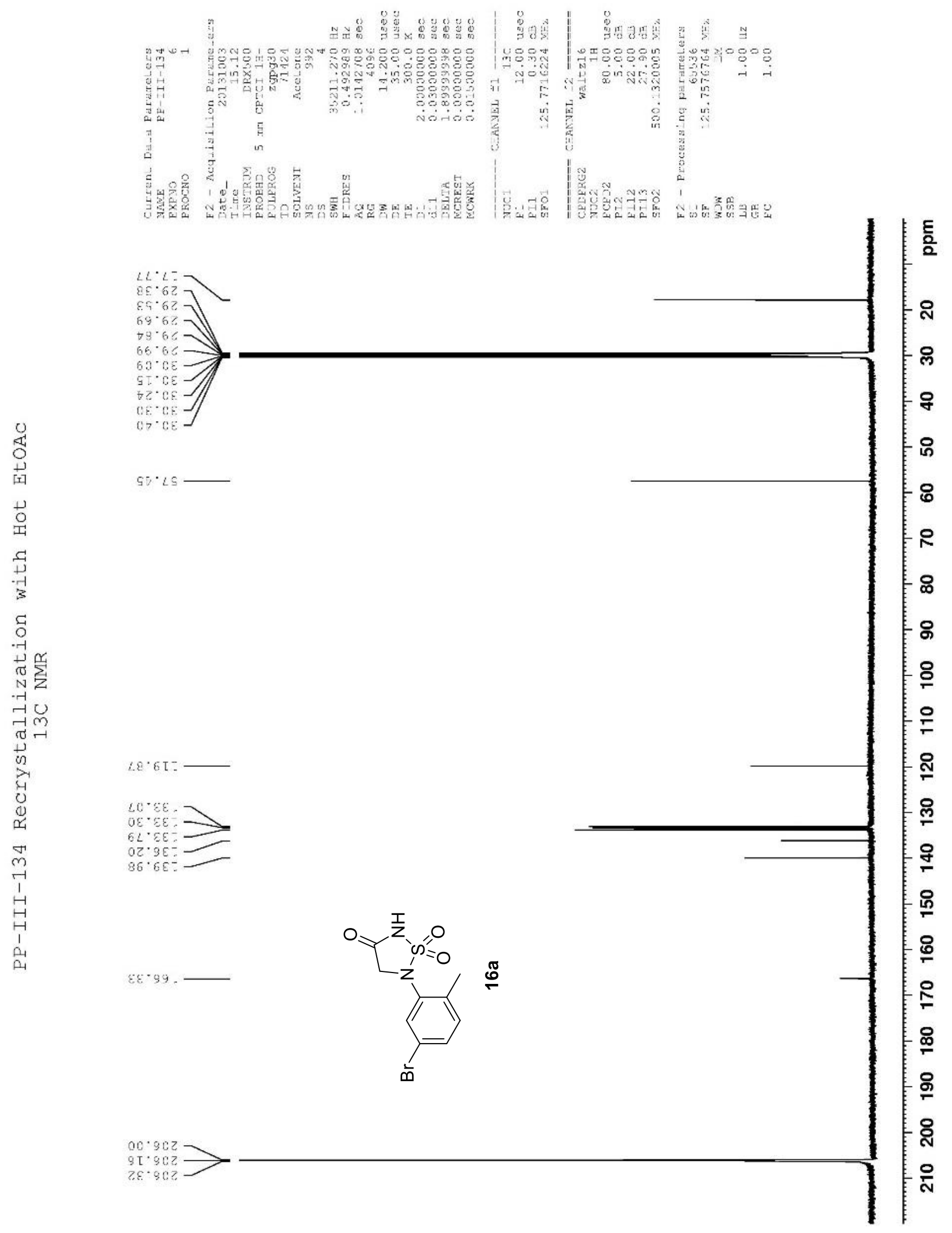



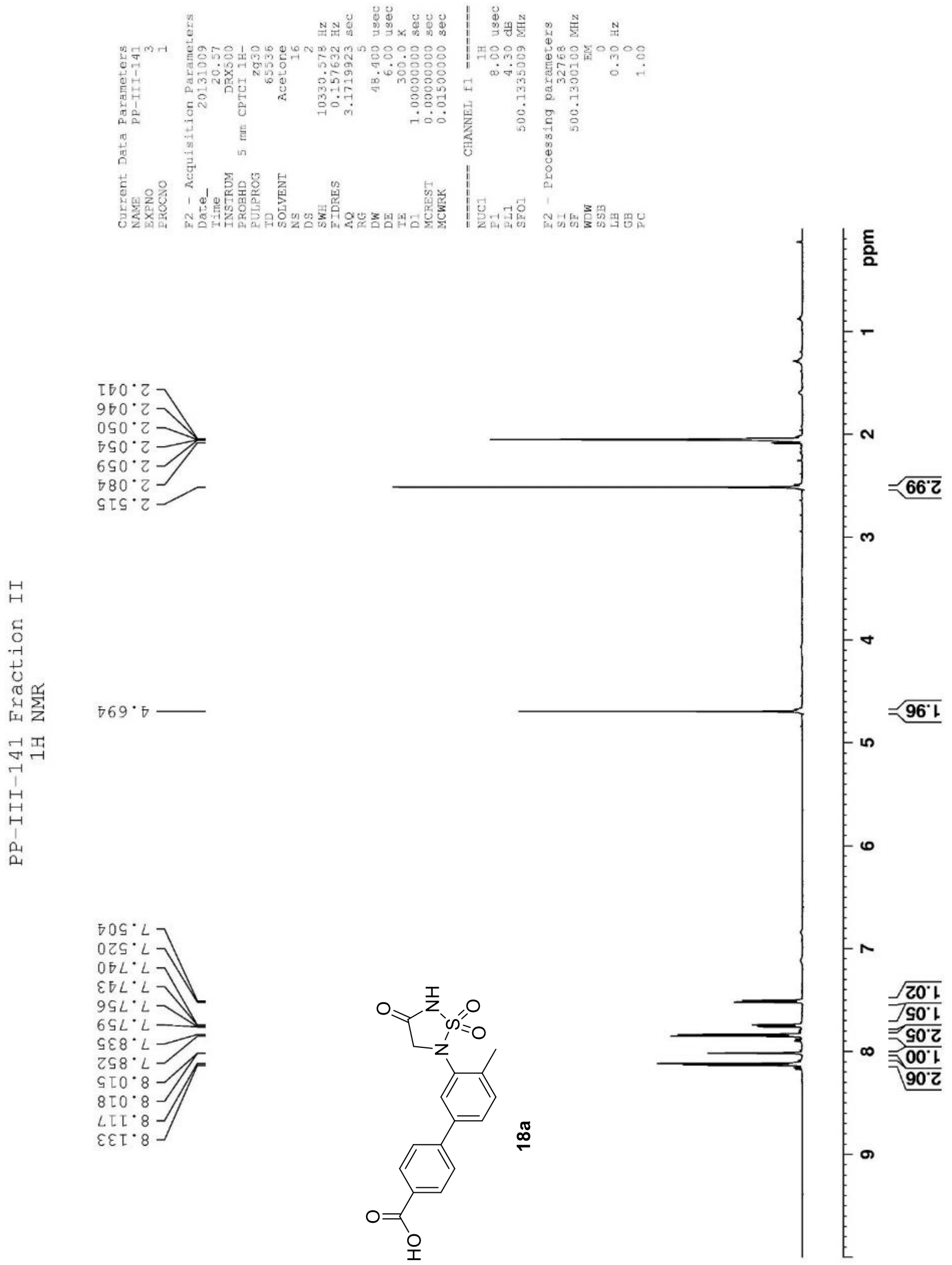

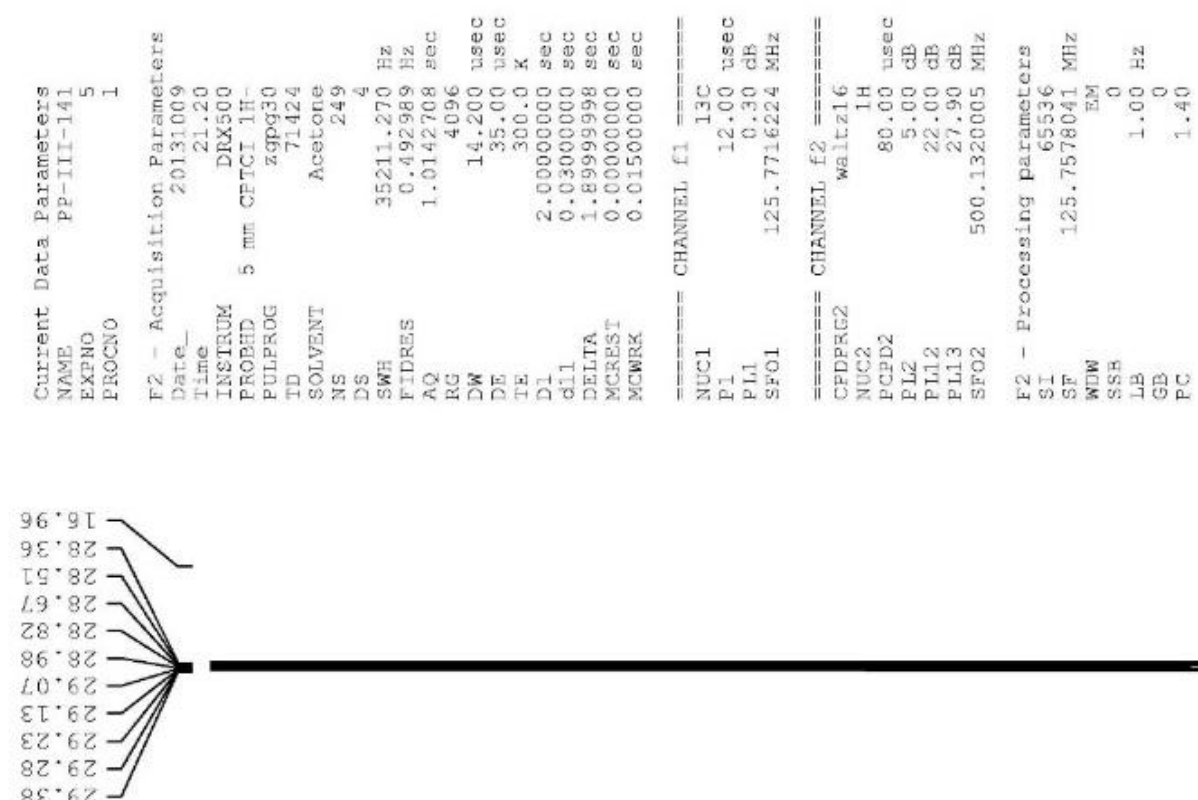

....
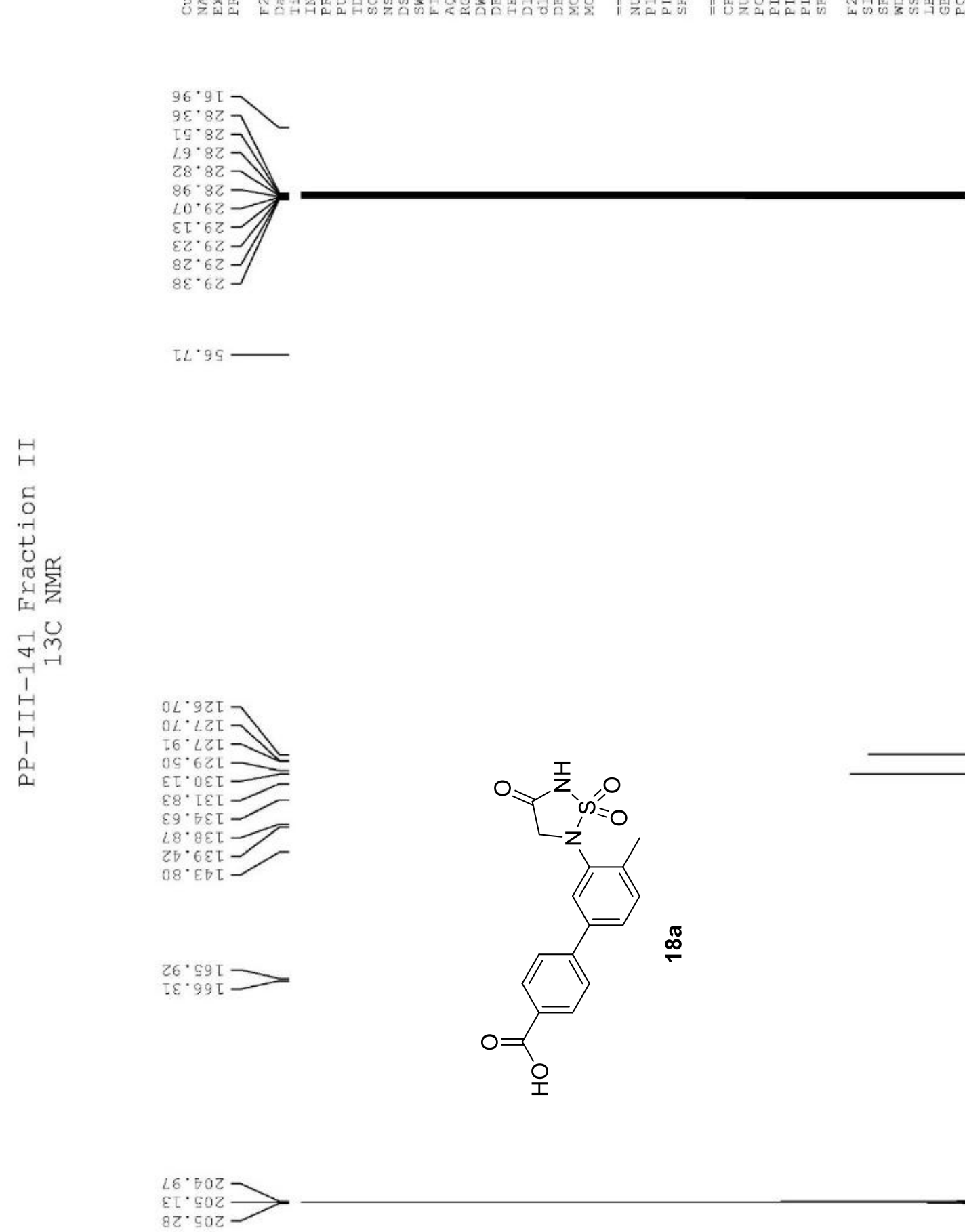

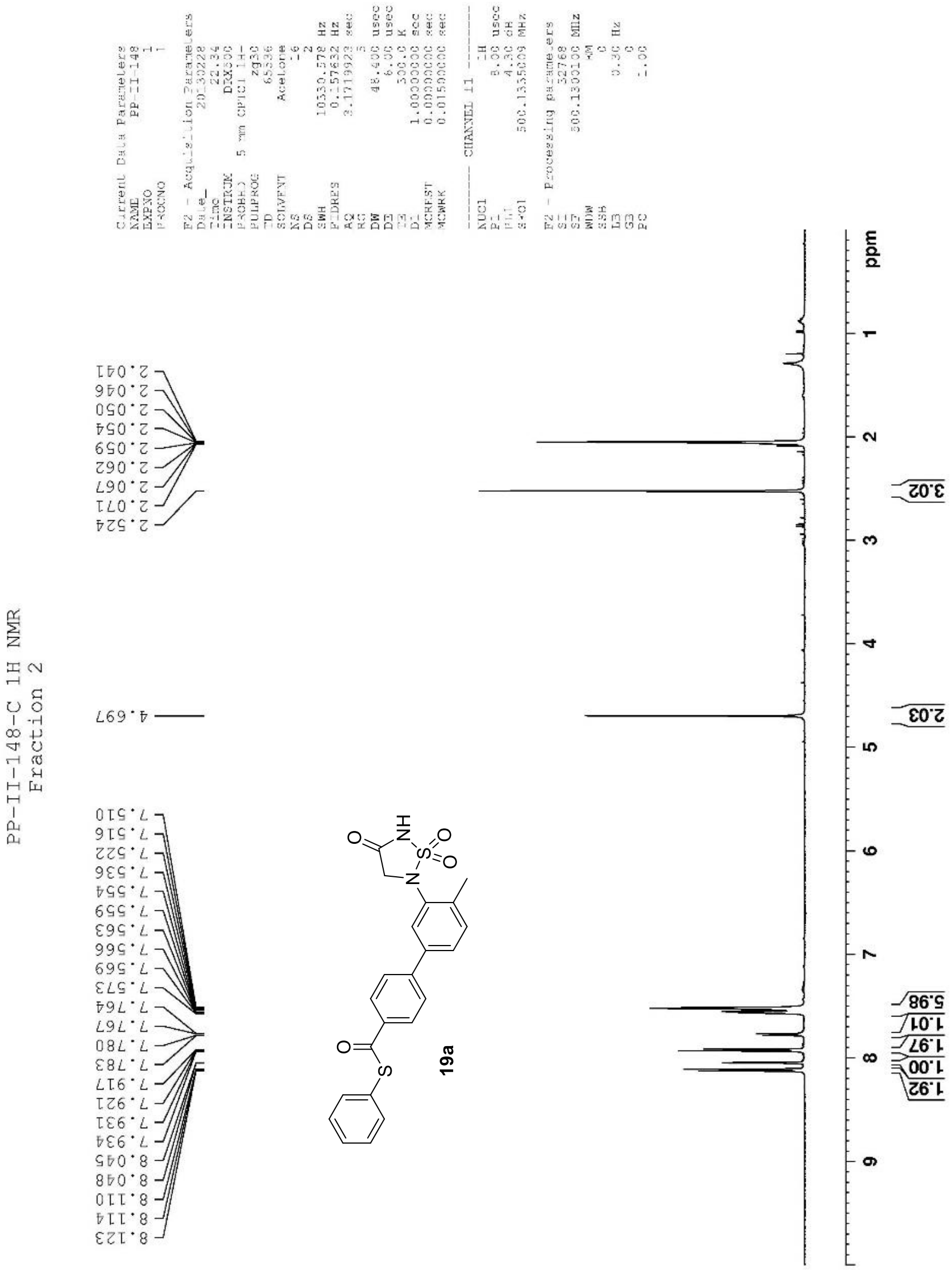


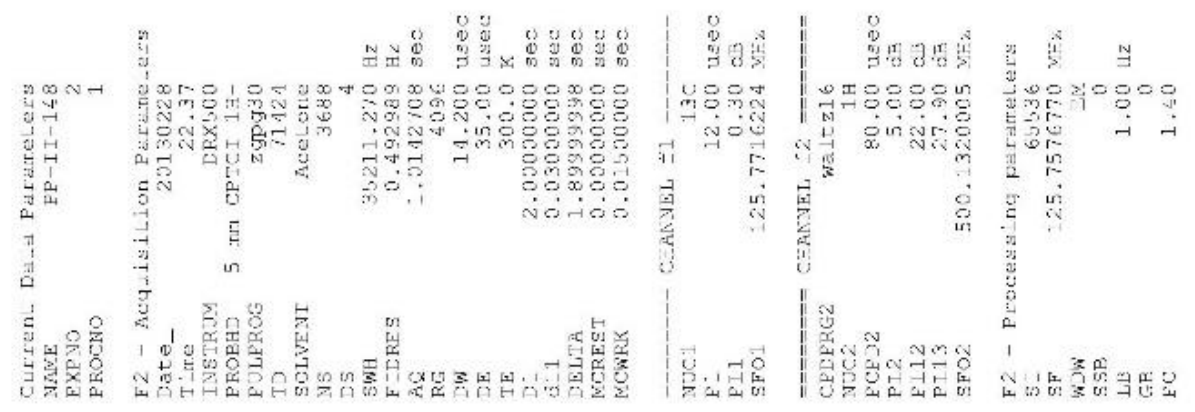

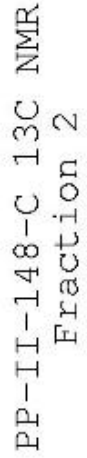
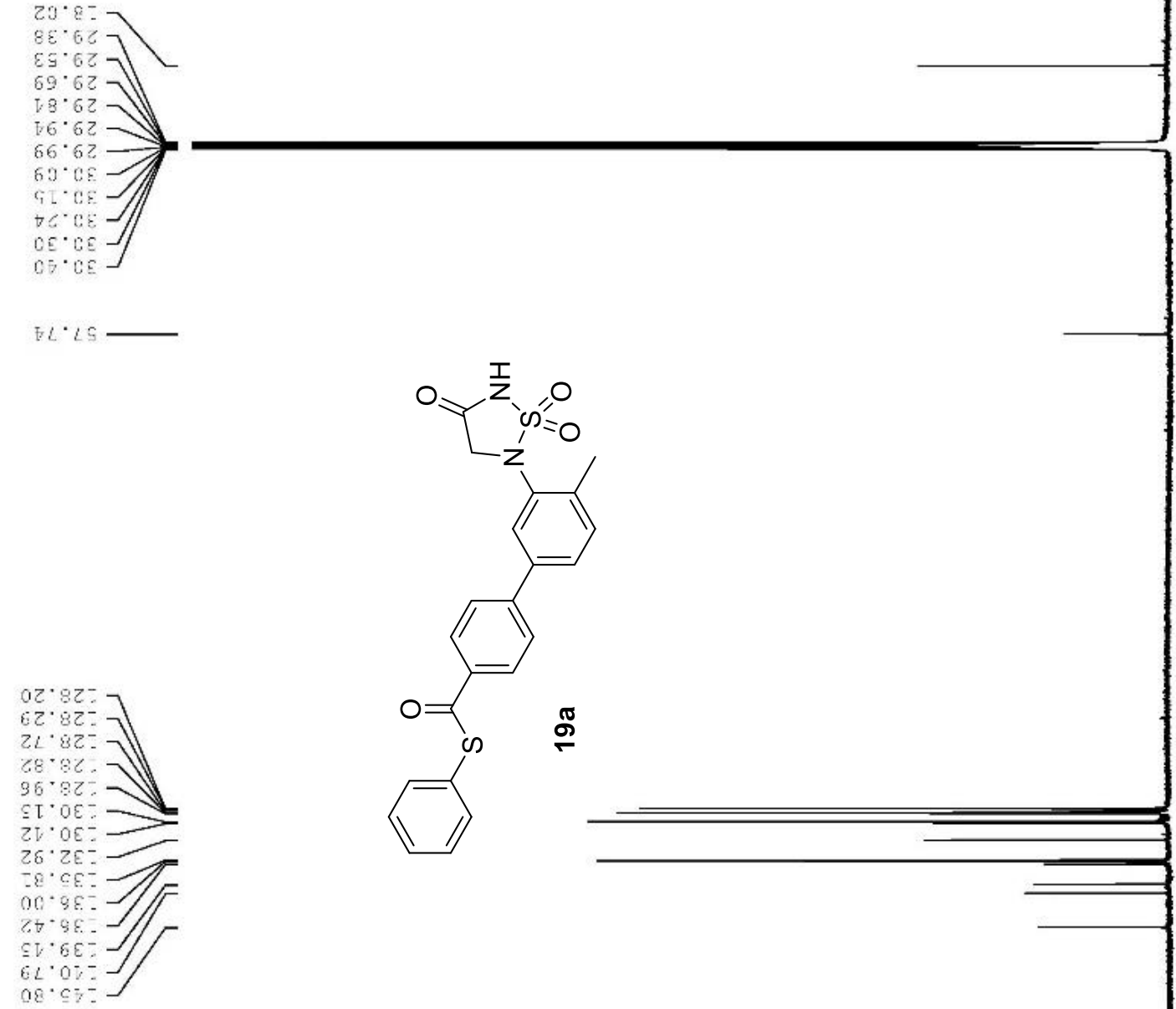

$\mathrm{F} L \angle S$

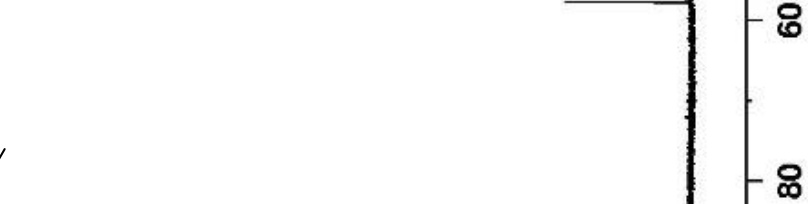

$4 \mathrm{~T} \cdot 29=$
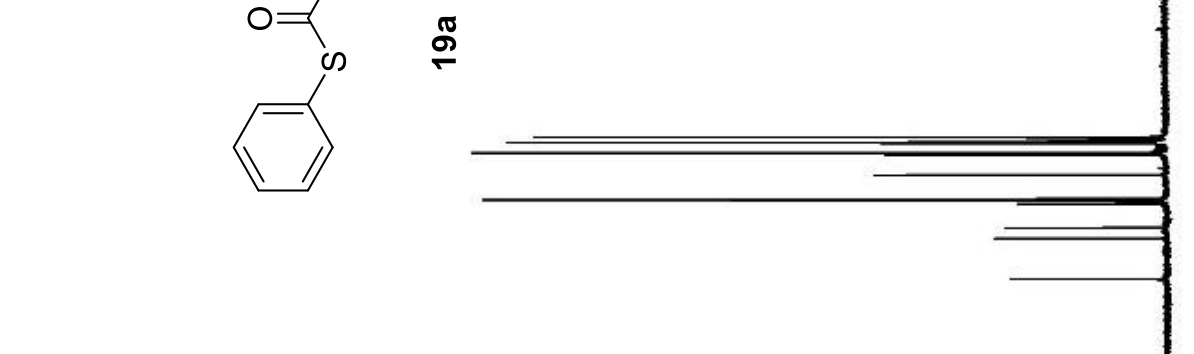

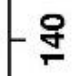

సิ

우

웅

$\stackrel{\square}{\square}$
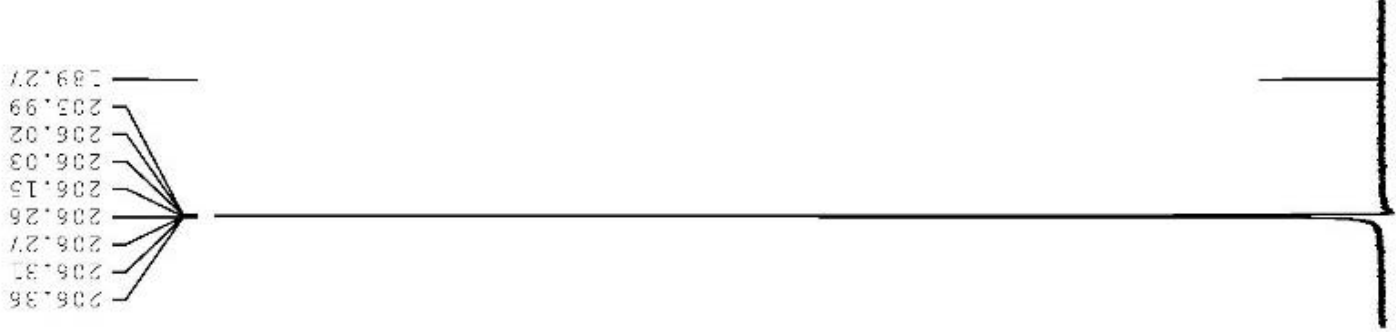

흥

ㅇํ

우

8

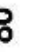

(1)

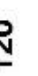

- 오 

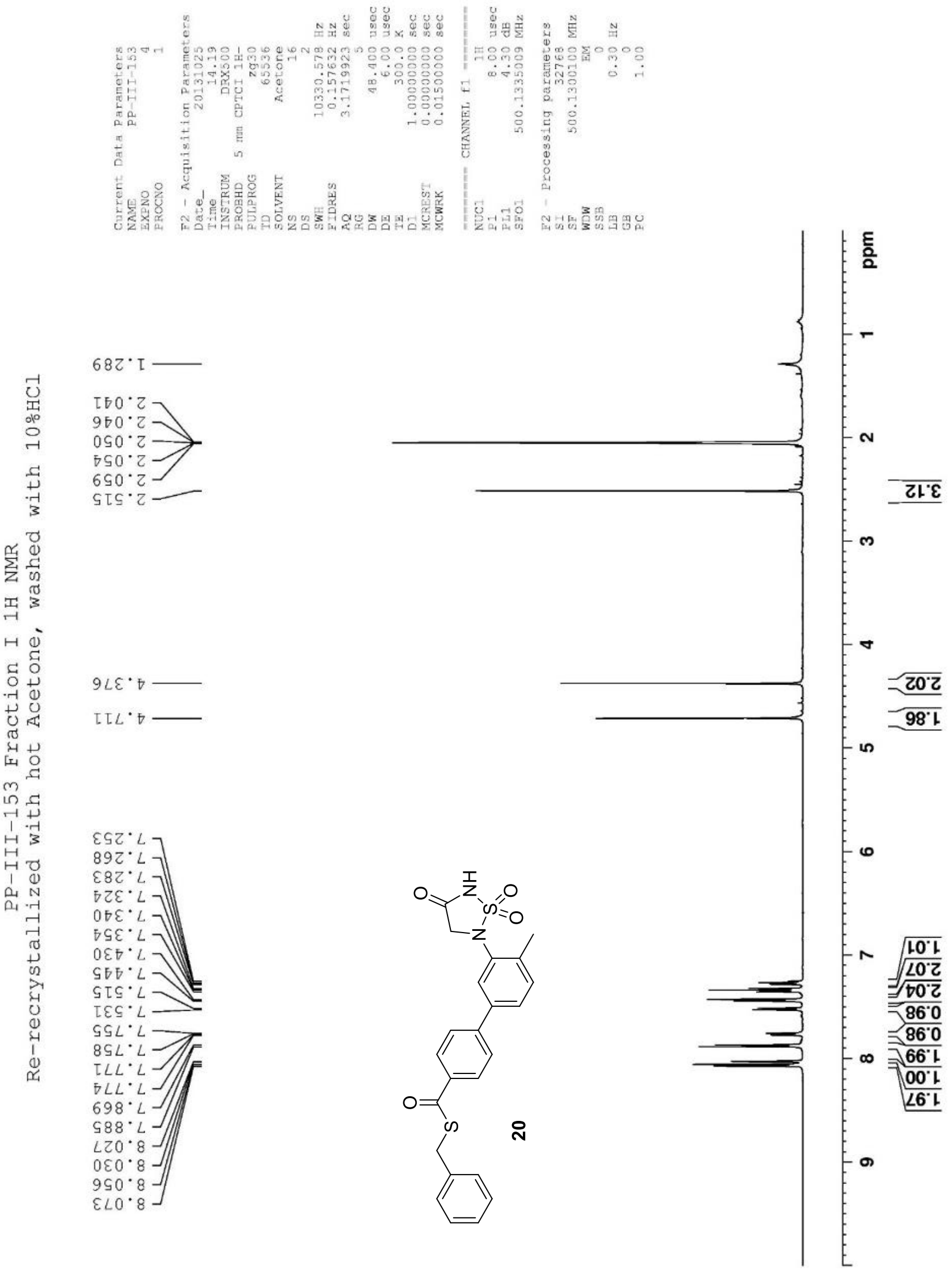

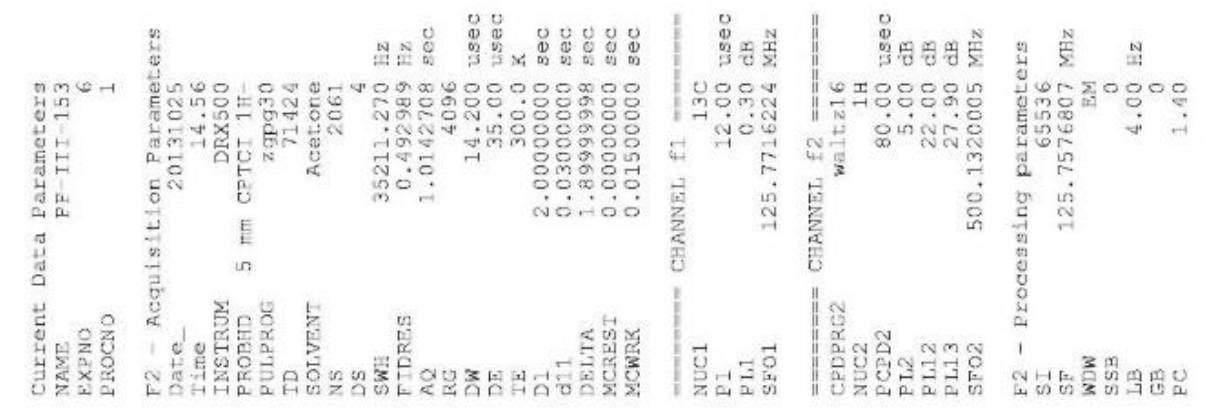

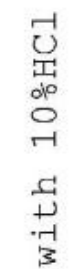

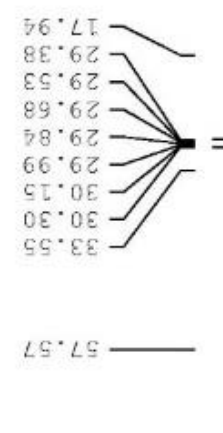

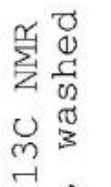

$H \stackrel{\text { ¿ }}{0}$

द્

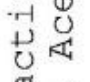

(o)

मा

$m$.

담담

1
-1

H。

펑

A. N

a. .

त)

政
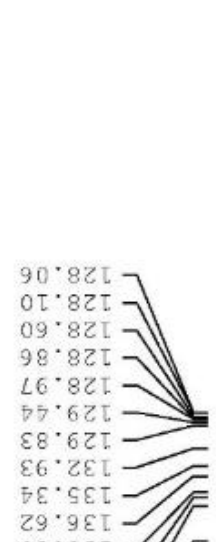

(

$\left.{ }_{7 \mathrm{C}} \cdot 6 \varepsilon \mathrm{E}\right]$

ZL.0Di

$S 7$.

$80.99 \mathrm{I}$

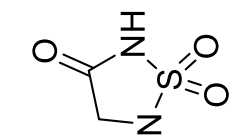<smiles>[C]1C=CC=C1</smiles>

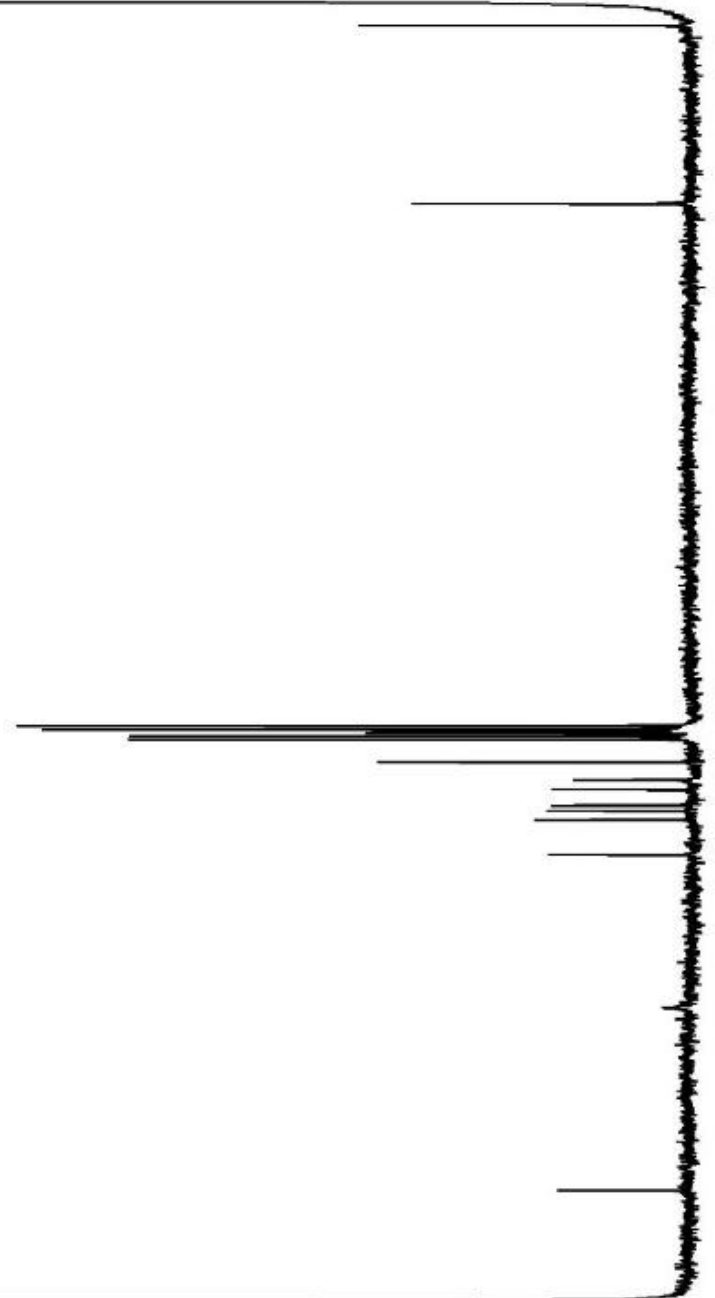

$\nabla L \cdot 06 \tau$

กิ

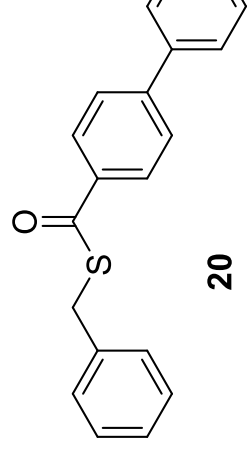

웅

- ลิ

$-\infty$

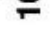

F

:

$\nsubseteq$

ลั

T. $90 z$

สิ

온 


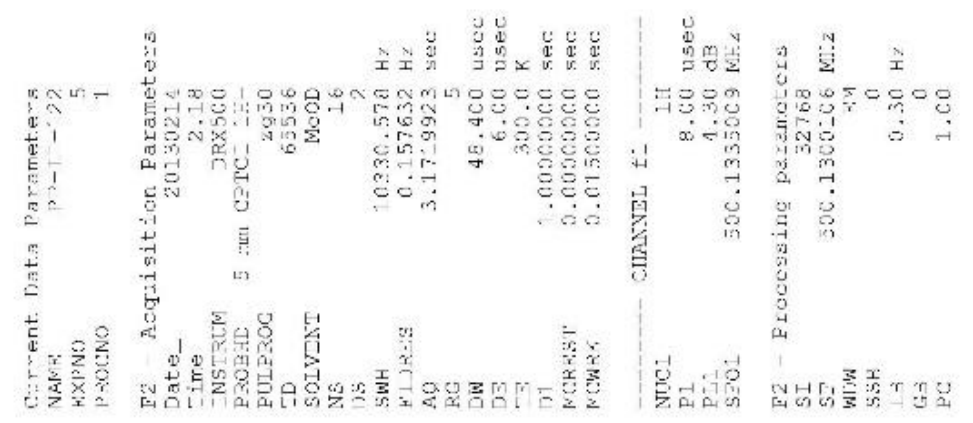

$506 \cdot 1=$

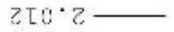

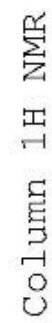
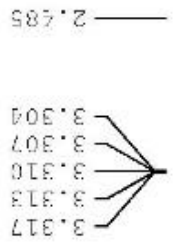

U
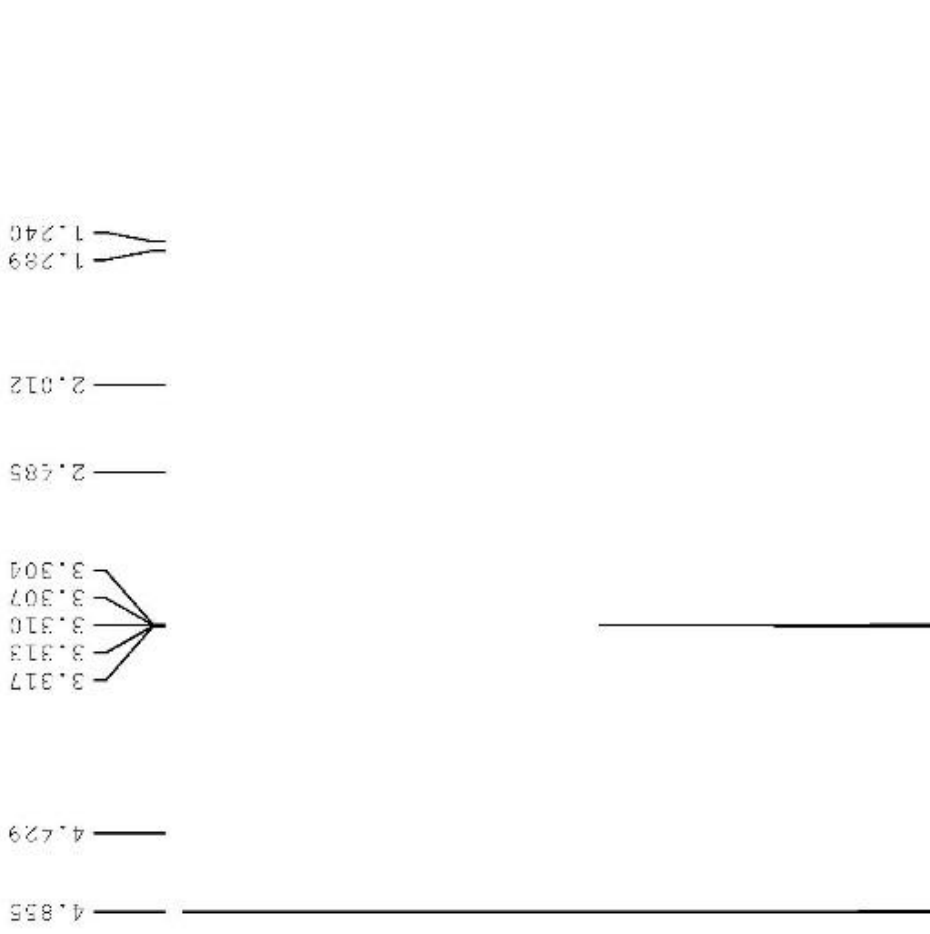

가엄

10

苟获

1

퐁

U

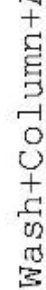
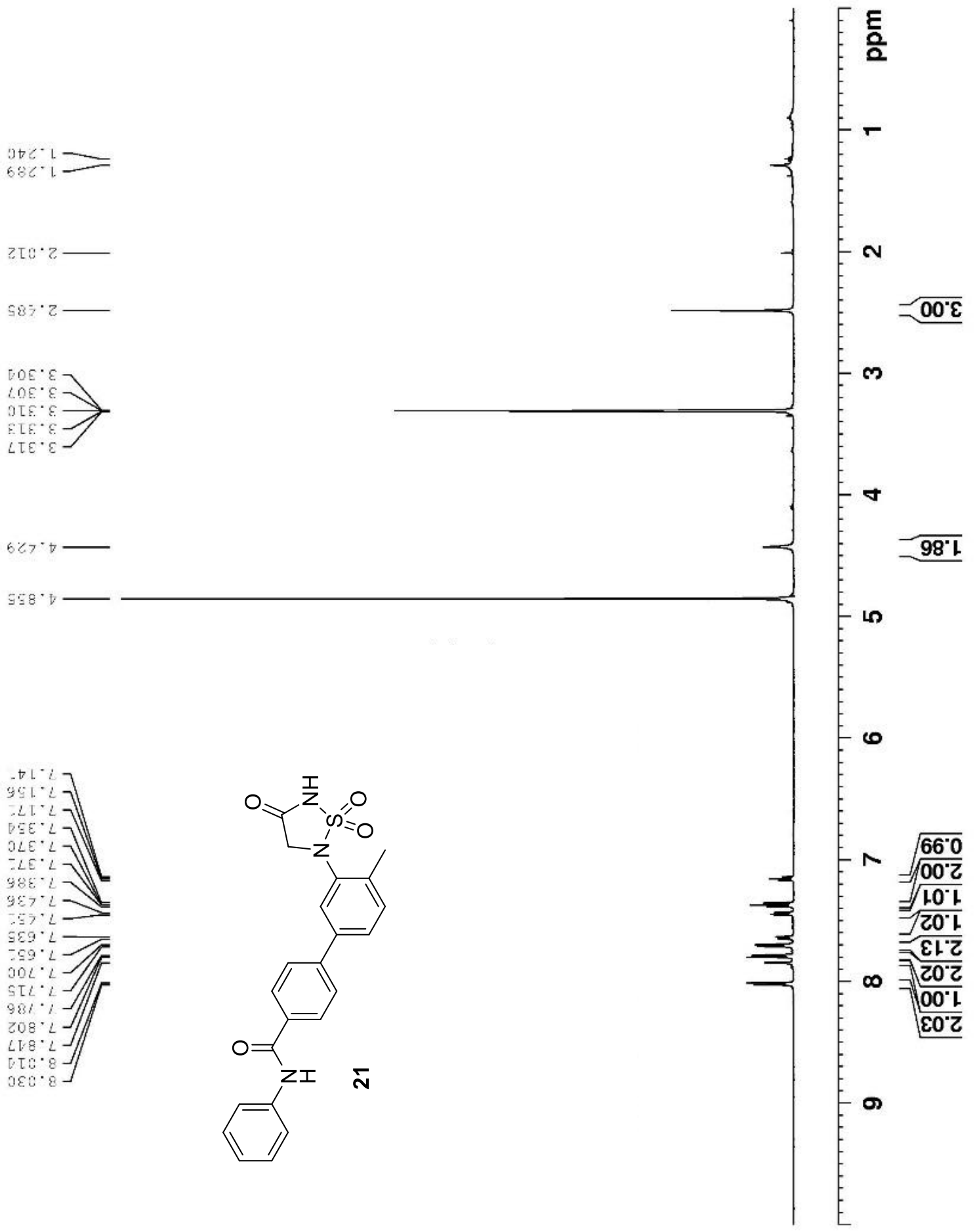

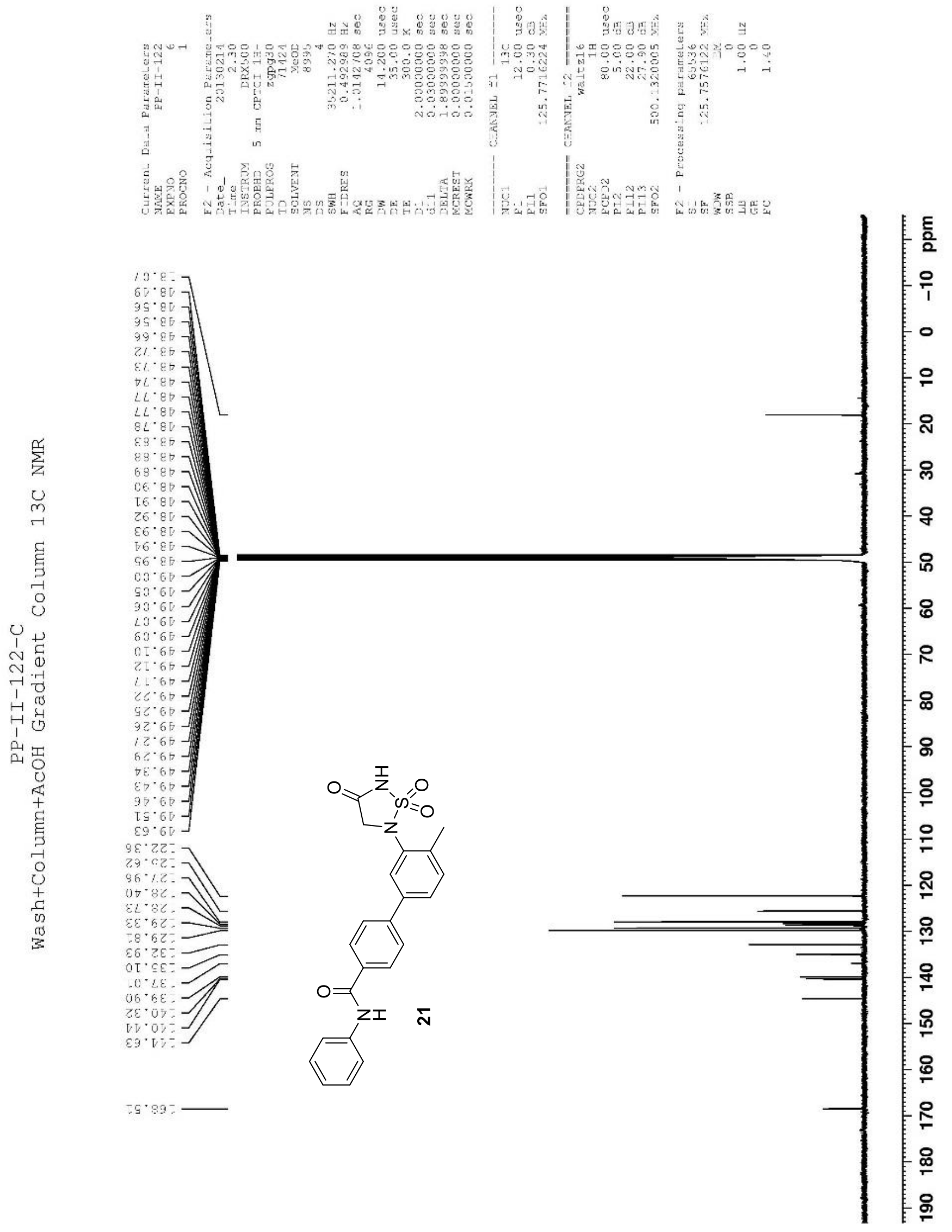